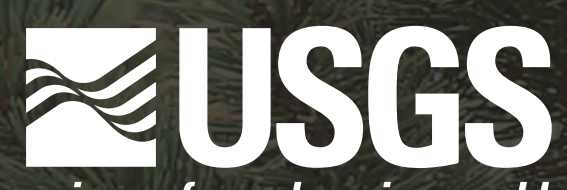

science for a changing world

\title{
Growth-Form Characteristics of Ancient Rocky Mountain Bristlecone Pines
} (Pinus aristata),
Colorado

Scientific Investigations Report 2006-5219 


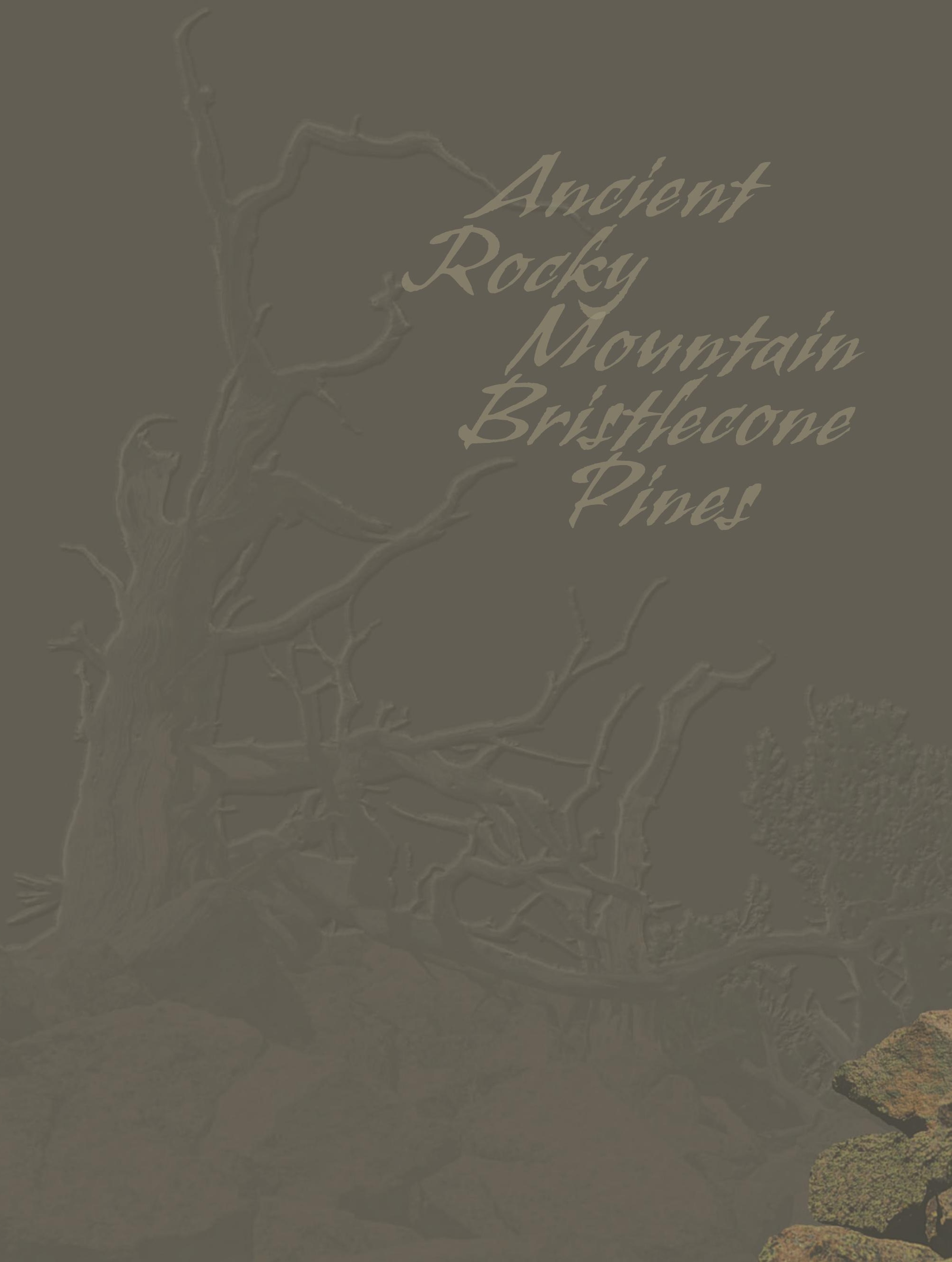




\section{Growth-Form Characteristics of Ancient Rocky Mountain Bristlecone Pines (Pinus aristata), Colorado}

By F. Craig Brunstein

Publication design and graphic layout by Carol A. Quesenberry

Scientific

Investigations Report 2006-5219 


\section{U.S. Department of the Interior DIRK KEMPTHORNE, Secretary}

\section{U.S. Geological Survey Mark D. Myers, Director}

U.S. Geological Survey, Reston, Virginia: 2006

For product and ordering information:

World Wide Web: http://www.usgs.gov/pubprod

Telephone: 1-888-ASK-USGS

For more information on the USGS--the Federal source for science about the Earth, its natural and living resources, natural hazards, and the environment:

World Wide Web: http://www.usgs.gov

Telephone: 1-888-ASK-USGS

Any use of trade, product, or firm names is for descriptive purposes only and does not imply endorsement by the U.S. Government.

Although this report is in the public domain, permission must be secured from the individual copyright owners to reproduce any copyrighted materials contained within this report.

\section{Suggested citation:}

Brunstein, F.C., 2006, Growth-form characteristics of ancient Rocky Mountain bristlecone pines (Pinus aristata), Colorado: U.S. Geological Survey Scientific Investigations Report 2006-5219, 90 p. 


\section{Contents}

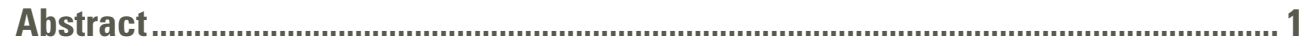

Introduction and Previous Studies.................................................................................... 4

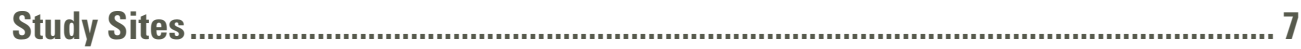

Methods.................................................................................................................... 8

Growth-Form Characteristics of Bristlecone Pines Less than 1,000 Years 0ld......... 12

Trees 20-500 Years Old ...................................................................................................

Trees 501-750 Years 0ld .....................................................................................................14

Trees 751-999 Years 0ld ..................................................................................................14

Spiral Grain............................................................................................................................. 15

Bark-Enclosed Trunks and Cambial Dieback .............................................................. 15

Crown Dieback ............................................................................................... 15

Growth-Form Characteristics of Bristlecone Pines 1,000-2,500 Years Old................ 24

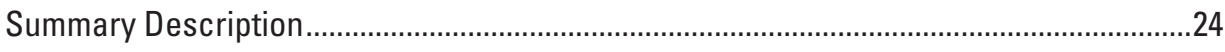

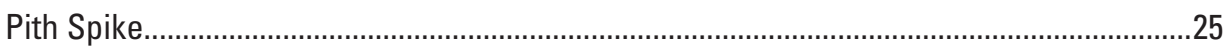

Heights of the Pith Spike and Living Branches................................................................29

The Succession of Major Branches on a Living Limb ......................................................29

Orientations of Limbs and Branches ...............................................................................29

Eroded Dead Limbs.........................................................................................................46

Living Limb Attachment Height............................................................................................46

Strip-Bark Growth on Trunks and Limbs ...........................................................................49

The Number of Bark Strips and Living Limbs ................................................................50

Location of Bark Strip....................................................................................................50

Advantages of Having a Bark Strip on the Upslope Side of a Tree ....................................52

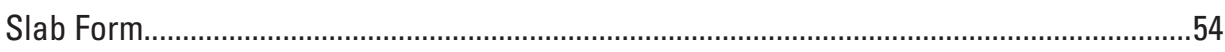

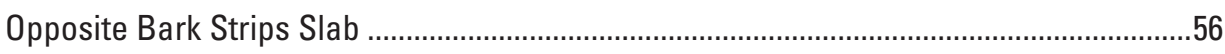

Twisted Slab (or Spiral Slab) .............................................................................................60

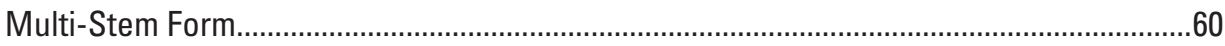

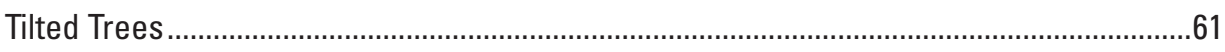

Young Branches on Old Trees........................................................................................61

Some Examples of Trees that are Exceptions to Predominant Growth Trends..................63

Selected Types of Injuries that Possibly Cause Growth-Form Changes or Death in Bristlecone Pines .............................................................................................. 65

Damage Caused by Lightning Strikes.................................................................................65

Damage Caused by Falling and Tumbling Rocks ................................................................67

Damage Caused by Porcupines ......................................................................................70

Fire Damage ...................................................................................................................70

Conclusions ....................................................................................................... 73

Acknowledgments ............................................................................................... 74

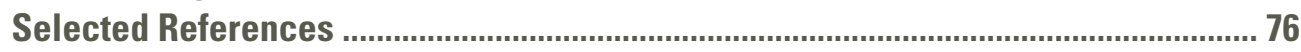




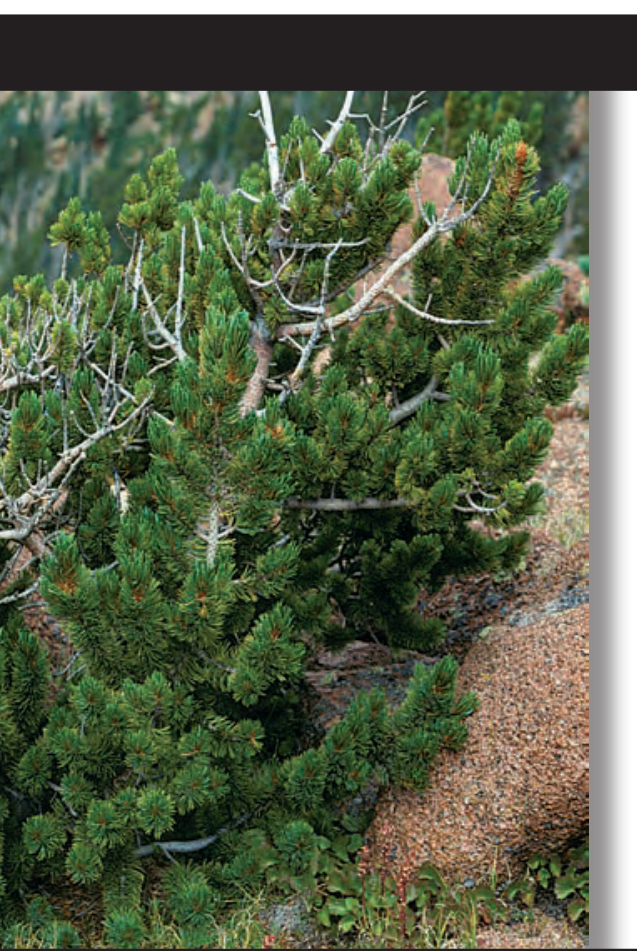

\section{Appendix}

Brief Descriptions of Growth Forms of Rocky Mountain Bristlecone Pines in this Study.

Growth Forms Based on Inferred Horizontal Section View of Trunk Above Basal Root Flare 81

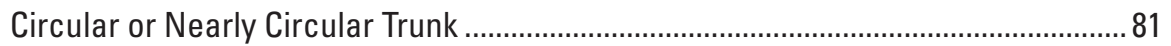

Oval, Elliptical, Nearly Semicircular, or Semicircular Trunk ...................................... 81

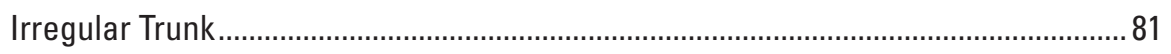

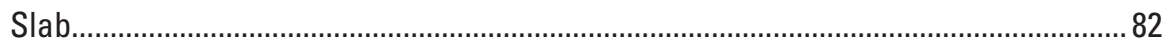

Growth Form Based on Long-Axis View and Inferred Horizontal Section View

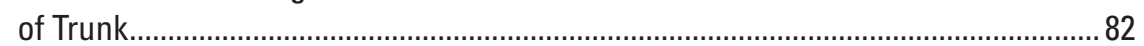

Twisted Slab (also referred to as Spiral Slab)......................................................... 82

Growth Form Based on Long-Axis View of Tree ......................................................... 83

Multi-Stem (also Referred to as Forked or Eagle's Aerie).......................................... 83

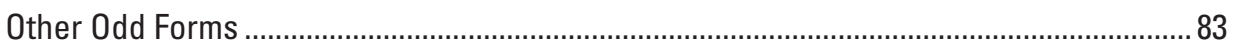

Krummholz

\section{Figures}

1. Index maps showing study areas and other selected features.................................. 5

2. Typical appearance of young (about $20-40$ years old) bristlecone pines at the study sites.

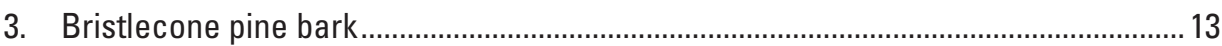

4. Inferred horizontal section views of bristlecone pines 2-4 feet above ground

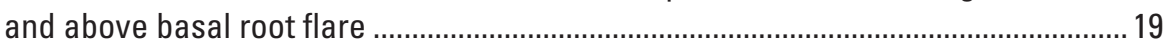

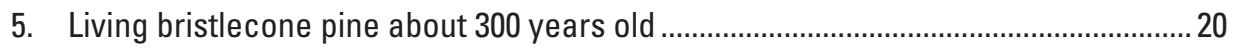

6. Vertical sections through two dead bristlecone pine limbs ......................................... 21

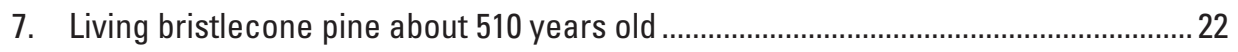

8. Living slab-form bristlecone pine about 1,100 years old (tree 88-5) ............................30

9. Interpretive and simplified sketch showing major structures of tree 90-1, which is a living slab-form bristlecone pine about 2,220 years old.............................. 32

10. Interpretive and simplified sketch showing major structures of tree 68-3, which is a living slab-form bristlecone pine about 2,050 years old..............................33

11. Living slab-form bristlecone pine about 1,210 years old (tree 88-8) .............................34

12. Living slab-form bristlecone pine about 1,410 years old (tree $88-10$ )......................... 39

13. Interpretive and simplified sketch showing major structures of a living, opposite bark strips, slab-form bristlecone pine about 1,660 years old ..................... 40

14. Two living bristlecone pines that are twisted (or spiral) slabs .................................. 42

15. Multi-stem living bristlecone pine about 1,030 years old............................................ 44

16. Interpretive and simplified sketch showing the single living limb of tree $90-10 \ldots \ldots . . .47$

17. Eroded dead limbs (first-order branches) on the trunks of two bristlecone pines.... 48

18. Horizontal section of the slab-form trunk of a dead bristlecone pine showing the extent of selected annual rings.

19. The upslope base of this living bristlecone pine is dead, and the tree has nearly tipped over 
20. Sediment damming on the upslope side of bristlecone pines growing on mountain slopes.

21. Inferred horizontal section view of a bristlecone pine showing long radius and long diameter.

22. Rose diagrams showing long diameter bearings and bark-strip growth directions of 760- to 2,500-year-old bristlecone pines.

23. Living bristlecone pine (tree 90-15) that is an opposite bark strips slab that has three bark strips

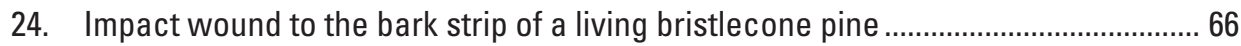

25. Impact wound to living bristlecone pine.

26. Porcupine damage to living bristlecone pine . .71

27. Fire damage to trunk of living bristlecone pine . .72

28. Timeline summarizing selected growth characteristics of bristlecone pines in this study. .73

29. Old ponderosa and limber pines (in Appendix) .90

\section{Tables}

1. Minimum ages and selected other features of young sapling bristlecone pines......12

2. Heights of living bristlecone pines. .23

3. Diameters of living bristlecone pines that have circular or nearly circular trunks...23

4. Long diameters and long radii of living slab-form bristlecone pines. . .23

5. Names (nomenclature) of major above-ground parts of living bristlecone pines $1,000-2,500$ years old .28

6A. Average, minimum, and maximum attachment heights of living limbs on bristlecone pines 1,000-2,500 years old . .46

6B. Ranges of attachment heights of living limbs on bristlecone pines $1,000-2,500$ years old. .46

7. Widths of bark strips on bristlecone pines $1,000-2,500$ years old . .51

8. Number of bark strips and living limbs on bristlecone pines $1,000-2,500$ years old..

9. Bark-strip location at the base of bristlecone pines $1,000-2,500$ years old 51

10. Average long-diameter bearings (LDB) for living slab-form bristlecone pines $760-2,500$ years old

11. Approximate thicknesses of slab-form bristlecone pines 1,000-2,500 years old ..... 61

12. Field classifications of growth forms of 134 bristlecone pines in this study (in Appendix).....

13. Data for selected bristlecone pines (in Appendix).

\section{Conversion Factors}

\begin{tabular}{lll}
\hline Multiply & By & To Obtain \\
\hline inches & 2.54 & centimeters \\
feet & 0.3048 & meters \\
miles & 1.609 & kilometers \\
\hline
\end{tabular}




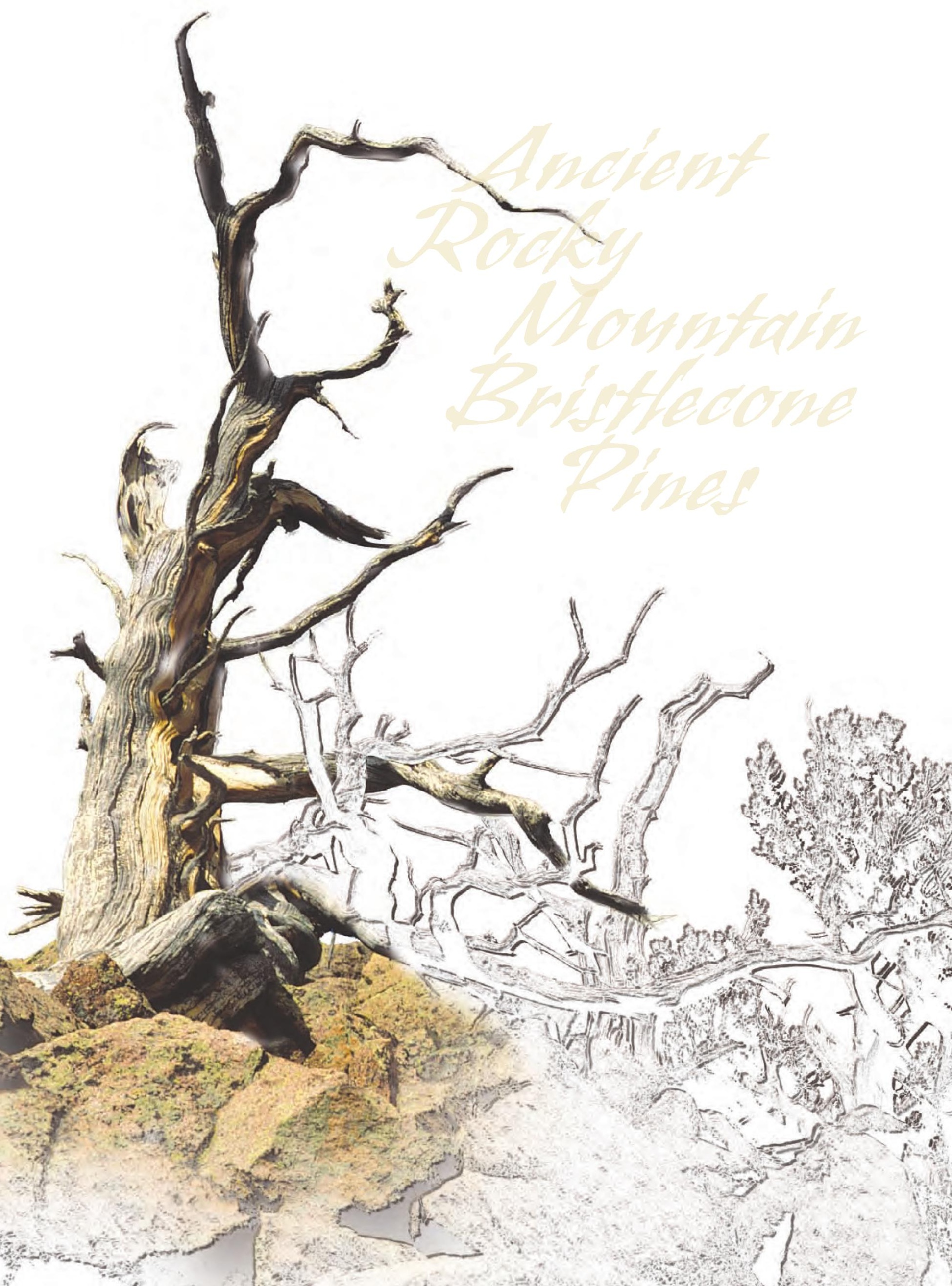




\section{Growth-Form Characteristics of Ancient Rocky Mountain Bristlecone Pines (Pinus aristata), Colorado}

\author{
By F. Craig Brunstein
}

\section{Publication design and graphic layout by Carol A. Quesenberry}

\section{Abstract}

he sample population for this study consists of 134 dated Rocky Mountain bristlecone pines (Pinus aristata) ranging in age from about 20 to 2,500 years. Typical young bristlecone pines about 40-100 years old have circular or nearly circular, bark-enclosed trunks, no crown dieback, and as many as 71-100 or more living limbs (firstorder branches). In contrast, typical bristlecone pines 1,000-2,500 years old have trunks that have exposed, erosion-sculpted wood; crown dieback; a prominent dead, erosion-sculpted pith spike; usually only one bark strip covering as little as 5-10 percent of the circumference of the trunk; and usually only one or two living limbs. However, some of the studied trees 1,000 or more years old have as many as three bark strips and four living limbs. Each of the six oldest bristlecone pines (ranging in age from about 1,980 to 2,500 years old) has only one bark strip and one living limb. The width, location, orientation, and number of living bark strips and the location, orientation, number, size, and attachment heights of living limbs and branches determine the forms of most of the studied bristlecone pines that are 1,000-2,500 years old. Forms of 45 of the 1,000- to 2,500-year-old trees were classified as follows: slab (34 trees), opposite bark strips slab ( 4 trees), twisted slab ( 3 trees), irregular-shape trunk ( 3 trees), and multi stem (1 tree). All of the dated trees more than about 700 years old have cambial dieback on their trunks, and all of the dated trees more than about 550 years old have partial to complete crown dieback.

Cambial dieback due to wind-induced dessication and scouring by wind-driven ice and soil seems to be the precursor or beginning of strip-bark growth for most bristlecone pines as suggested by other researchers. Evidence at the bristlecone pine sites in this study supports that finding. However, observations made in this study suggest that as most bristlecone pines growing on steep mountain slopes get older, the erodibility and instability of the substrate on which the trees grow become major factors that determine the eventual location and radial growth direction of the trees' bark strips. Most of the 1,000- to 2,500-year-old bristlecone pines growing on steep slopes composed of relatively erodible and unstable substrates (loose talus, loose gravelly soil, friable granite bedrock) each have exposed dead roots on the downslope side of their trunk and a bark strip at the base of the upslope side of their trunk; such bark strips have radial growth toward the mountain slope. Sediment damming on the upslope base of the trunk provides a protective covering for roots on that side of the tree and helps to maintain tree stability (due to roots in the sediment anchoring the upslope side of the tree, thus preventing the tree from falling downslope). Such sediment damming and radial growth toward the mountain slope possibly also serve to decrease the distance from roots to living branches on some of the trees. In contrast, the downslope base of the trunk is eventually undercut by erosion, which increases the distance from roots to living branches and eventually causes the death of undercut roots. Such factors probably contribute to a higher mortality rate for bark strips on the downslope side of the trees as compared to bark strips on the upslope side. 
The average long-diameter bearing of slab-form bristlecone pines on southeast-facing slopes is N. $10^{\circ} \mathrm{E}$., and for southwest-facing slopes it is N. $28^{\circ} \mathrm{E}$. The predominant northnortheasterly bearings are possibly the result of a combination of optimum (1) root growth and bark-strip radial growth on the upslope side of the trees (with radial growth of bark strips toward the mountain slope), which enhances tree stability and increases the chances of root survival as compared to the downslope side of trees where roots are usually undercut by erosion and (2) radial growth of bark strips in a north-northeasterly direction, which probably provides some protection of the bark strip from wind-induced desiccation and scouring by wind-driven ice and soil from westerly, southwesterly, southerly, and southeasterly wind directions.

Several bristlecone pines more than 1,000 years old are growing on steep slopes composed of stable subtrates (solid bedrock, stable boulder talus, or stable bouldery soil) that have relatively low erodibility. Such trees have few or no undermined dead roots on the downslope side (or any other side) of the trunk and bark strips at locations other than the upslope base of the tree. The relatively low erodibility of these substrates probably prevents undercutting of the trees' roots and enables survival of bark strips and roots at the base of the trunk at locations not limited to the upslope side of the trees. The stability of such substrates enables the trees to remain stable (not fall over) regardless of where the bark strips and roots are located.

For trees 1,000-2,500 years old, the average bark-strip width is 15 inches (minimum 2-3 inches; maximum 48 inches), tree height ranges from 6 to about 30 feet, and the average attachment height of living limbs is 6 feet (minimum 1 foot; maximum 16 feet). For slabform trees 1,000 or more years old, long diameters range from 10.5 to 48 inches and long radii range from 9 to 30 inches. Of 33 trees 1,000-2,500 years old, 26 each have a single bark strip on the upslope side of the tree. Damage to some living bristlecone pines by falling and tumbling rocks, gnawing animals, fire, and lightning strikes was observed to include various wounds that cause cambial dieback and (or) loss of living limbs and branches, resulting in potential changes in the growth forms of some bristlecone pines. In order to better describe the trees in this study, several growth forms and some tree-structure nomenclature are introduced in this report.

(Facing page) View from a bristlecone pine site high (about 12,100 feet altitude) in the Colorado Rockies. The summit of the peak in the distance is over 14,000 feet. (Photograph taken July 11, 1996. Sawatch Range.) 


\section{Introduction and Previous Studies}

his report describes growth-form characteristics of Rocky Mountain bristlecone pines (Pinus aristata) at several sites in the Rocky Mountains in Colorado (fig.

1). Most of this study concentrates on 1,000- to 2,500-year-old bristlecone pines in the Front Range, South Park area, and Sawatch Range (fig. 1). These sites have a variety of bristlecone pine growth forms. This report also describes the growth forms of younger trees (about 20 to less than 1,000 years old) in order to show the continuous changes of tree form from youth to old age.

Trees in this study are Rocky Mountain bristlecone pines, which are native to parts of Colorado, New Mexico, and Arizona (fig. 1; Bailey, 1970; Krebs, 1972). They are related to Great Basin bristlecone pines (Pinus longaeva), which are native to parts of California, Nevada, and Utah, and to foxtail pines (Pinus balfouriana), which are native to California (Bailey, 1970). Numerous white resin specks on the needles of Rocky Mountain bristlecone pines are one of the diagnostic features that distinguish them from Great Basin bristlecone pines and foxtail pines (Bailey, 1970).

In order to describe the trees, this report (1) introduces some new nomenclature for naming certain parts of the old bristlecone pines and (2) provides a bristlecone pine growthform classification system that is in part based on the work of Schulman (1958), Wright and Mooney (1965), and LaMarche (1969) with Pinus longaeva. However, several previously undescribed growth forms are presented in this report. The growth-form classification system presented in this report is intended to be a general guide for classifying and describing the forms of relatively slow-growing Pinus aristata that are likely to be present at relatively arid sites within the range of this tree species. It is hoped that it will also be useful for other tree species in this and other regions. The sample populations for some of the age classes in this study are relatively small, and readers should note that some of the observations in this study are based on fewer than 10 trees.

Schulman (1958; p. 363 and 365) briefly described the growth forms of ancient Pinus longaeva in the White Mountains of California (fig. 1). These forms include massive slab, eagle's aerie, and pickaback (Schulman, 1958, p. 363). He described his "pickaback" form of Pinus longaeva as having three "stems" in a "Junior-Dad-Granddad" sequence (p. 363). His "Great-granddad Pickaback" (p. 364-366) has four "stems" in a "JuniorDad-Granddad-Great-granddad" sequence. He provided photographs of a dwarf specimen (p. 365), a massive slab (Pine Alpha; p. 371), eagle's aerie (p. 363), and pickaback forms (p. 363-364), but he did not go into detail to explain or label the major structures of each tree form. LaMarche (1969) referred to the ancient Pinus longaeva he studied as having "slab-like" stems, and Fritts (1976, p. 153) referred to such trees as having a "flattened slab-shaped stem form."

Since the early 1970s, several reports have concentrated on the taxonomy, ecology, stand structure, and dendrochronology of Pinus aristata (Bailey, 1970; Schubert and Rietveld, 1970; Krebs, 1972, 1973; LaMarche and Stockton, 1974; LaMarche and Hirschboeck, 1984; Baker, 1992; Brunstein and Yamaguchi, 1992; Schoettle, 1994; Brunstein, 1995, 1996; Ranne, 1995; Ranne and others, 1997; Salzer, 2000; Schauer and others, 2001; and Schoettle, 2004). This report provides new interpretations and data that are intended to (1) help people better understand this tree species and (2) prove useful to future studies involving Pinus aristata and other tree species.

Figure 1. (Facing page) $\quad \boldsymbol{A}$, Index map of the Southwestern United States showing distributions of Rocky Mountain bristlecone pine (Pinus aristata), Great Basin bristlecone pine (Pinus longaeva), and foxtail pine (Pinus balfouriana); from Bailey (1970) and Krebs (1972). Black circles in Colorado are study areas where data were gathered for this report. $\boldsymbol{B}$, Map of part of Colorado showing mountain ranges mentioned in this report, as well as other selected features. Shading on figure $1 B$ indicates mountainous areas. 


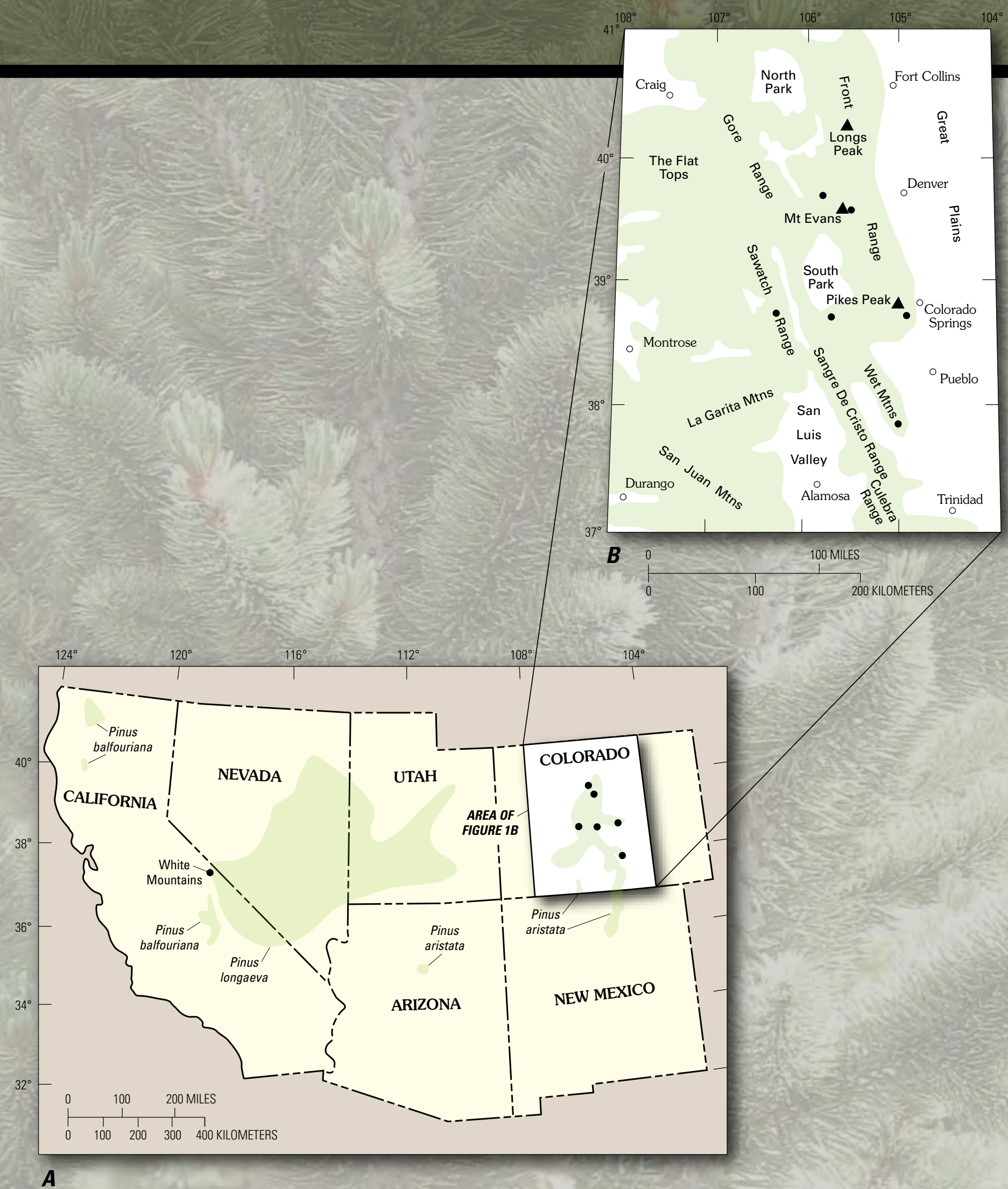




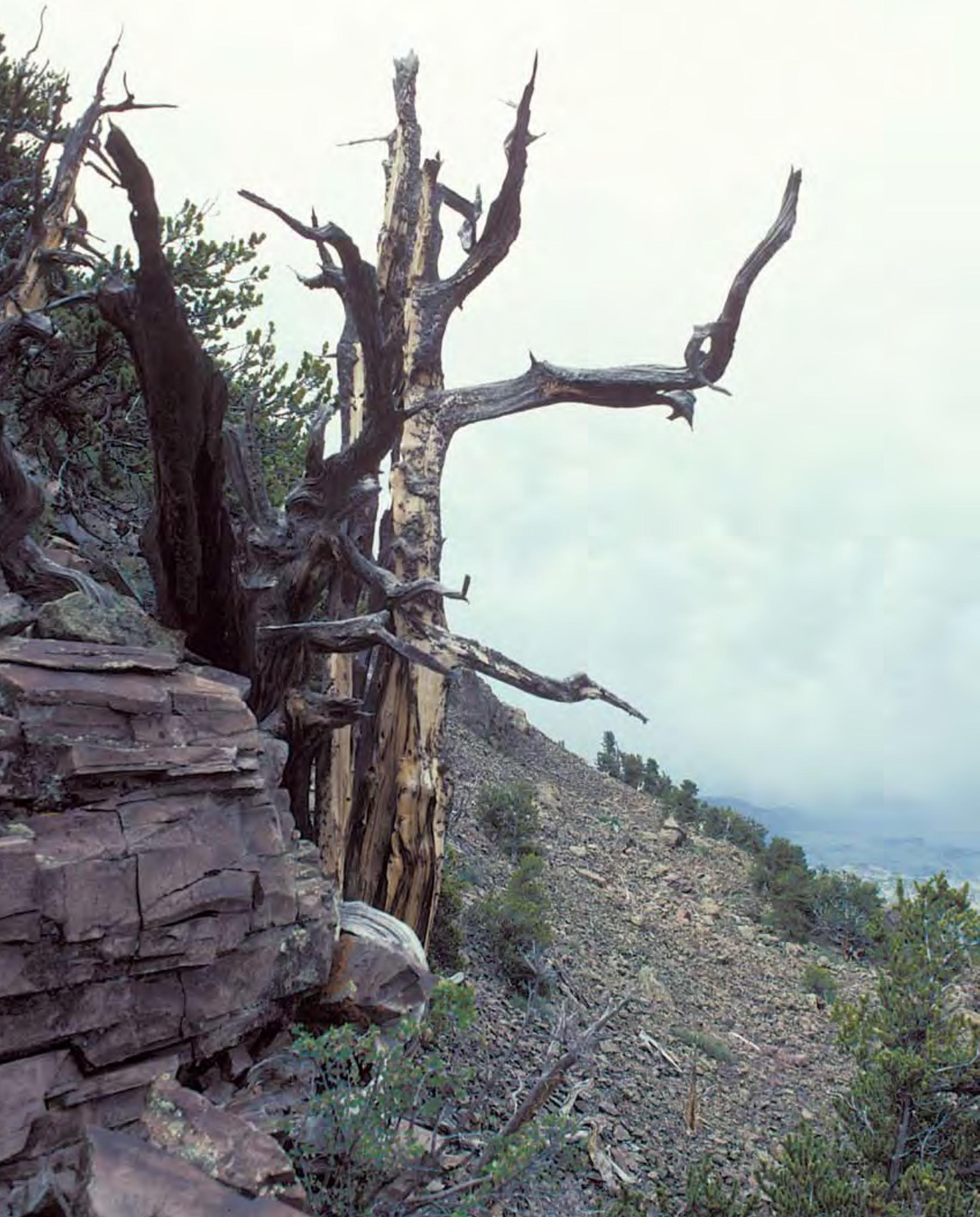




\section{Study Sites}

ata for this report were obtained from Pinus aristata in the Front Range, South Park area, Sawatch Range, and Wet Mountains (fig. 1). Sites in the Front Range, South Park area, and Sawatch Range were the primary focus of this study because they have living bristlecone pines that have been documented to be more than 1,000 years old (Krebs, 1972; Brunstein and Yamaguchi, 1992; Brunstein, 1995; this report) and because they have a variety of bristlecone pine growth forms. Other sites in the range of Pinus aristata also have living bristlecone pines more than 1,000 years old. Schulman and Ferguson (1956) described a bristlecone pine in the San Francisco Peaks area of Arizona that was probably at least 1,500 years old, and Currey (1965) found a bristlecone pine in the Culebra Range in Colorado that he dated at about 1,300 years old. These sites were not visited in this study.

The living trees in this study are at altitudes ranging from about 10,800 to 12,100 feet. The trees range from about 1,200 to 50 feet below local upper treeline, which is the highest altitude at which erect, mature trees grow. Above that altitude, tree species generally grow as low, sprawling shrubs (krummholz). The altitude of upper treeline at each of the sites varies due to topography and aspect. For example, at one Front Range site, upper treeline on the eastern flank of the mountain is about 11,880 feet, but on the southern flank it is about 12,000 feet.

In Colorado, strong prevailing winds are generally from westerly directions during the "cool half of the year;" however, outbreaks of polar air during the fall and winter can bring occasional strong northerly winds (Doeskin and others, 2003). Moist air from the Southwest Monsoon originates to the south of Colorado (Doeskin and others, 2003) and probably brings southerly and westerly summer winds. Occasional hot, dry southwesterly winds originate from the desert Southwest (Doeskin and others, 2003).

(Facing page) Rugged and rocky terrain of a remote bristlecone pine site in central Colorado. Bedrock and angular boulder talus are composed of extrusive andesitic volcanic lava and welded ash-flow tuff of Oligocene age. The ancient wood of dead bristlecone pines is attractive but should be left in place and untouched for future generations to enjoy and study. (Photograph taken

June 21, 1992.)
At all bristlecone pine sites in this study, evidence indicates that strong westerly winds are prevalent during winter months. Such evidence consists of the following:

(1) Wind-deposited snowfields and snow cornices on the leeward east side of north-south-trending ridges near the summits of peaks in the southern Front Range and in the Sawatch Range. Such snowfields can persist into the late spring and early summer.

(2) Distribution of vegetation (such as aspen, ponderosa pine, and bristlecone pine) and wind-deposited snowdrifts on the leeward east-facing side of small valleys and exposed ridges and hills at the South Park site.

(3) Longer branches (flagging) on the east side of trees on exposed ridge crests and other exposed areas at the southern Front Range site and at the South Park study site.

(4) Instrumental recordings of prevailing strong westerly winter winds at Goliath Peak near the northern Front Range study site (Schauer and others, 2001).

However, during some periods, wind directions at the bristlecone pine sites probably vary from prevailing westerlies. Schauer and others (2001) used instrumentation over a period of about 9 months to record prevailing easterly and southeasterly winds during the summer months at Goliath Peak in the Front Range west of Denver, CO.

In addition, wind directions are influenced by local topography (Doeskin and others, 2003) such that the wind probably also follows the orientation of valleys. For example, at one of the southern Front Range sites, a large northeast-trending valley probably funnels some of the prevailing westerly winds upvalley so that they blow from the southwest and up the steep, southwestfacing mountain slope. Evidence for such a southwesterly flow is apparent in longer branches on the upslope side (as compared to the downslope side) of many midslope trees; however, a strong westerly component to the wind is also evident at the site as evidenced by longer branches on the east side (as compared to the west side) of many of the trees. 


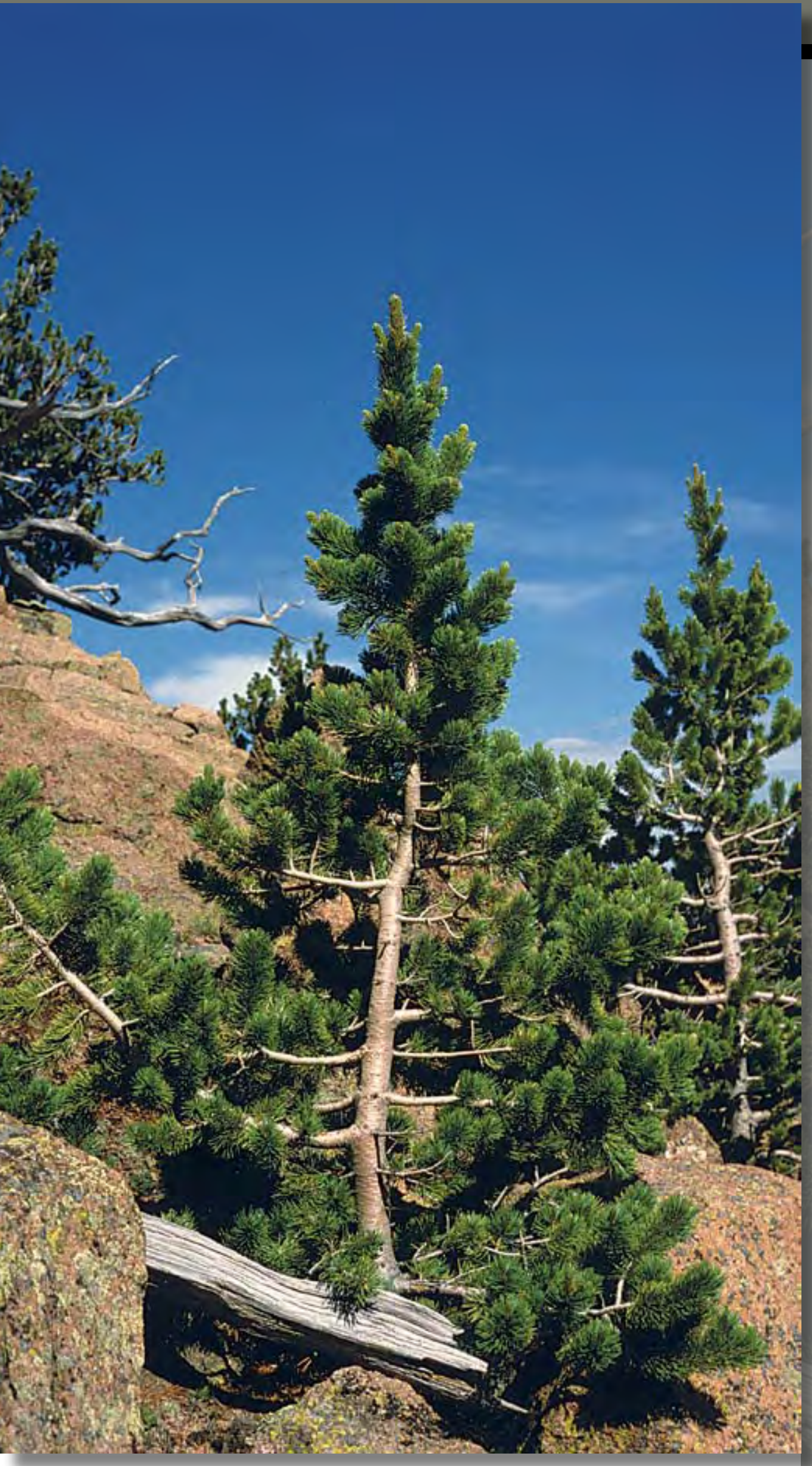

Figure 2. Typical appearance of young (about 20-40 years old) bristlecone pines at the study sites. This tree is less than 6 feet tall. The smooth bark is typical of the trunks of young bristlecone pines. The minimum ages of such trees were determined by counting apical bud scars and (or) "rosettes" of first-order branches (table 1). (Photograph taken July 14, 1990. Southern Front Range.) 
Final estimated ages of the trees were made by adding the estimated years in the missing inner radius of the cores to the minimum crossdated age, and then adding a conservative figure of 10 years to account for the time the trees grew to sampling heights of 2-4 feet (see table 1 for the basis of this addition). Such an addition has a negligible effect on the estimated age of trees that are 500 to 2,500 years old, accounting for less than 0.5 to as much as 2 percent of their ages. However, for a tree that is about 80 years old, such an addition accounts for about 13 percent of the tree's age. One tree (90-11) was sampled at a height of 12 feet; a conservative figure of 50 years was added to the age of this tree to account for the time the tree grew to the sampling height. Age estimates were then rounded to the nearest 10 years. The lifespans of the three dead trees, all of which have (1) no bark, (2) weathered wood along the entire circumference of the trunk, and (3) outer-ring dates before A.D. 1500, were rounded up to the nearest 50 years. Estimated ages are used in this report (instead of inner-ring dates) to enhance the readability of the text and to provide readers with ages that are probably more accurate for sampled trees that are less than 200 years old. Estimated ages in this report may differ slightly from those of the same trees in other reports (Brunstein and Yamaguchi, 1992; Brunstein, 1995, 1996) due to slightly different methods of calculating ages and because of the passage of time since those reports were published. Throughout the text, age classes for growth-form characteristics are generally rounded to the nearest 50 or 100 years.

Some or all of the following data were collected for each tree in this study: diameter or long diameter, compass orientation of long diameter, radius or long radius, altitude, slope orientation and dip, presence of crown dieback, presence of cambial dieback, number of living limbs, limb attachment height and orientation, number and orientation of bark strip(s), width(s) of bark-strip(s), amount of erosion sculpting, tree height, and field classification of tree form. Detailed trunk measurements were made for more than 20 of the dated bristlecone pines-such measurements and the dated core samples were used to make sectionview drawings of the stems of these trees. A steel tape was used to make trunk measurements about 2-4 feet above ground and above the basal root flare. Measurements of two tree trunks were made by surrounding the trunks with a rectangle of meter sticks (F.C. Brunstein, U.S. Geological Survey, unpublished method, 1992). Using this apparatus, detailed measurements were made for trees 68-3 and 88-10. Compass bearings of long-diameter orientation and slope orientation, as well as measurement of dip of slope, were measured using a Brunton pocket transit. Tree heights and attachment heights of living limbs were either measured with a steel tape or were visually estimated for heights of 14 feet or lower; all heights above 14 feet were visually estimated. A check of some of the visual estimates with a steel tape revealed a difference of less than 5 percent for trees and limbs having heights of 10 feet or less. Thus, accuracies of visually estimated heights are probably \pm 0.5 foot for heights of 10 feet or less. I suggest that the accuracy of visual estimates varies from about \pm 0.5 feet for heights 10 feet to \pm 5 feet for heights of 35 feet. The trees were not harmed while performing the various measurements. English customary units of measure are used throughout most of this report because the 1:24,000-scale U.S. Geological Survey topographic maps for all of the study sites have altitudes in feet and distances in miles.

One section was drawn from a sawed-off stump that was cut by woodcutters who gathered wood in the 1960s and 1970s near access roads through one of the tree sites. Some of the observations related to damage caused by falling and tumbling rocks, porcupines, fire, and lightning strikes were made on about 40 additional trees whose ages were either visually estimated or were determined from crossdated core samples. Various other observations were made on numerous other bristlecone pines less than about 200 years old. 


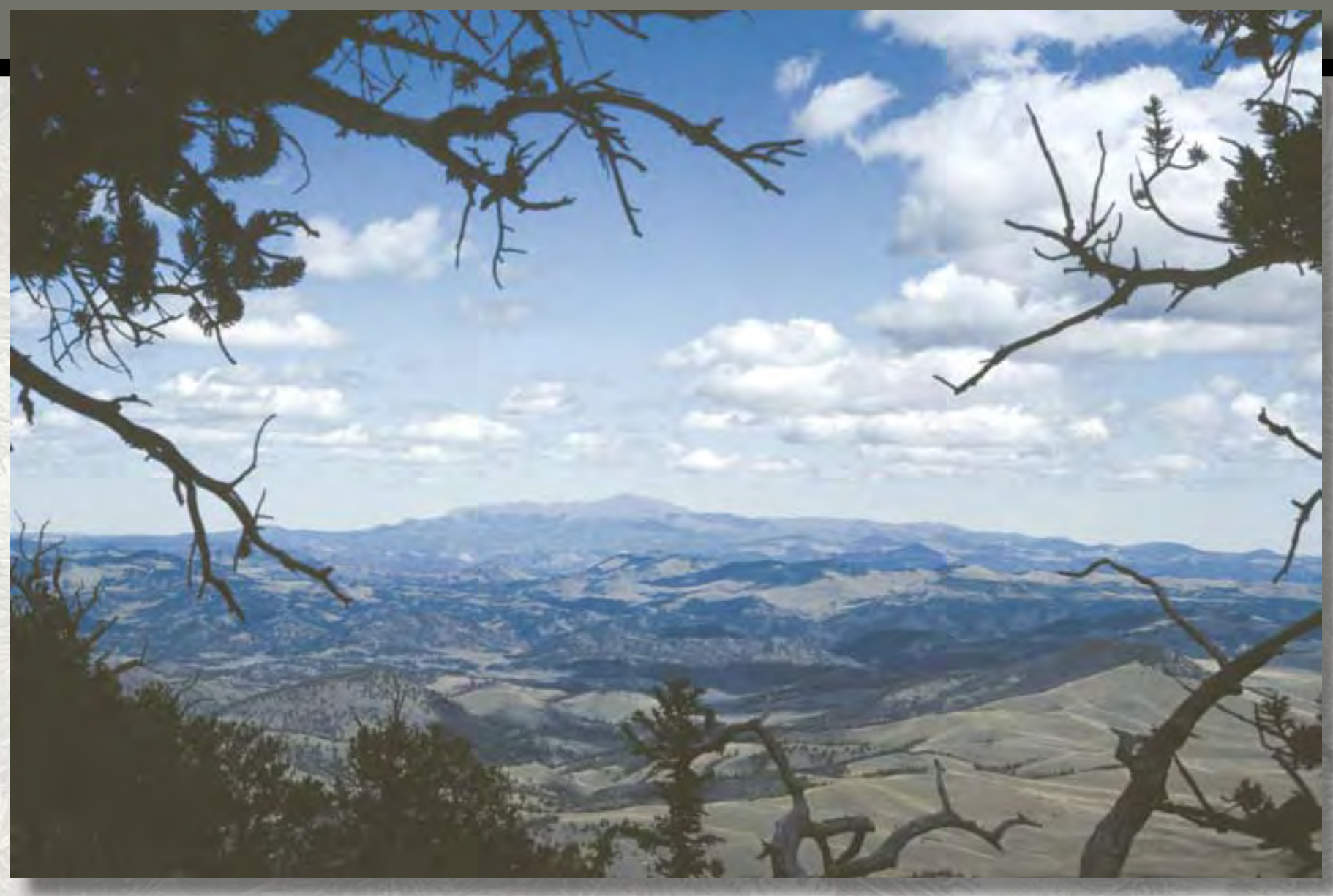

Bristlecone pine branches frame a scenic view in central Colorado. In the distance are granitic peaks of the Front Range. (Photograph taken September 14, 1991.)

The interpretive tree sketches were made in the following manner: a single suitable photograph of each tree was chosen, and it was used to trace some of the major structures of each tree; then other structures were added to the tracings by using data from field notes, data from dated core samples, and photographic studies of the trees.

Photographs were taken using the following equipment: 1969, Agfa Optima; 1988-89, Minolta SRT 101 (MC Rokkor 28 mm F2.5 and 35 mm F1.8 lenses); 1990-96, Nikkormat FTN (Nikkor AI/AIS $24 \mathrm{~mm}$ F2.8, $28 \mathrm{~mm}$ F3.5, and $55 \mathrm{~mm}$ F3.5 micro lenses); 2005-06, Canon G3 (4 megapixel); and lightweight Cullman tripod and Bogen (3001 with 3028 head) full-size tripod. The following films were used in the film cameras: Kodak Kodachrome 25 and 64, T-MAX 100; Fuji Velvia 50. 


\section{Growth-Form Characteristics of Bristlecone Pines Less than 1,000 Years Old}

\section{Trees 20-500 Years Old}

ith a few exceptions, sampled trees in this age class have full crowns and no cambial dieback. Most of the young trees in this age class have a cone-shaped crown and a single, defined, central trunk (fig. 2). Such a form is caused by a tree that has apical dominance; that is, each year such a tree produces a single apical leader shoot that outgrows the lateral shoots beneath it (Brown and others, 1967; Cline, 1997; fig. 2). However, some of the trees have multiple stems, and such trees can have a bushy appearance. (See the section "Multi-Stem Form" for an explanation of the possible causes of that form.) Young trees have smooth, silver bark that is sometimes tinged red (fig. 2). Counting of apical bud scars and (or) branch rosettes on young sapling trees reveals that they have minimum ages from about 20 to 35 years (table 1). Such age estimates apparently underestimate the ages of the trees. The evidence for underestimated ages is shown in the following example. In 1993, at an altitude of about 11,750 feet at a Front Range site, a section from a recently dead young tree 48 inches tall was taken an inch above ground level. The tree was 37 years old by ring count (table 1). Ring widths appeared to be normal up until the year of death. The needles were still attached but were dry and brown with a hint of pale green on a few of the branches. A count of apical bud scars and branch rosettes revealed an equal number of each: 24 . Thus, a count of apical bud scars and branch rosettes under-represented the age of this tree by 13 years-an error of 35 percent. Possible reasons for this age discrepancy include (1) years when the tree did not produce an apical leader shoot or lateral shoots, (2) apical bud scars that are not readily visible, (3) branch rosettes that have died and have been eroded away, and (or) (4) very slow growth as a tiny seedling with the lack of discernible apical bud scars near the base of the plant stem. The possible existence of intra-annual growth rings (false rings) in young bristlecone pines is considered improbable because not one instance of intra-annual growth rings was found in the $100,000+$ rings crossdated in this study.

Table 1. Minimum ages and selected features of young sapling bristlecone pines.

[Trees are in the southern Front Range at altitudes of 11,300-11,700 feet. --, not counted; na, not applicable. Figures for minimum age based on assumption that only one apical bud scar, one rosette of first-order branches, and one annual ring form per year]

\begin{tabular}{cccccl}
\hline $\begin{array}{c}\text { Tree height } \\
\text { (inches) }\end{array}$ & $\begin{array}{c}\text { Number of } \\
\text { apical } \\
\text { scars }\end{array}$ & $\begin{array}{c}\text { Number of } \\
\text { rosettes }\end{array}$ & $\begin{array}{c}\text { Ring } \\
\text { count }\end{array}$ & $\begin{array}{c}\text { Minimum age } \\
\text { (years) }\end{array}$ & \multicolumn{1}{c}{ Remarks } \\
\hline 20 & 35 & -- & -- & 35 & Living stunted tree \\
30 & -- & 20 & -- & 20 & Living tree \\
38 & 34 & 34 & -- & 34 & Living tree \\
44 & -- & 31 & -- & 31 & Living tree \\
48 & 24 & 24 & 37 & 37 & Recently dead (see text) \\
58 & -- & 26 & -- & 26 & Living tree; 52 living limbs \\
63 & -- & 23 & -- & 23 & Living tree \\
about 72 & -- & 31 & -- & 31 & Living tree; 49 living limbs ${ }^{2}$ \\
about 72 & -- & -- & -- & na & Living tree; 71 living limbs ${ }^{3}$ \\
\hline
\end{tabular}

${ }^{1}$ Diameter 8 inches above ground is about 1.5 inches.

${ }^{2}$ Tree has one unopened (immature) seed cone at the top of the tree.

${ }^{3}$ Tree has four unopened (immature) seed cones at the top of the tree. No seed cones observed on any of the other trees listed in this table. 
Until the age of about 50-80 years, the trunks of the trees are covered with smooth, silver bark that is sometimes tinged red. Trees about 80-140 years old have dark-gray, scaly bark on the lower 1-4 feet of their trunks; above that, such trees have mostly smooth, silver bark (fig. $3 A$ ). Trees about 150-300 years old have dark-gray scaly bark covering most or all of their trunks (fig. $3 B$ ). Older trees (about 400-500 years old) in this age class and in older age classes usually have rough, furrowed, scaly and platy bark that is various shades of gray, often with reddish-brown.

Four trees ranging in age from about 40 to 100 years and ranging in height from about 6 to 12 feet have as many as 71-100 or more living limbs. Trees younger or older than this age range were observed to have fewer living limbs. This suggests that most of the trees younger than about 40-100 years are in the process of gaining limbs, and trees older than about 40-100 years are losing limbs faster than they are gaining them. Future work involving a larger sample population could help to more accurately delineate these trends.
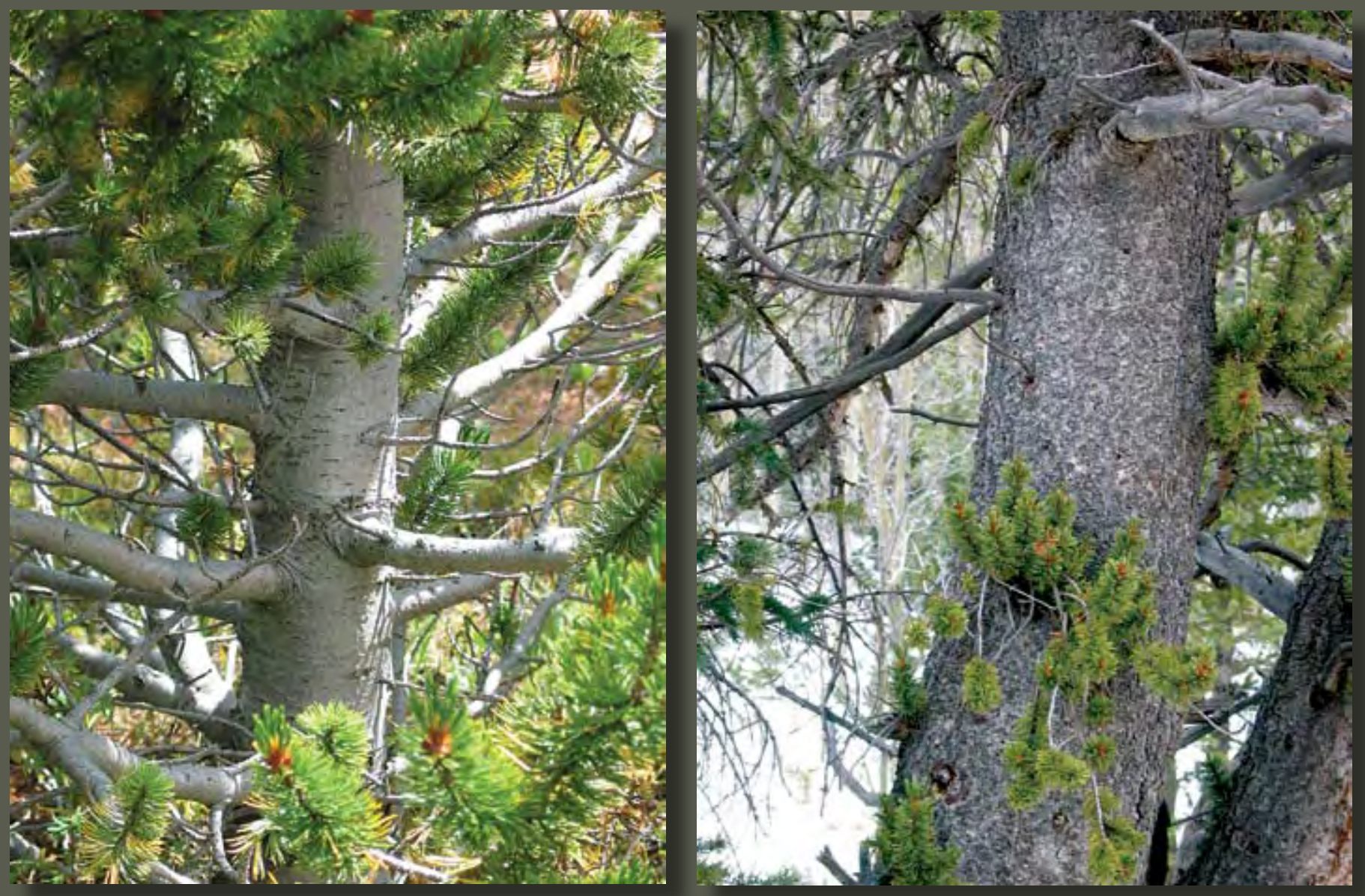
A

B

Figure 3. Bristlecone pine bark. A, Typical appearance of the middle to upper trunk of bristlecone pines about $80-140$ years old. The mostly smooth, silvery bark is tinged red on some trees. (Photograph taken September 9, 2005. Southern Front Range.) B, Typical appearance of the trunk of bristlecone pines about 150-300 years old. Note the young branches growing from old branch nodes on the trunk. A few dead limbs are also visible. (Photograph taken January 15, 2006. South Park area.) 


\section{Spiral Grain}

ounterclockwise spiral grain similar to that observed by many other researchers in other coniferous species is visible on the trunks of some of the bristlecone pines-in the exposed wood of living and dead trees and in the bark-enclosed trunks of relatively young trees. Some of the trees that have bark-enclosed trunks have spiral wounds in the bark, and such wounds have seeping pitch. Such wounds might be rips caused by the spiral twisting itself, or they might be wounds caused by lightning that has followed the spiral grain.

The origin of spiral grain is attributed to various causes. One proposed cause is the Coriolis effect of the Earth's rotation, which causes hurricanes and water in drains (in the Earth's northern hemisphere) to have a counterclockwise rotation (Gedney, 1986). Another cause is proposed by Skatter and Kucera (1998), who studied wind maps to determine that most coniferous forests have prevailing westerly winds, which when combined with crown asymmetry (Skatter and Kucera state that most trees have heavier crowns on the south side of the tree), cause a counterclockwise torque to be exerted on the crown. They state that such torque, over time, possibly causes a tree trunk to twist slowly in a counterclockwise rotation. Skatter and Kucera (1998) postulate that "Right-handed [counterclockwise] spiral grain in the outermost layers of mature trees is a strategy to withstand this torque, i.e. to avoid stem breakage." Trefil (1986) notes the prevalence of right-handed spiraling over left-handed spiraling of DNA in living things, and he suggests a genetic origin of spiral grain in trees.

\section{Bark-Enclosed Trunks and Cambial Dieback}

ree trunks that have cambial dieback have small to large areas of exposed, weathered or erosion-sculpted wood (see fig. 4). A few dated trees as young as about 200 years old (as well as a few undated trees that look to be less than about 100 years old) have mostly small areas of cambial dieback on their trunks; the rest of the sampled trees younger than about 500 years old have bark-enclosed trunks. About half of the dated trees that range in age from about 500 to 700 years have bark-enclosed trunks, and the other half have some to extensive cambial dieback. All of the dated trees more than about 700 years old have some to extensive cambial dieback on their trunks.

\section{Crown Dieback}

rees that have crown dieback have partially to completely dead crowns (see fig. 7). Two dated trees about 200 and 350 years old have crown dieback; all of the other dated trees less than about 450 years old have no discernible crown dieback. About half of the dated trees that range in age from about 450 to 550 years have no discernable crown dieback, and the other half have crown dieback. All of the dated trees more than about 550 years old have crown dieback. Some of the trees possibly continue to grow slightly taller at ages of as much as about 550 years, because that is the maximum age at which some of the trees do not have crown dieback. 

Bristlecone pines on a steep, rocky slope at an altitude of about 11,100 feet. Note how most of the trees lean downslope, which is probably caused by the slow, downslope movement (creep) of the cobble and boulder talus. View is toward the northeast. None of the living trees in this view are older than 1,000 years; however, some of the trees elsewhere on this mountain slope are more than 2,000 years old. The cobble and boulder talus is composed of extrusive andesitic volcanic lava and welded ash-flow tuff of Oligocene age. (Photograph taken September 1, 1990. South Park area.)

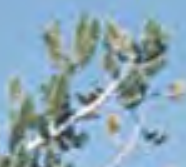

litis: $2=$

to.

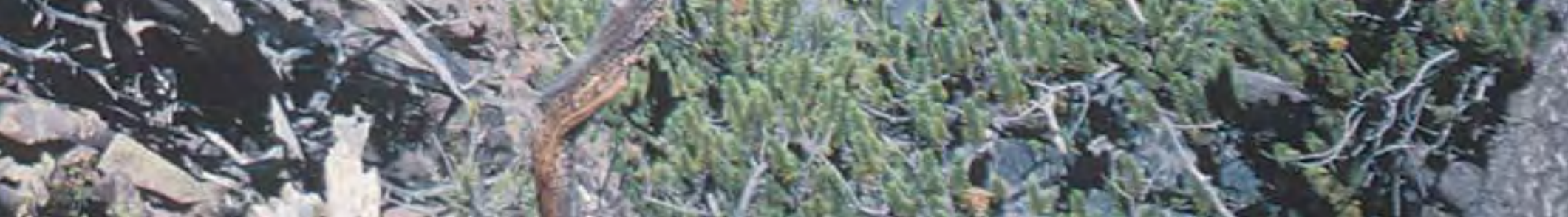
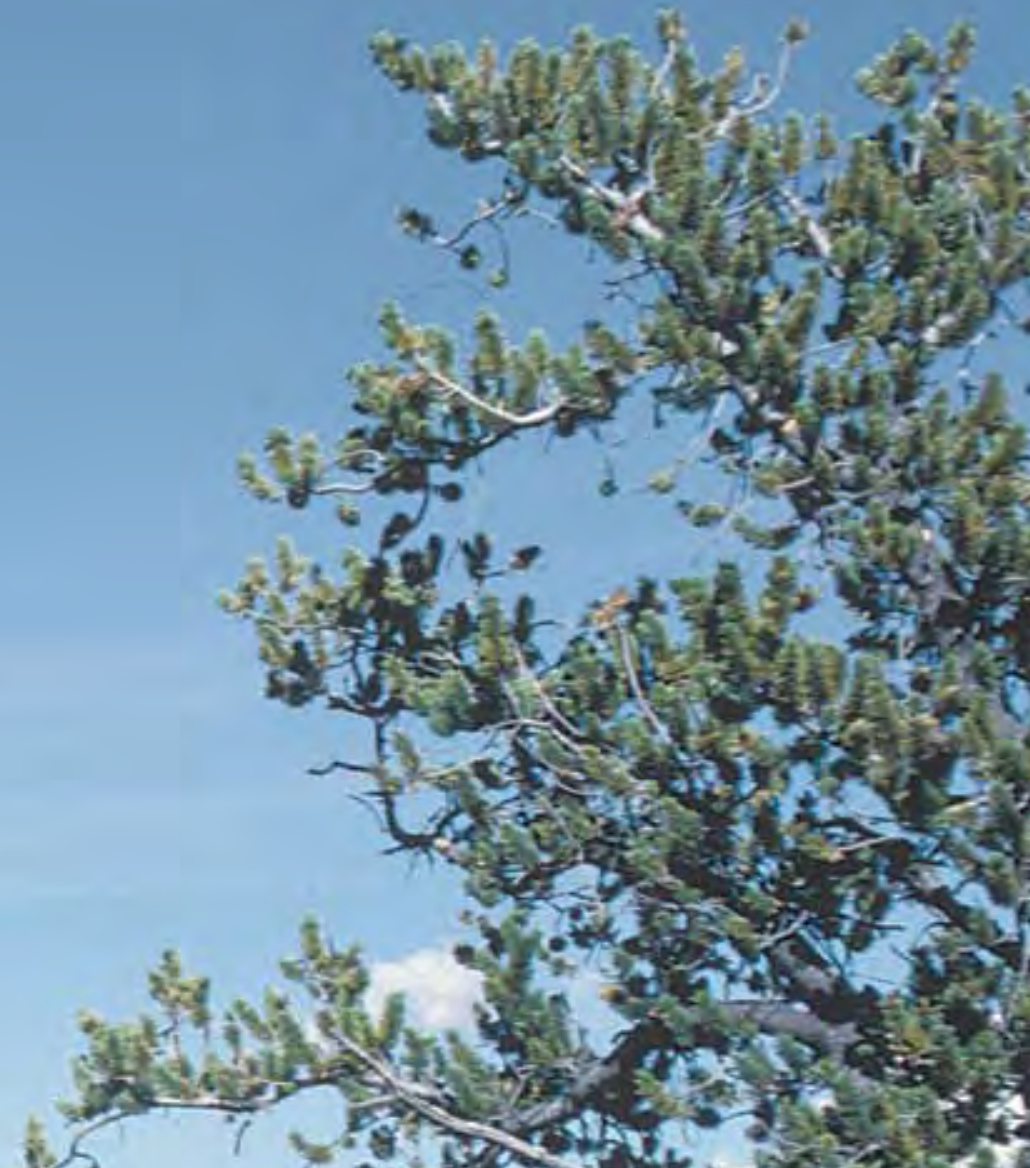

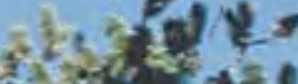

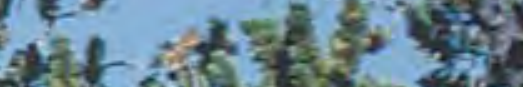

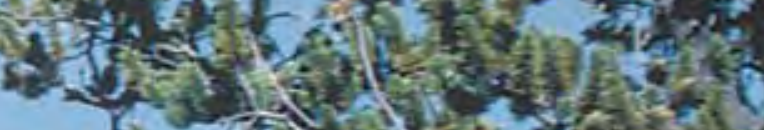

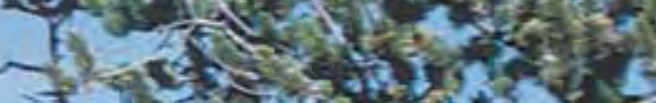

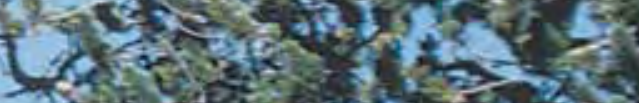
(3)

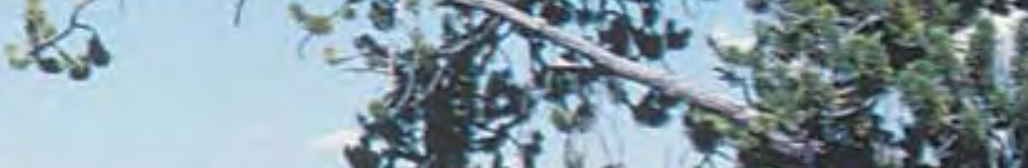

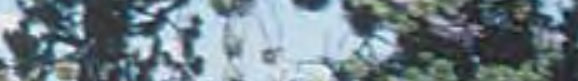

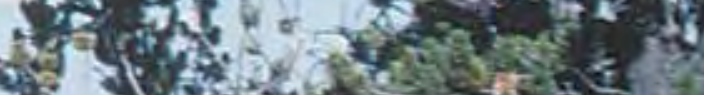

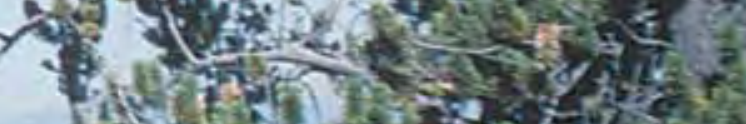

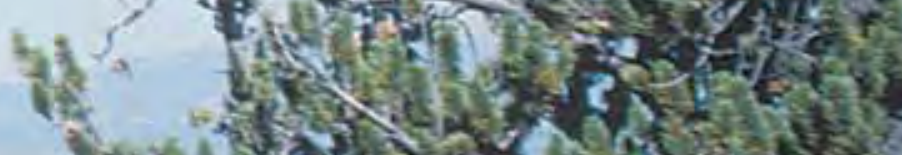

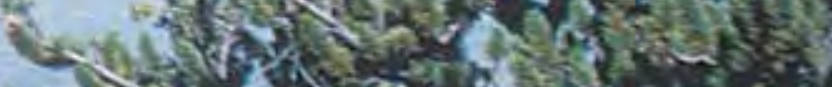

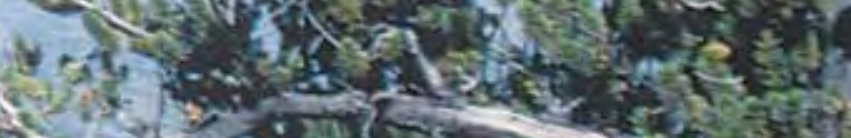
W

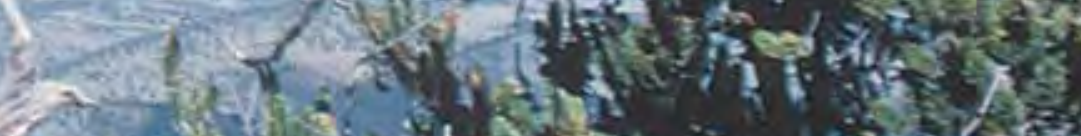

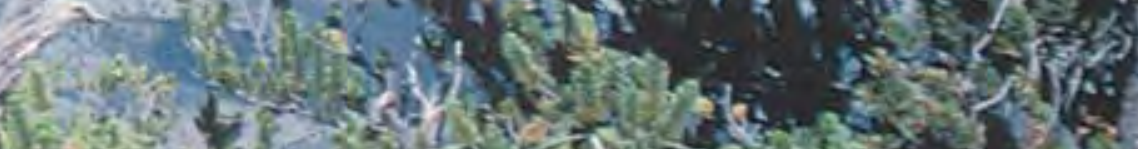

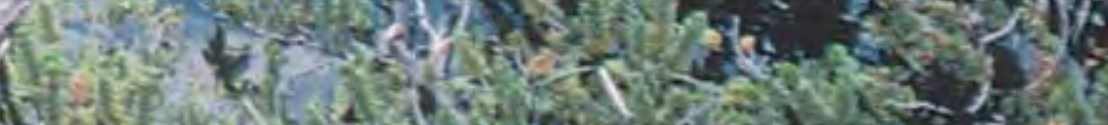


Figure 4. (Facing page) Inferred horizontal section views of bristlecone pines $2-4$ feet above ground and above basal root flare. (None of the trees were harmed to make these sketches.) Inferred sections are shown in order of increasing tree age. North is at the top of the page. Scale is the same for all drawings. Additional data for some of the trees are in table 13 in the Appendix. Note that on trees 91-14 and 91-28, the pith has eroded away, and circle with dot indicates approximate location where pith was probably located earlier in these trees' lifetimes. Probable past location of pith is also inferred in areas of heart rot on trees 68-R4, 68-3, 90-10, and 90-11. Extent of heart rot in tree 90-11 is approximate, and was determined from two core samples; heart rot in other trees could be visually observed. Inferred sections for most of the trees were made from detailed measurements around the circumference of each tree by using a tape measure. Section sketches for trees 88-10 and 68-3 are the most accurate sketches presented here because they were drawn using the aid of a rectangular meter stick apparatus that was placed on the trunk of these trees (F.C. Brunstein, USGS, unpublished method, 1992). The section view for tree 91-2 was drawn hurriedly in the field and is the least accurately drawn of the sketches. Growth-form classifications of the trees in this figure (see Appendix and text for descriptions of these forms):

91-41AL, 93-17, 90-3, 93-10-circular trunk

90-5-nearly semicircular trunk

95-11—nearly semicircular trunk or nearly circular trunk

91-8—nearly circular trunk

95-13, 91-2-irregular trunk

91-7, 93-38, 88-7, 93-45, 88-20, 88-8, 93-R18, 88-10, 93-55, 68-R4, Krebs 34, 90-4, 68-3, 90-1, 91-28, 90-10, 90-11-slab. (Trees 91-7 and 91-38 arguably might be classified as having elliptical trunks. On tree 88-20, the prominent southward-jutting lobe nearly disappears 2 feet higher on the trunk.)

\section{1-14, 93-39—opposite bark strips slab}

Tree $91-7$ is about 15 feet from tree $91-8$. The trees are comparable in age, but the difference in form is striking. The likely reason for the difference in form is that tree 91-7 probably developed cambial dieback at a much earlier age than tree 91-8. In addition, tree 91-7 has developed strip-bark growth, but tree 91-8 retains living bark on most of the circumference of its trunk, enabling the tree to produce a relatively large, nearly circular trunk.

For most bristlecone pines that have cambial dieback, such dieback is probably initiated by wind-induced desiccation and scouring by wind-driven ice and soil particles (Schauer and others, 2001; La Marche, 1969). All of the trees in this figure that are about 500 or more years old have some to extensive cambial dieback. Initial cambial dieback for most of the trees seems to have started on the northwest, west, or southwest side of the trees. Such initial cambial dieback is probably caused by northwesterly, westerly, and southwesterly regional and (or) topographically influenced winds. Note, however, that the location of the bark strip and the radial growth direction of the bark strip on many of the trees do not seem to be directly related to the inferred prevailing wind directions. This study suggests that as cambial dieback progresses to strip-bark growth, the eventual location of the bark strip and the radial growth direction of the bark strip are strongly influenced by the erodibility and stability of the substrate.

The inferred, topographically influenced, prevailing wind direction is upslope for trees 88-7 and 88-8. Thus, for these trees, both the prevailing wind direction that probably caused initial cambial dieback and the upslope radial-growth direction coincide.

Initial cambial dieback for some of the trees seems to be caused by factors unrelated to prevailing wind direction. For example, for trees 88-10 and 93-39, initial cambial dieback seems to have occurred on the upslope, north side of the trees. The presence of impact scars on the upslope side of several nearby bristlecone pines suggests that impact damage to the upslope side of tree 88-10 might have been the cause of initial cambial dieback on this tree. A healed lightning scar seems to be present on the upslope side of tree 93-39, which might be a contributing or causal factor of initial cambial dieback on this tree.

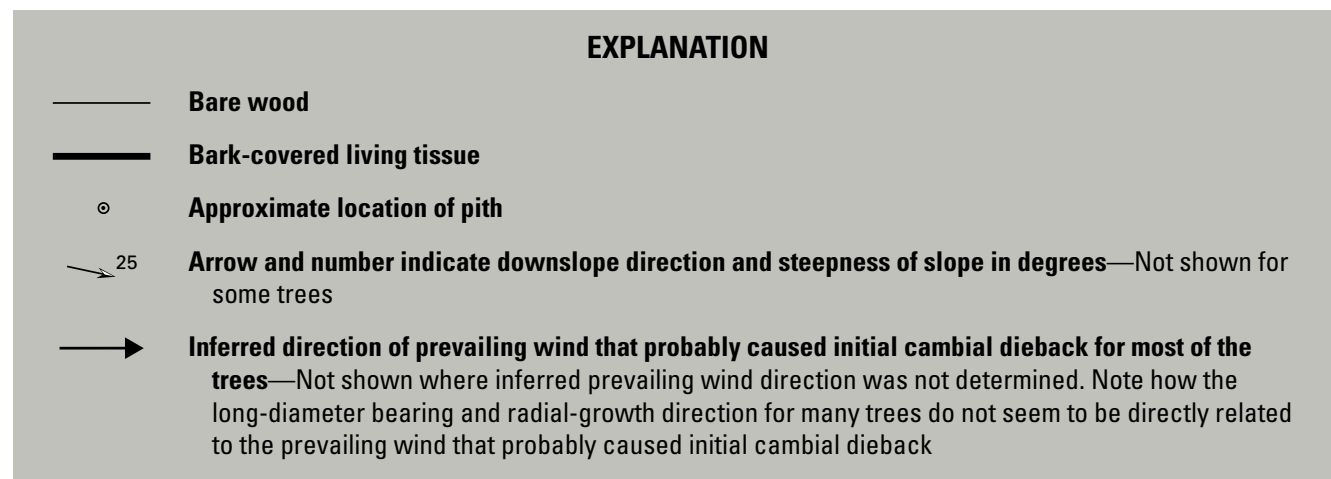




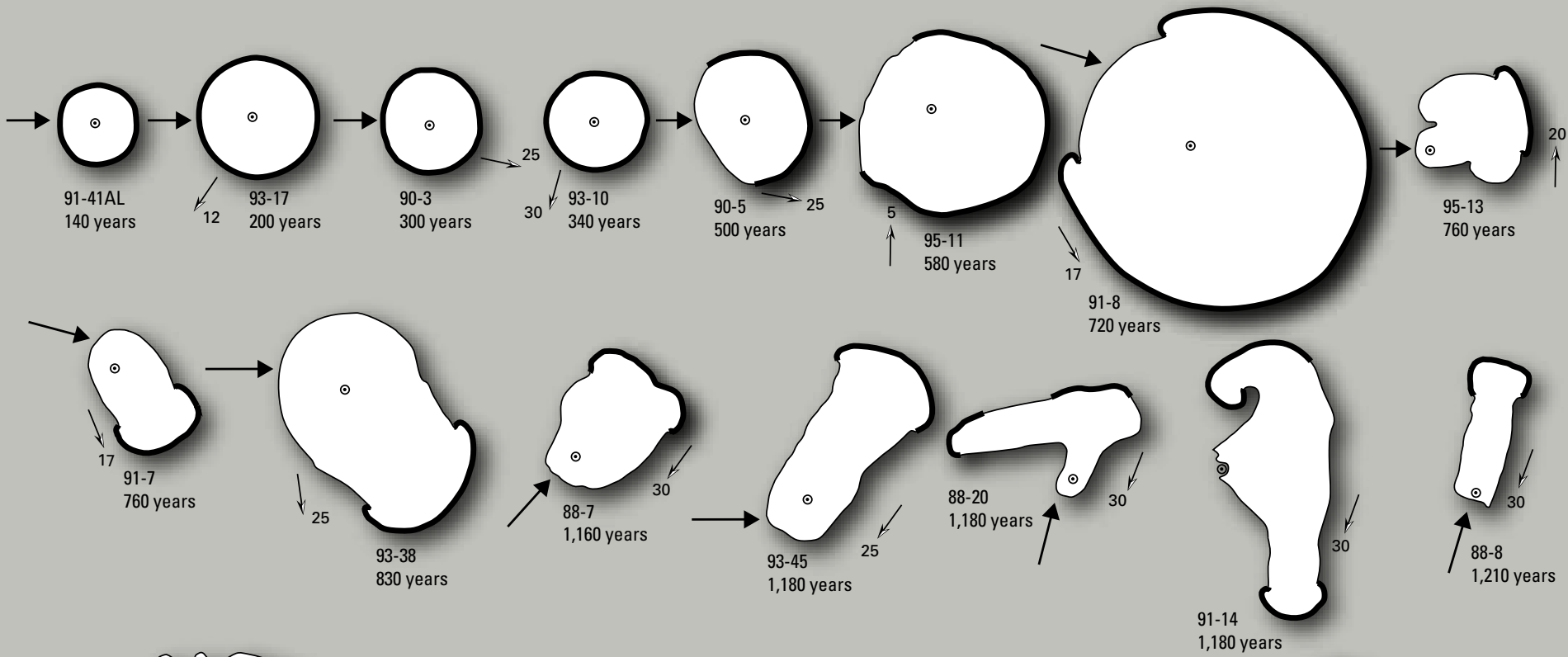

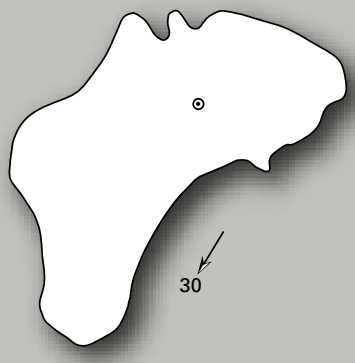

93-R18 (dead tree) 1,400 years

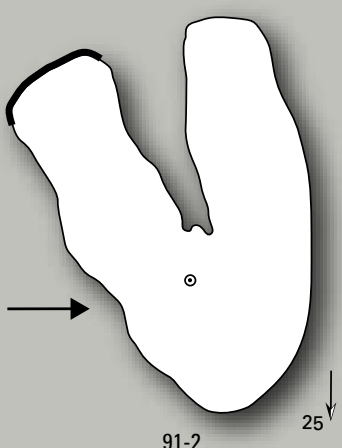

1,850 years
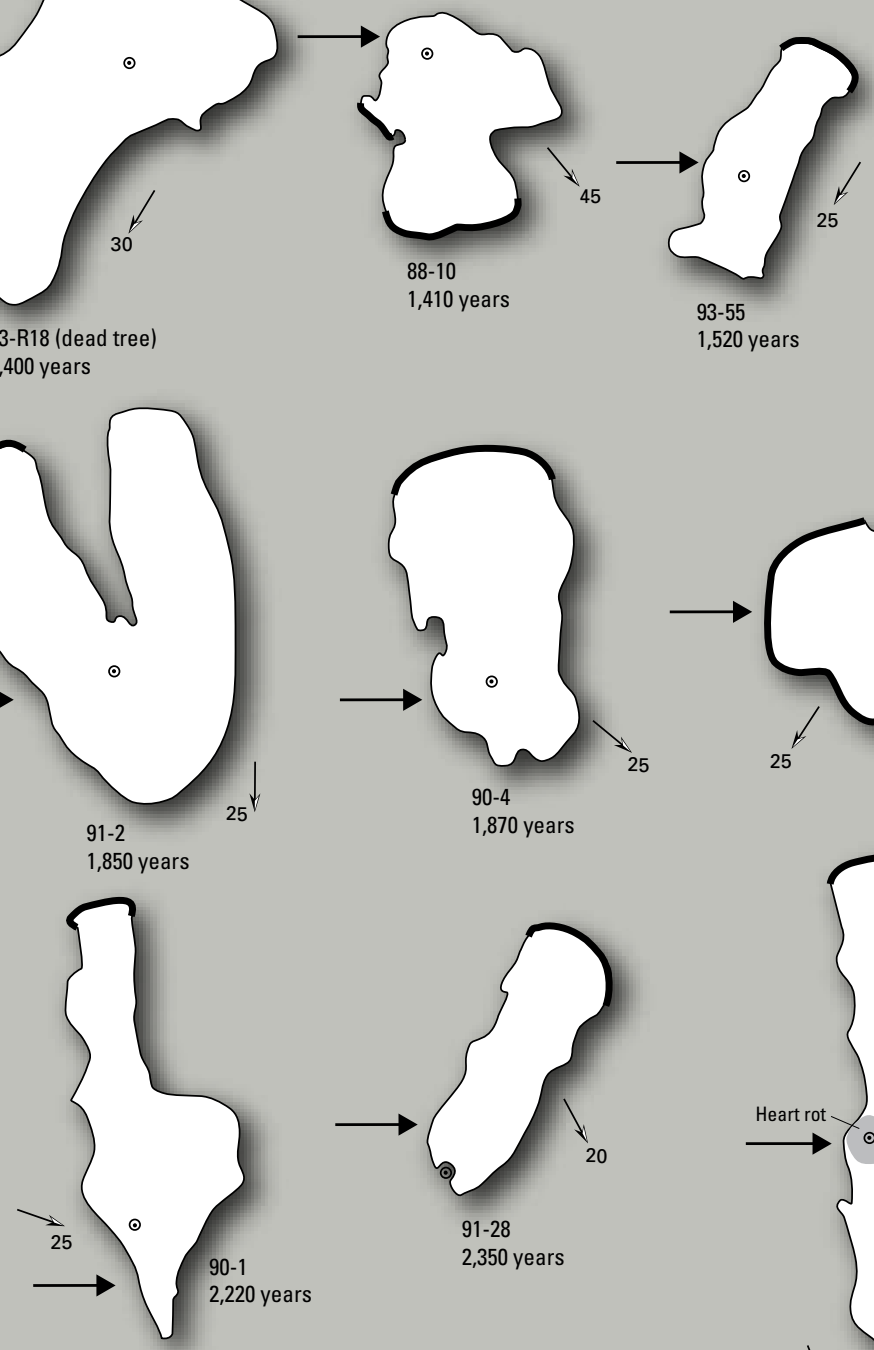

1,520 years
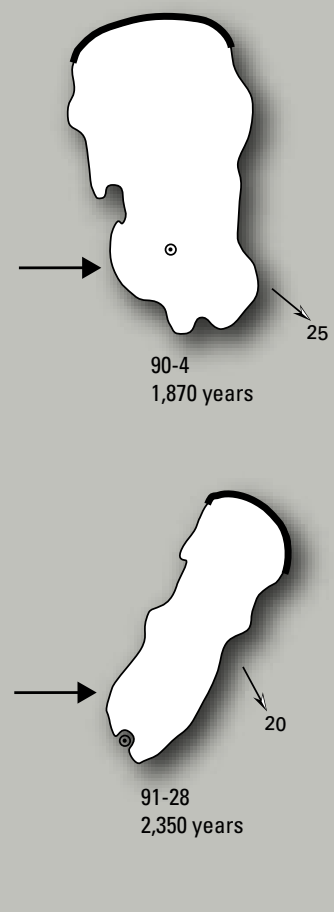
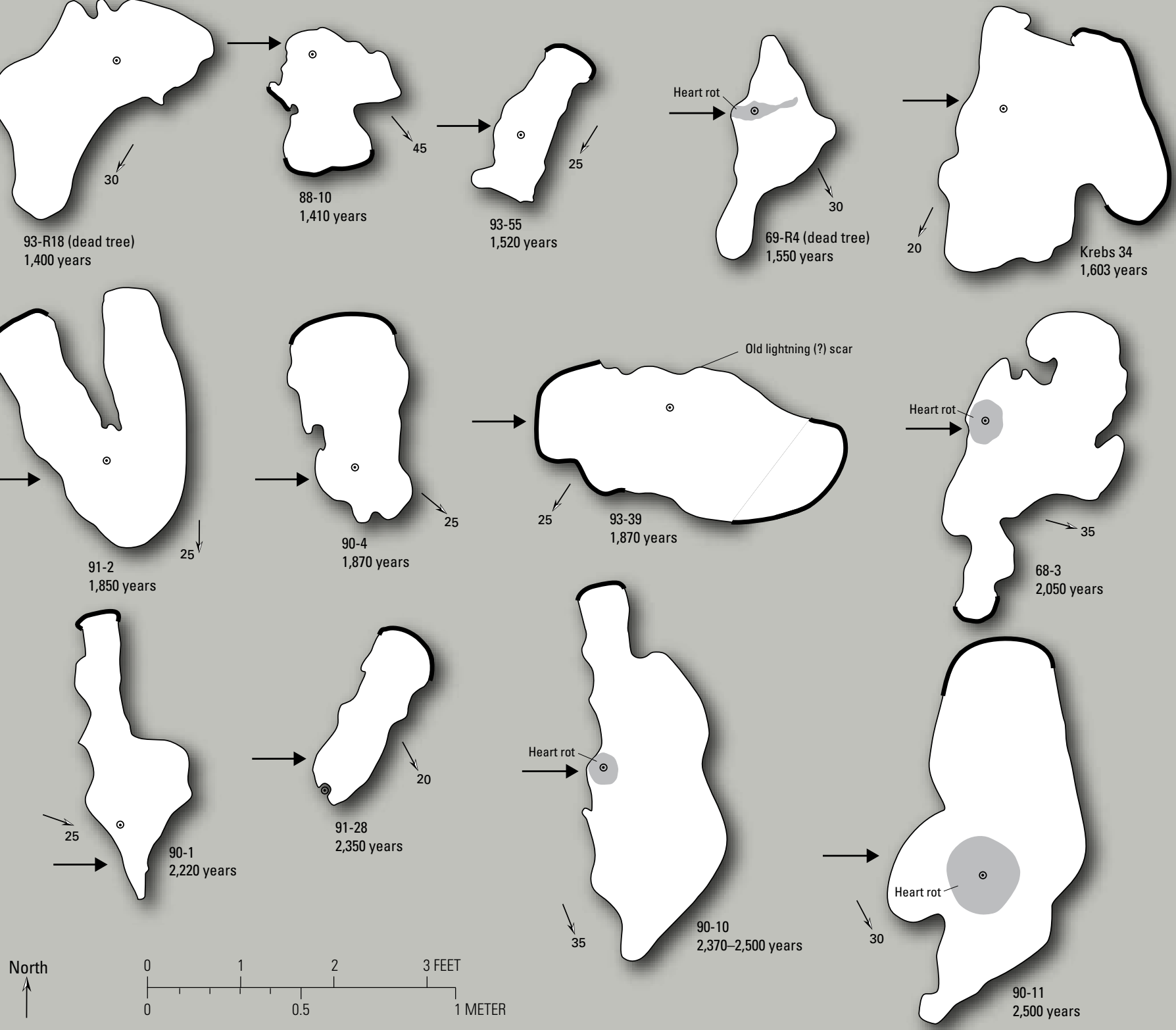
Figure 5. Living bristlecone pine about 300 years old (tree $90-3$ ). This tree has a circular trunk (see fig. 4) that is completely bark enclosed. It has more than 20 living limbs (first-order branches), and the tree does not have crown dieback. The lower trunk of the tree is covered with dark-gray, scaly, furrowed bark. Prevailing winds are from the right. Note that limbs and branches on the windward side of the tree are shorter than those on the leeward side. The tree is about 15 feet tall and is growing on a relatively arid site- some of its neighbors include living trees that range in age from about 1,870 to 2,220 years. Bedrock and cobble and boulder talus are composed of extrusive andesitic volcanic lava and welded ash-flow tuff of Oligocene age. (Photograph taken September 1, 1990. South Park area.)

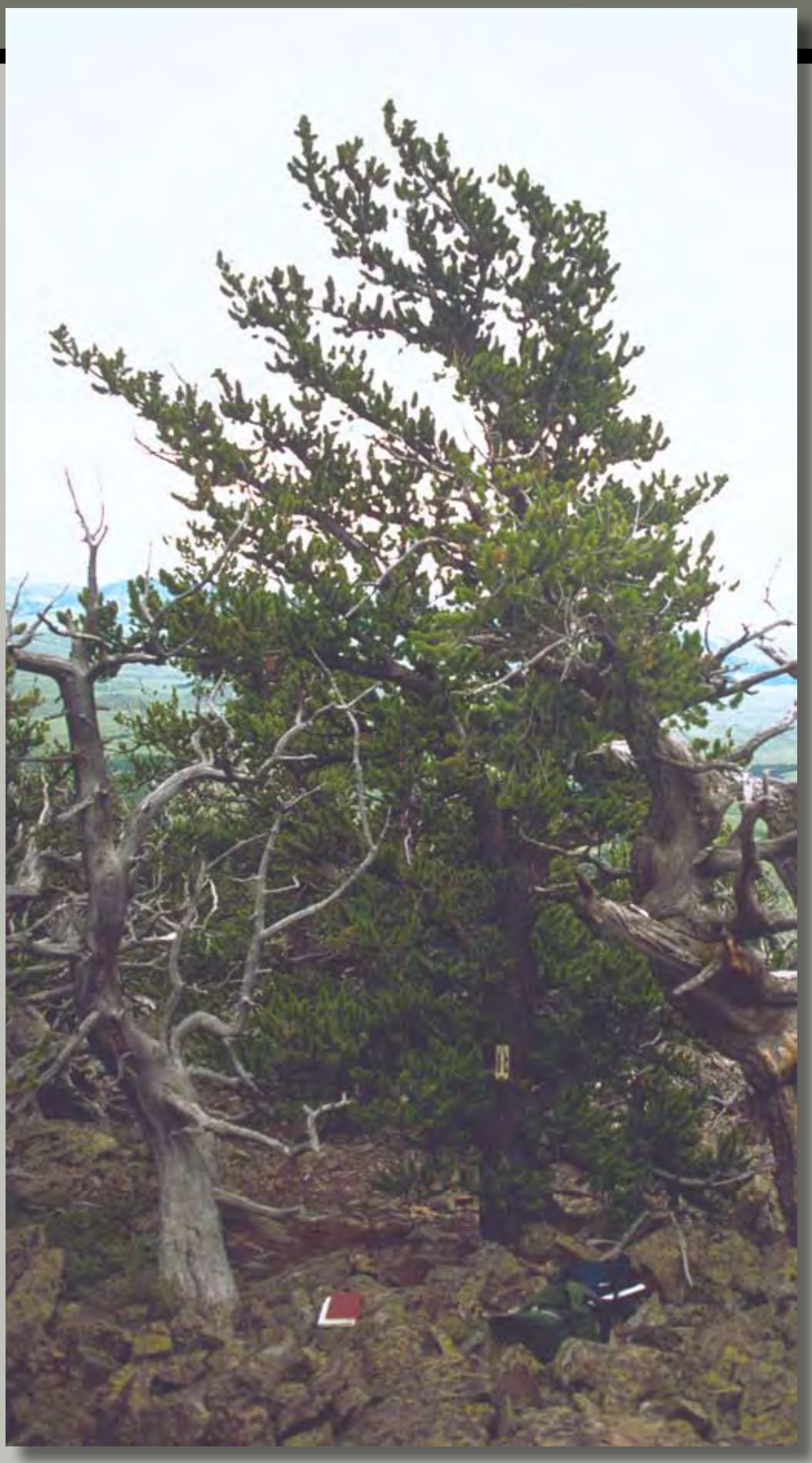




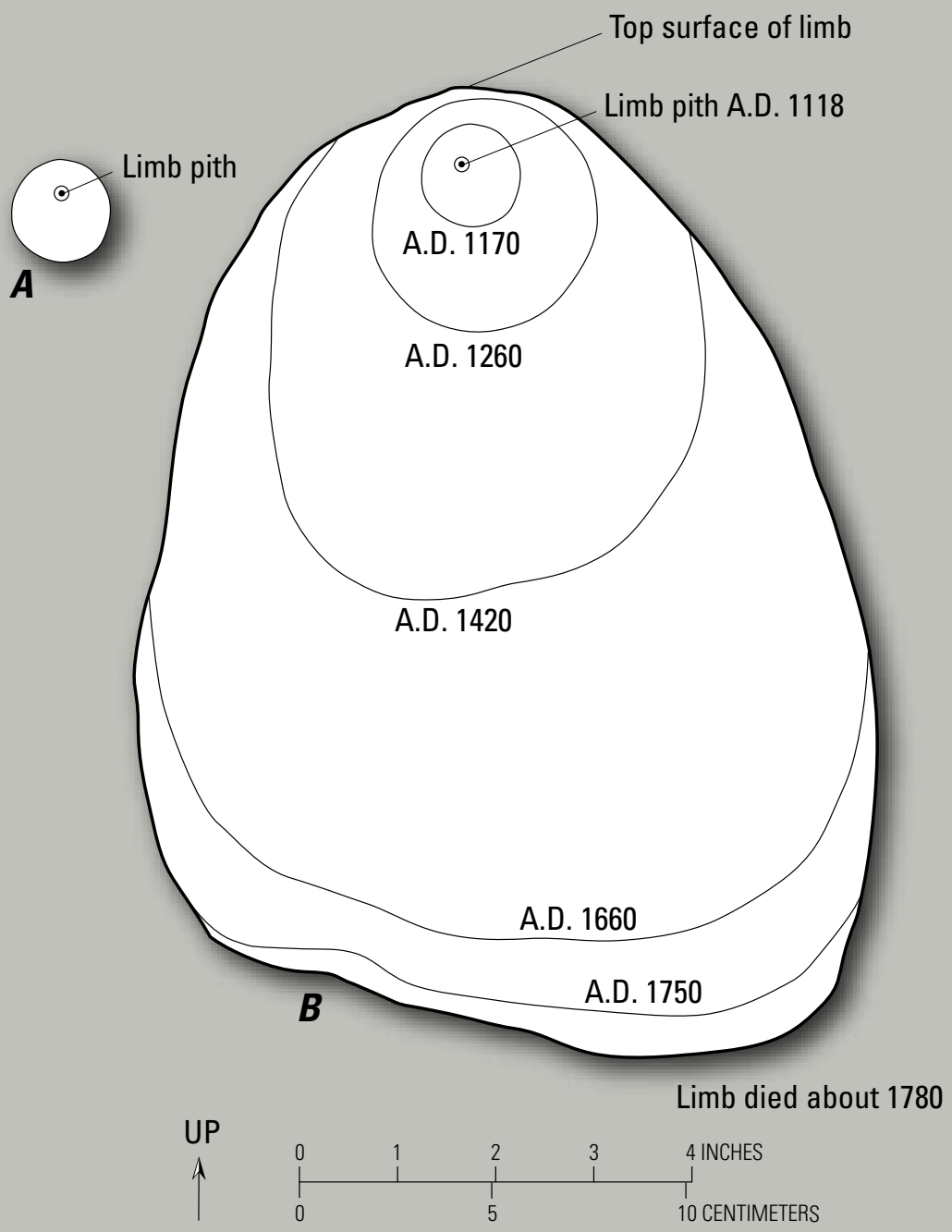

Figure 6. Vertical sections through two dead bristlecone pine limbs. Both limbs do not have bark. Sections are near the trunks of the trees (within 6 inches). $\boldsymbol{A}$, Section through small dead limb on a bristlecone pine at an altitude of about 11,300 feet, southern Front Range. Limb was about 50 years old when it died (as determined from radius extending from the limb pith to the lower side of the limb). Annual rings in the lower radius have typical reaction (compression) wood. Radius extending from the limb pith to the upper surface of the limb has only 35 rings. $\boldsymbol{B}$, Limb section from dead bristlecone pine at an altitude of about 11,600 feet. Such growth is probably typical of most old limbs on ancient bristlecone pines. Inner-ring date of the limb is A.D. 1118, and the limb died about A.D. 1780. Note how the growth rate on the underside of the limb exceeds that of the upper side. The upper side of the limb died (cambial dieback) early on in the lifespan of this limb. The extent of annual rings in this drawing shows how the limb developed strip-bark growth similar to that seen on the trunks of bristlecone pines (see fig. 18). Reaction (compression) wood is evident in many of the annual rings from A.D. 1118 to about 1250 in the lower radius. Ring widths are greatest near the mid points of the arcs formed by the A.D. 1420,1660, and 1750 annual rings; rings become progressively narrower toward the ends of the arcs. Limbs that have longer lifespans are more elongated along the vertical axis. Inferred vertical sections through such limbs can have rectangular or slab-like forms, similar to inferred section views of some of the slab-form trunks of old bristlecone pines (see fig. 4). 
Figure 7. Living bristlecone pine about 510 years old. Note crown dieback (numerous dead limbs and branches at the top of the tree). Fewer than 20 limbs are living. The lower half of the trunk of this tree is completely enclosed in rough, furrowed, platy bark that is various shades of gray; however, the platy bark is tinged reddish brown on the lower trunk. Over the next 1,500 years, if this tree survives, all remaining living limbs except for one probably will die. This tree is growing on a relatively arid site-its neighbors include living trees that range in age from about 1,870 to 2,220 years. Red increment borer handle is about 18 inches long. Bedrock and cobble and boulder talus are composed of extrusive andesitic volcanic lava and welded ash-flow tuff of Oligocene age. (Photograph taken September 1, 1990, of tree 90-8, South Park area.)

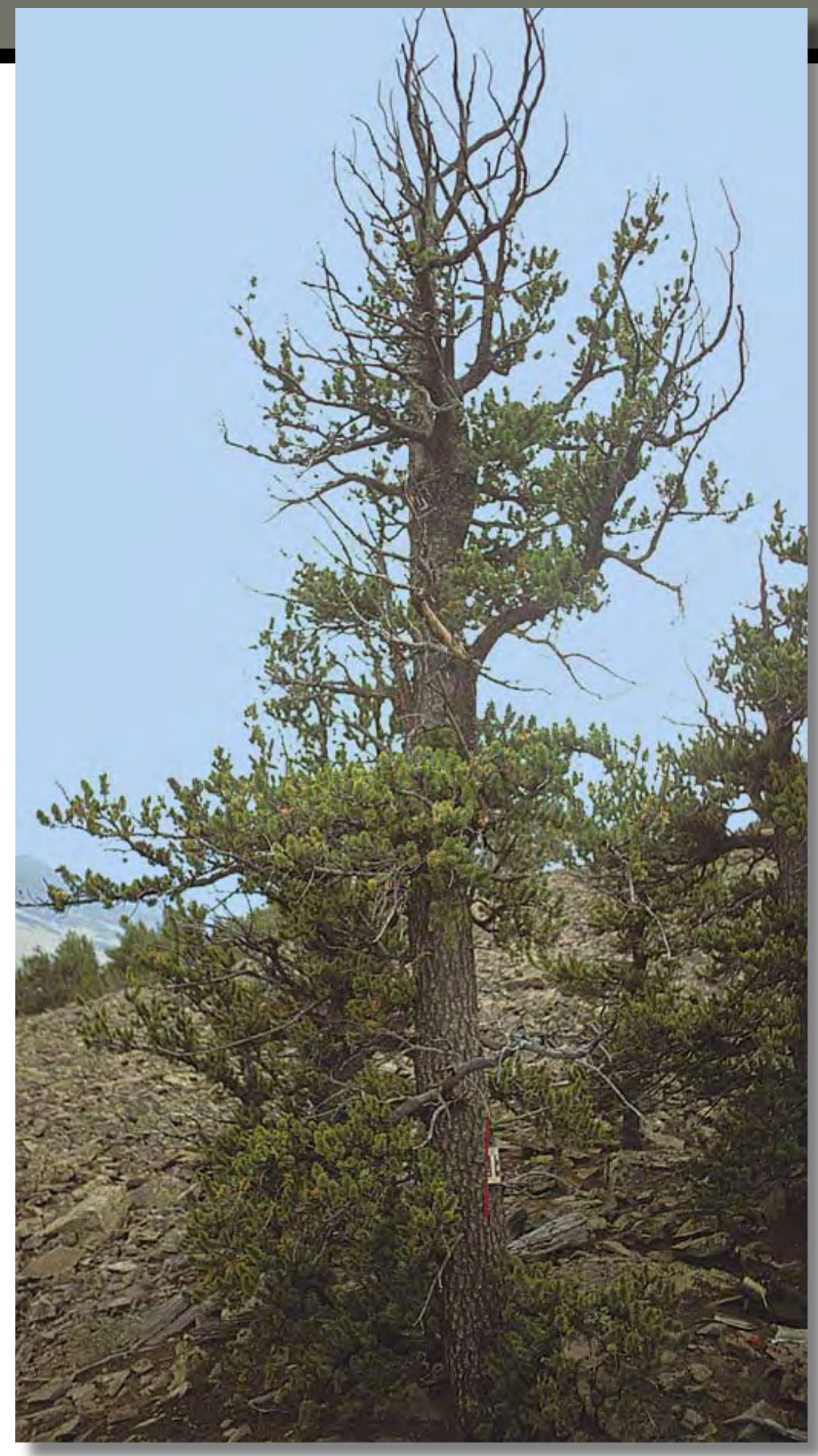


Table 2. Heights of living bristlecone pines in this study.

[Total number of trees is 100 . Heights of some of the trees were measured with a tape measure; however, most were visually estimated. See "Methods" section for an explanation of the suggested accuracy of height measurements and estimates]

\begin{tabular}{l|lllll}
\hline Age class & $80-200$ & $201-350$ & $351-500$ & $501-999$ & $1,000-2,500$ \\
Height range (feet) & $12-30$ & $15-35$ & $12-30$ & $14-35$ & $6-30$ \\
Number of trees & 16 & 13 & 14 & 15 & 42 \\
\hline
\end{tabular}

Table 3. Diameters of living bristlecone pines that have circular or nearly circular trunks.

[Total number of trees measured is 52. Measurements were made 3-4 feet above ground. Diameter measurements include the thickness of the bark-typically $1-2$ inches]

\begin{tabular}{lccccc}
\multicolumn{1}{c}{ Age class } & $\mathbf{8 0 - 1 5 0}$ & $\mathbf{1 5 1 - 2 5 0}$ & $\mathbf{2 5 1 - 3 5 0}$ & $\mathbf{3 5 1 - 5 0 0}$ & 501-999 \\
\hline Average diameter (inches) & 8 & 10 & 11 & 14 & 22 \\
Diameter range (inches) & $5-11$ & $5-12$ & $9-16$ & $11-16$ & $13-30$ \\
Number of trees & 11 & 11 & 14 & 11 & 5 \\
\hline
\end{tabular}

Table 4. Long diameters and long radii of living slab-form bristlecone pines.

[See figure 21 for an illustration showing long radius and long diameter. Total number of trees measured is 50 . Measurements were made 2-4 feet above ground. Long diameter and long radius measurements include the thickness of the bark-typically $1-2$ inches]

\begin{tabular}{llllc}
\multicolumn{1}{c}{ Age class } & $\mathbf{7 5 0 - 9 9 9}$ & $\mathbf{1 , 0 0 0 - 1 , 5 0 0}$ & $\mathbf{1 , 5 0 1 - 2 , 0 0 0}$ & $\mathbf{2 , 0 0 1 - 2 , 5 0 0}$ \\
\hline Long diameter average (inches) & 18 & 19 & 33 & 40 \\
Long diameter range (inches) & $13-27$ & $10.5-28$ & $19-45$ & $23-48$ \\
& & & & \\
Long radius average (inches) & 13 & 14 & 20 & 25 \\
Long radius range (inches) & $9.5-17$ & $9-19$ & $12-23$ & $22-30$ \\
& 7 & 25 & 13 & 5 \\
\hline
\end{tabular}




\section{Growth-Form Characteristics of Bristlecone Pines $1,000-2,500$ Years Old}

\section{Summary Description}

ypical bristlecone pines in this age class have trunks that have exposed, erosionsculpted wood; crown dieback; a prominent, dead, erosion-sculpted pith spike; usually only one bark strip covering as little as 5-10 percent of the circumference of the trunk; and usually only one or two living limbs. However, some of the trees have as many as three bark strips and four living limbs. Each of the six oldest bristlecone pines in this study (ranging in age from about 1,980 to 2,500 years old) has only one bark strip and one living limb. The width, location, orientation, and number of living bark strips and the location, orientation, number, size, and attachment heights of living limbs and branches determine the forms of most of the studied bristlecone pines 1,000-2,500 years old. Forms of 45 of the trees in this age class were classified as follows: slab (34 trees), opposite bark strips slab (4 trees), twisted slab ( 3 trees), irregular-shape trunk ( 3 trees), and multi-stem ( 1 tree). The shortest tree measured is 6 feet tall, and the tallest tree was visually estimated to be about 30 feet tall. Tree height generally decreases as altitude increases, and trees on ridge tops and other exposed and windy sites are shorter than trees on more sheltered midslope sites. The average bark-strip width is 15 inches (minimum 2-3 inches; maximum 48 inches), and the average attachment height of living limbs is 6 feet (minimum 1 foot; maximum 16 feet). For slab-form trees, long diameters range from 10.5 to 48 inches and long radii range from 9 to 30 inches. Of 33 trees 1,000-2,500 years old, 26 each have a single bark strip on the upslope side of the tree.

Cambial dieback due to wind-induced dessication and scouring by wind-driven ice and soil seems to be the precursor or beginning of strip-bark growth for most bristlecone pines as suggested by other researchers. Evidence at the bristlecone pine sites in this study supports that finding. However, observations made in this study suggest that as most bristlecone pines growing on steep mountain slopes get older, the erodibility and instability of the substrate on which the trees grow become major factors that determine the eventual location and radial growth direction of the trees' bark strips. Most of the 1,000- to 2,500-year-old bristlecone pines growing on steep slopes composed of relatively erodible and unstable substrates (loose talus, loose gravelly soil, friable granite bedrock) each have exposed dead roots on the downslope side of their trunk and a bark strip at the base of the upslope side of their trunk; such bark strips have radial growth toward the mountain slope. Sediment damming on the upslope base of the trunk provides a protective covering for roots on that side of the tree and helps to maintain tree stability (due to roots in the sediment anchoring the upslope side of the tree, thus preventing the tree from falling downslope). Such sediment damming and radial growth toward the mountain slope possibly also serve to decrease the distance from roots to living branches on the upslope side of some of the trees. In contrast, the downslope base of the trunk is eventually undercut by erosion, which increases the distance from roots to living branches and eventually causes the death of undercut roots. Such factors probably contribute to a higher mortality rate for bark strips on the downslope side of the trees as compared to bark strips on the upslope side.

The average long-diameter bearing of slab-form bristlecone pines on southeast-facing slopes is N. $10^{\circ}$ E., and for southwest-facing slopes it is N. $28^{\circ}$ E. The predominant northnortheasterly bearings are possibly the result of a combination of optimum (1) root growth and bark-strip radial growth on the upslope side of the trees (with radial growth of bark strips toward the mountain slope), which enhances tree stability and increases the chances of root survival as compared to the downslope side of trees where roots are usually undercut by erosion and (2) radial growth of bark strips in a north-northeasterly direction, which probably provides some protection of the bark strip from wind-induced desiccation and scouring by wind-driven ice and soil from westerly, southwesterly, southerly, and southeasterly wind directions. 
Several bristlecone pines more than 1,000 years old are growing on steep slopes composed of stable substrates (solid bedrock, stable boulder talus, or stable bouldery soil) that have relatively low erodibility. Such trees have few or no undermined dead roots on the downslope side (or any other side) of the trunk and bark strips at locations other than the upslope base of the tree. The relatively low erodibility of these substrates probably prevents undercutting of the trees' roots and enables survival of bark strips and roots at the base of the trunks at locations not limited to the upslope side of the trees. The stability of the substrates probably enables the trees to remain stable (not fall over) regardless of where the bark strips and roots are located.

\section{Pith Spike}

All of the trees in this age class have crown dieback, and all that remains of the upper part of the trunk of most of the trees is an eroded, vertical wood "spike" that has a few erosion-sculpted dead limbs, or there are no projecting dead limbs because such limbs were long ago eroded flush with the surface of the spike (figs. 8-14). Such a spike contains the pith and is referred to in this report as a "pith spike" (figs. 8-14 and table 5). The pith spike is one of the most eroded parts of the tree, because it is one of the oldest parts of the tree-it is all that remains of the top of the tree's erect youthful stem.

In this report, the word "pith" in the term "pith spike" gives the term a unique meaning, because the pith is present only in the main stem of the tree. This usage differentiates the word "pith" and the term "pith spike" from other tree structures such as "limb pith, limb spike, second-order branch pith, second-order branch spike" (and so on), which are used throughout this report (see table 5 and figs. 8-14).

Some researchers use the term "spike top" to label the dead top of a tree that has crown dieback. However, this term was not satisfactory for this study for the following reasons:

(1) It indicates that the spike is the top of the tree, which is not the case for many of the bristlecone pines in this study. For many of the trees, living branches are taller than the spike.

(2) It does not indicate the origin of the spike as the dead upper part of the main stem. Several trees in this study have prominent limb spikes (see fig. 15). Therefore, a more specific term was needed.

Two of the trees in this study do not have a pith spike. On one of those trees, the top of the original main stem probably died early in the tree's life, and the dead top was probably eroded away (see fig. 15). A close examination of the other tree revealed that its pith spike had broken off. The upper stems of several trees in this study are forked-they split into two main stems (see fig. 11), thus each of these trees has two pith spikes. 


\section{Pollen Cones} Anclérit and Seed Cones
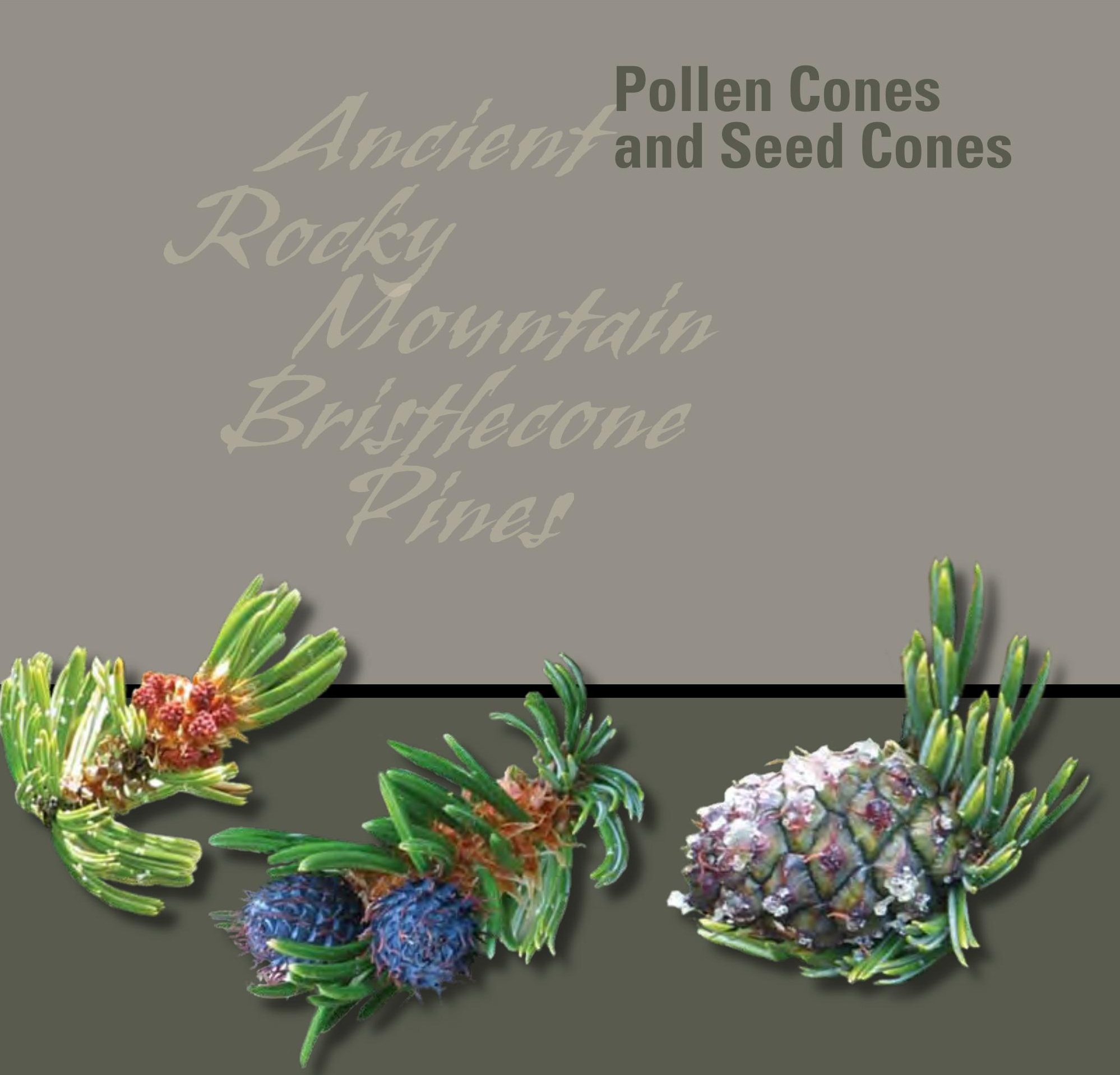
Table 5. Names (nomenclature) of major above-ground parts of living bristlecone pines $1,000-2,500$ years old. These features are labeled in figures $8-11$ and $13-15$.

\begin{tabular}{|c|c|}
\hline Nomenclature used in this study ${ }^{1}$ & Remarks \\
\hline trunk, main stem, stem & None. \\
\hline pith spike ${ }^{2}$ & $\begin{array}{l}\text { The pith spike is the dead part of the stem above the } \\
\text { junction of the stem with the highest living limb. }\end{array}$ \\
\hline pith & None. \\
\hline living limb, limb, first-order branch & None. \\
\hline limb spike, first-order branch spike & $\begin{array}{l}\text { The limb spike (first-order branch spike) is the dead part } \\
\text { of the limb above the junction of the limb with the } \\
\text { highest (or distal) living second-order branch. }\end{array}$ \\
\hline limb pith & None. \\
\hline second-order branch & None. \\
\hline second-order branch spike & $\begin{array}{l}\text { The second-order branch spike is the dead part of the } \\
\text { second-order branch above the junction of the } \\
\text { second-order branch with the highest (or distal) } \\
\text { living third-order branch. }\end{array}$ \\
\hline second-order branch pith & None. \\
\hline third-order branch & None. \\
\hline third-order branch spike & $\begin{array}{l}\text { The third-order branch spike is the dead part of the } \\
\text { third-order branch above the junction of the third-order } \\
\text { branch with the highest (or distal) living } \\
\text { fourth-order branch. }\end{array}$ \\
\hline third-order branch pith & None. \\
\hline fourth-order branch & None. \\
\hline fourth-order branch spike & $\begin{array}{l}\text { The fourth-order branch spike is the dead part of the } \\
\text { fourth-order branch above the junction of the } \\
\text { fourth-order branch with the highest (or distal) living } \\
\text { fifth-order branch. }\end{array}$ \\
\hline fourth-order branch pith & None. \\
\hline
\end{tabular}

${ }^{1}$ In this report, this nomenclature system was used for tree structures that are visible during nondestructive study. For each living limb (first-order branch), only the major structures of the limb and its higher order major branches that are part of the succession of branches that lead to living needle-bearing branches are labeled (see figs. 8-11 and 13-15). Small living branches near and at the end of the succession are not labeled in this study.

${ }^{2}$ Schulman's (1958; p. 363-366) "pickaback" form of Great Basin bristlecone pine has three "stems" in a "Junior-Dad-Granddad" sequence ( $p .363)$. His "Great-Granddad Pickaback" tree (p. 364-366) has four "stems" in a Junior-Dad-Granddad-Great-Granddad sequence. I interpret the "Granddad" stem in his "pickaback" form and the "Great-Granddad" stem in his "Great-Granddad Pickaback" tree to be equivalent to the pith spike in this table. 


\section{Heights of the Pith Spike and Living Branches}

The height of the the pith spike and the maximum height of living branches were visually estimated for 22 trees that range in age from about 1,000 to 2,500 years. Fourteen of the 22 trees have living branches that are taller than the pith spike, 2 of the trees have living branches that are about the same height as the pith spike, and 6 of the trees have living branches that are shorter than the pith spike. The maximum heights of the living branches range from about 10 feet higher to about 15 feet lower than the heights of the pith spikes. That living branches on most of the trees are taller than the pith spikes suggests that the pith spikes may be losing height due to centuries of erosion by wind-driven ice and soil particles. Such erosion of the pith spikes probably began at the time the trees underwent crown dieback - for most of the trees, probably when the trees were about 450-550 years old (see "Crown Dieback" section). Therefore, for living bristlecone pines that are 1,000 to 2,500 years old, such erosion probably has been occurring for as little as about 450 years (for a 1,000-year-old tree) to as much as 2,000 or more years (for a 2,500-year-old tree).

\section{The Succession of Major Branches on a Living Limb}

Each living limb (first-order branch) consists of a succession of increasingly younger and higher order major branches-the succession ending in the youngest and smallest needle-bearing branches (see figs. 8-16). The succession of major branches is similar in concept to the "separate stems" of Schulman's "Junior-Dad-Granddad" pickaback form of Pinus longaeva in the White Mountains, California (Schulman, 1958). Table 5 and figures 8-16 describe and show, respectively, the nomenclature used in this report for the major parts of living ancient Pinus aristata, including the major parts of living limbs.

When Schulman (1958, p. 366) sectioned one of the about 4,000-year-old Pinus longaeva he studied, he found evidence of hidden branch structure that was not otherwise visible. Similarly, it is possible that some hidden structures are not accounted for in some of the drawings presented in this study. However, Pinus aristata first-order branching structure is usually straightforward and relatively easy to view on many of the ancient trees, probably because it forms very early in each tree's lifespan, when tree structure is relatively simple. Likewise, in some of the studied trees, second-order and higher order branching also appear to be relatively straightforward and easily viewed. However, the living limbs on some of the trees do seem to have a complex, partly hidden second-order and higher order branching history, possibly similar to what Schulman describes. Readers should keep that in mind when viewing the drawings and when viewing bristlecone pines in their natural environment. However, one of the goals of this report is to present a useful naming scheme for structures that are visible during nondestructive study of bristlecone pines.

\section{Orientations of Limbs and Branches}

Most limbs (as delineated by the limb pith lines in figures 8-14 and 16 and excluding second-order and higher order branches) were observed to be mainly horizontal (varying from horizontal to inclined as much as about $45^{\circ}$ above horizontal). However, figure 15 shows a multi-stem tree that has vertical limbs. Second-order and higher order branches were observed to be vertical, horizontal, or some intermediate inclination (figs. 8-16). Such differences in limb and branch orientations contribute to the variation in overall appearance of the trees. 
Figure 8. (This page and facing page) A, Living slab-form bristlecone pine about 1,100 years old (long diameter in view). Tree 88-5 has one living limb (first-order branch) attached to the trunk about 7 feet above ground. Thin, gravelly granitic soil and rounded boulders have weathered from granite bedrock of Precambrian age. (Photograph taken July 25, 1988. Southern Front Range.) $B$, Interpretive and simplified sketch showing the major structures of tree 88-5. Note that the limb (excluding second-order and higher order branches) is essentially a horizontal structure. Compare to figure 15 , where the limbs (excluding second-order and higher order branches) are vertical structures. This fundamental difference in limb structure creates tree limbs and trees that look different from each other. The inferred horizontal section for this tree is in part diagrammatic and is not as accurately drawn as the sketches in figure 4. See table 5 and the text for descriptions of some of the structures on this tree.

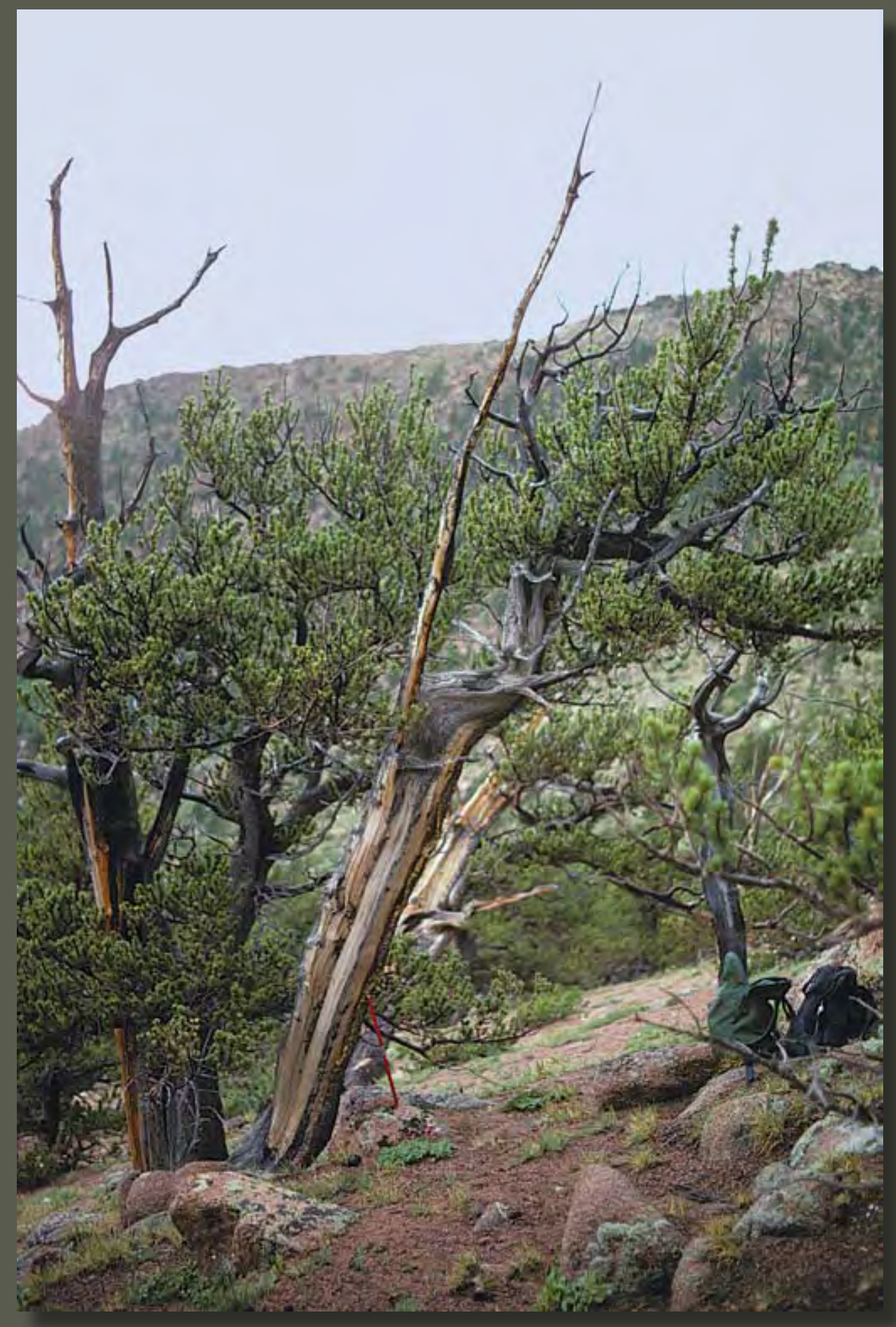




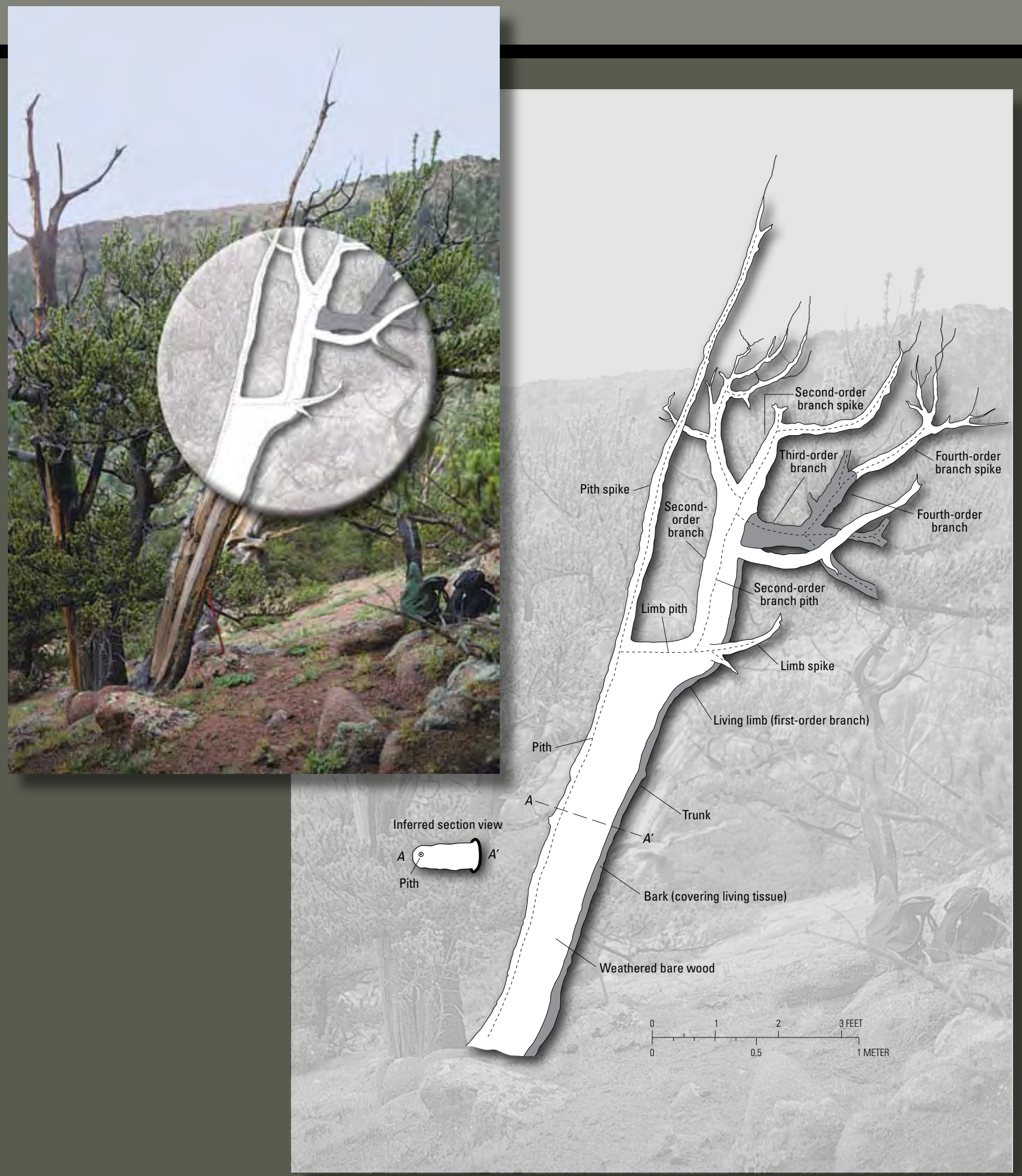




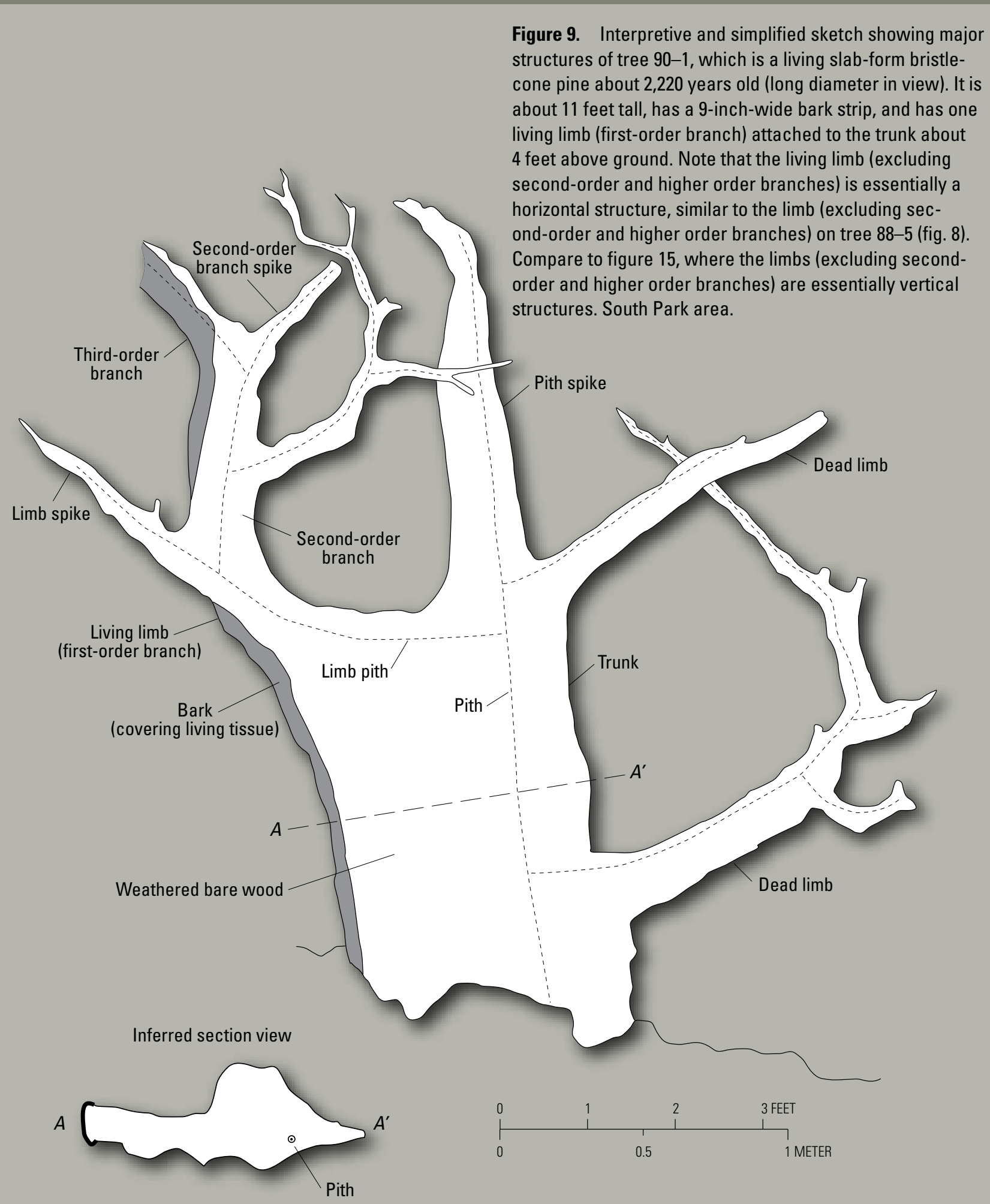


Figure 10. Interpretive and simplified sketch showing major structures of tree $68-3$, which is a living slab-form bristlecone pine about 2,050 years old (long diameter in view). It is about 15 feet tall, has a 9-inch-wide bark strip, and has one living limb (first-order branch) attached to the trunk about 3.5 feet above ground. Note that the living limb (excluding second-order and higher order branches) is essentially a horizontal structure, similar to the limbs (excluding second-order and higher order branches) on trees 88-5 (fig. 8) and 90-1 (fig. 9). The depiction of the upper right side of the tree has been generalized. Southern Front Range area.

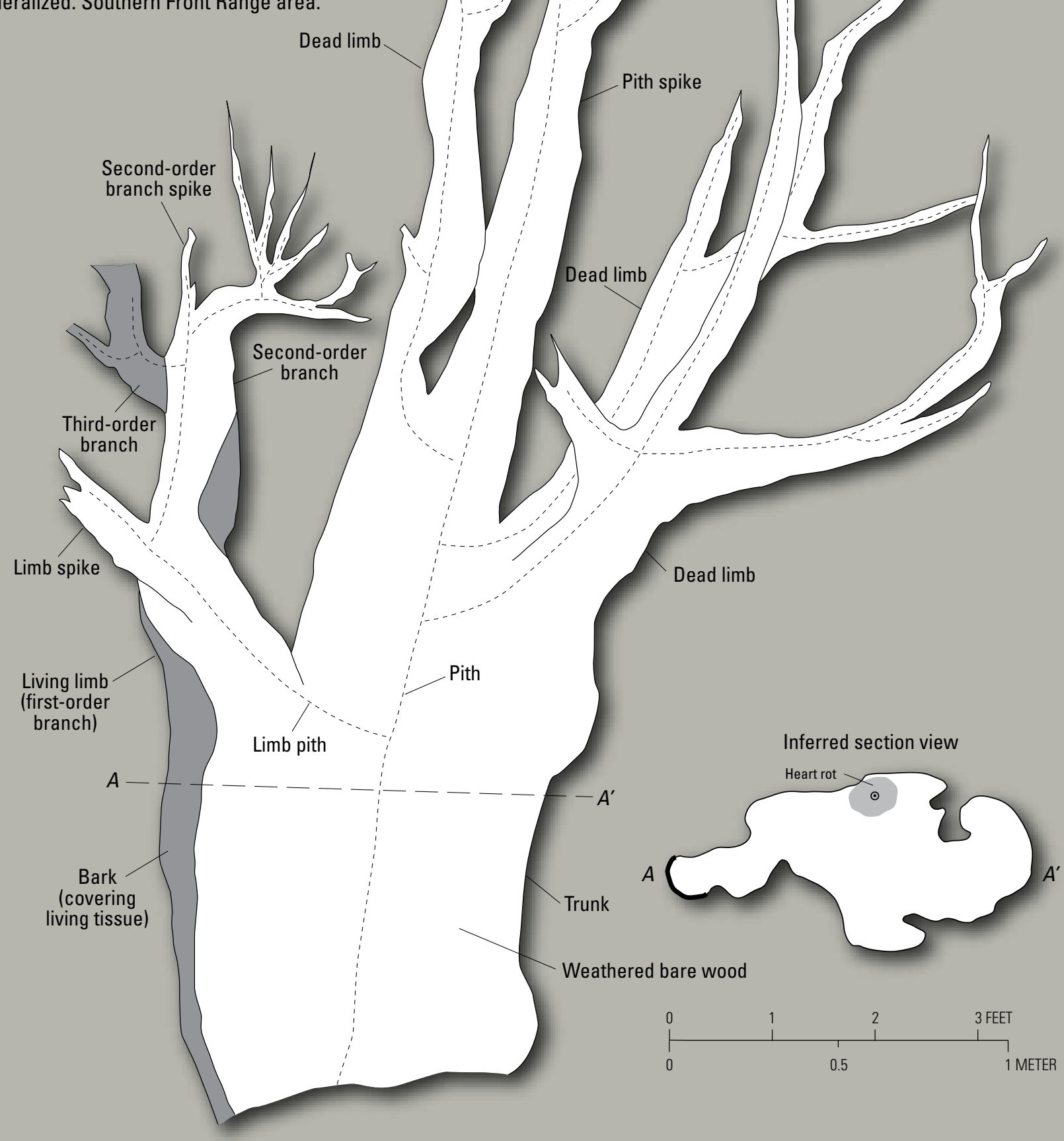


Figure 11. (Pages 34-38) Living slab-form bristlecone pine about 1,210 years old (tree 88-8), southern Front Range. The trunk of the tree is a thin slab that varies from about 4 to 6 inches thick (where measured for the inferred section in fig. 4). Tree is tilted. $\boldsymbol{A}$, View of part of the tree near the top. (Photograph taken October 15, 1988.) $\boldsymbol{B}$, Interpretive and simplified sketch of the photograph shown in view A. The top of this tree's stem is forked - the stem splits into two stems, one of which is dead and is much smaller than the other living stem. A few of the 1,000- to 1,300 -year-old trees in this study have a forked top similar to this tree. Although the top of the tree's stem is forked, the slab-form trunk dominates the appearance of the tree when the tree is viewed as a whole (see view D). C, View from the opposite direction as shown in views $A$ and $B$. In this view, there appear to be two living branches that are very close to each other and merge at their bases. PD, pith spike of dead stem; $P L$, pith spike of living stem; B, two large living branches. (Photograph taken October 19, 1990.) D, View of most of the tree (the lower trunk is obscured by fallen dead bristlecone pines) showing how the slab-form trunk dominates the form of this tree (long diameter in view; long diameter is about 16 inches at about waist-high level). $E$, Edge-on view of the slab-form trunk. Increment borer handle is about 18 inches long. Inferred horizontal section view of this trunk (see fig. 4) was measured near the top of this image. Thin, gravelly granitic soil and rounded boulders have weathered from granite bedrock of Precambrian age. (Photographs of views $D$ and E taken May 18, 1991. Southern Front Range area.)

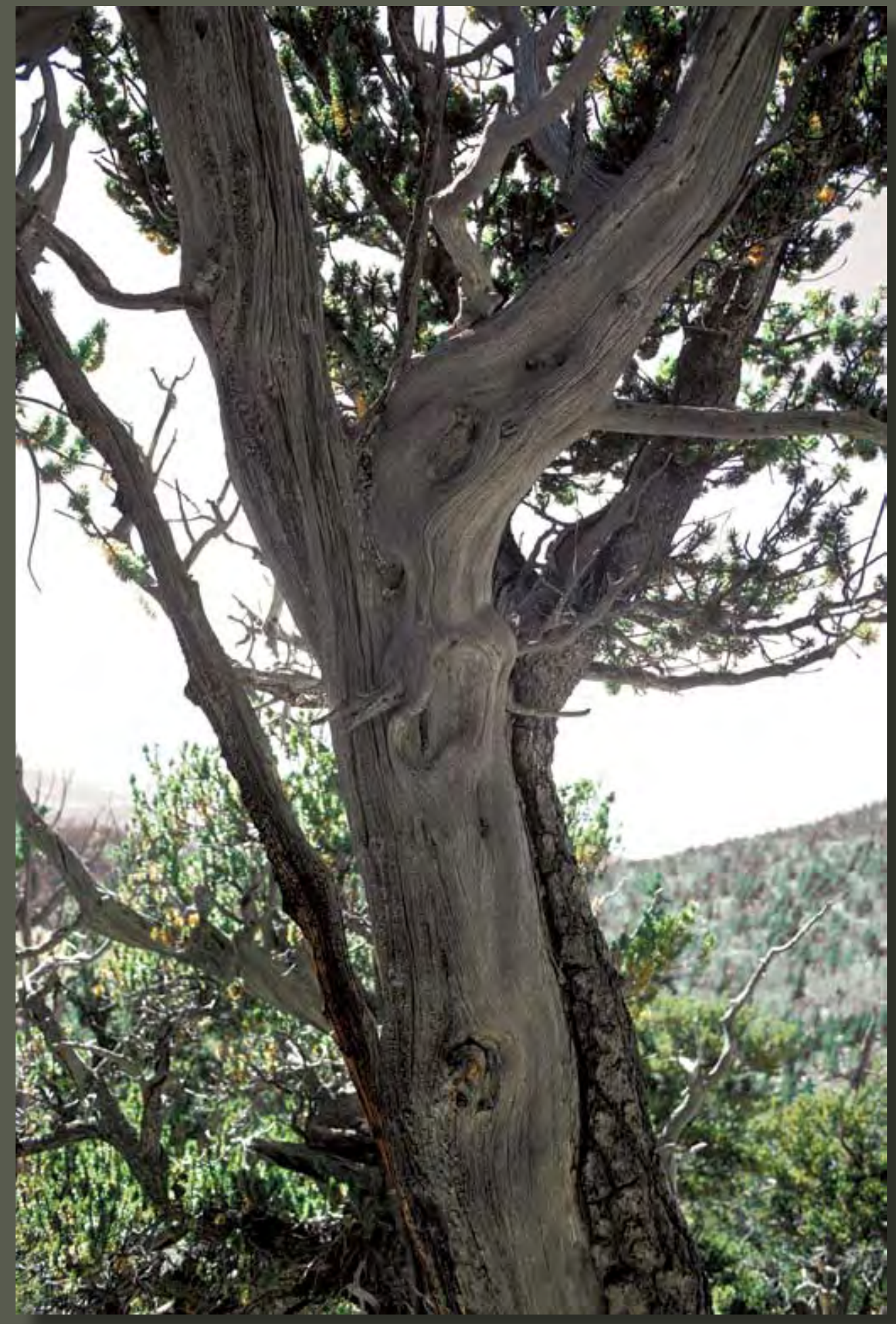

A 


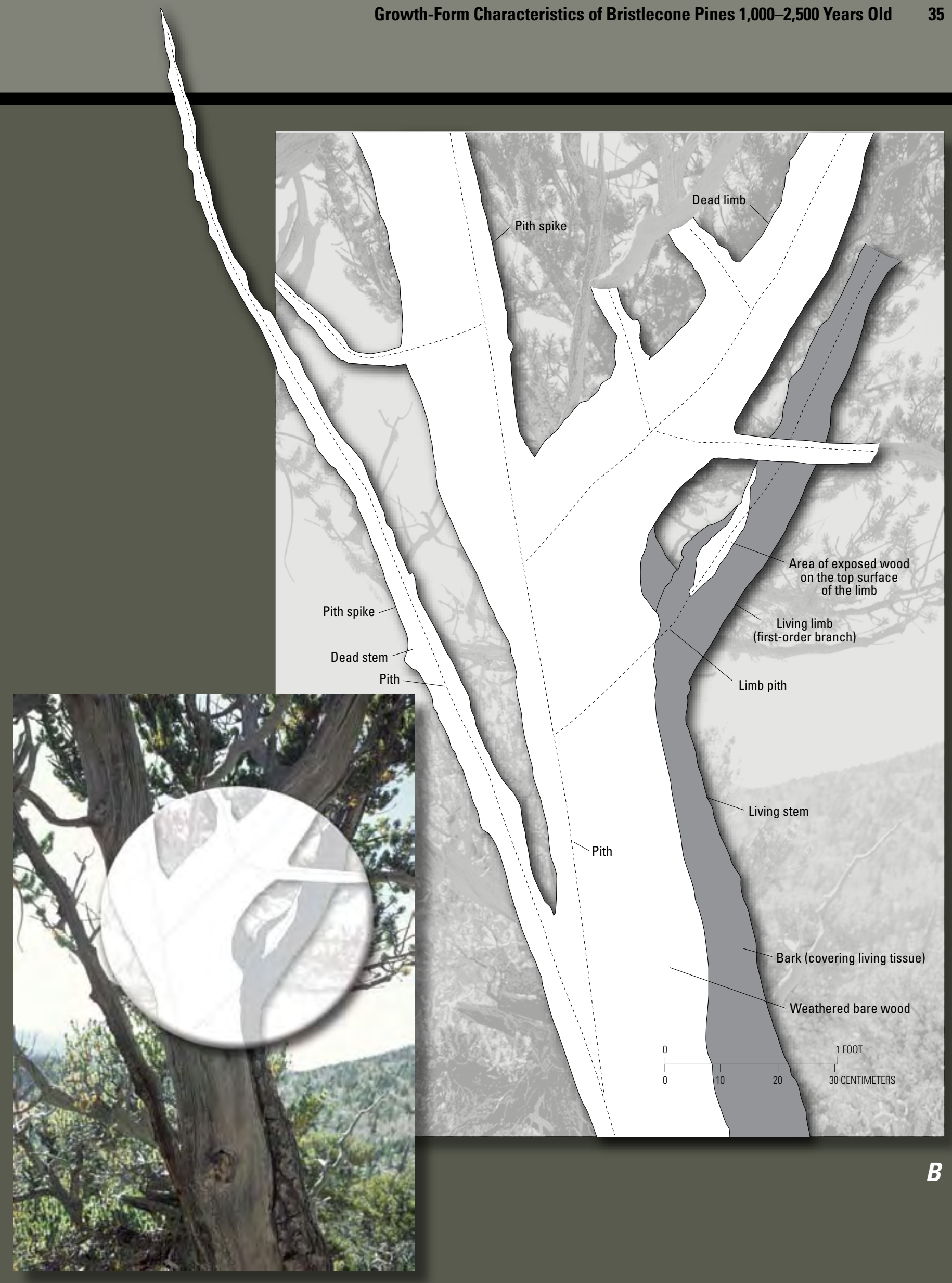




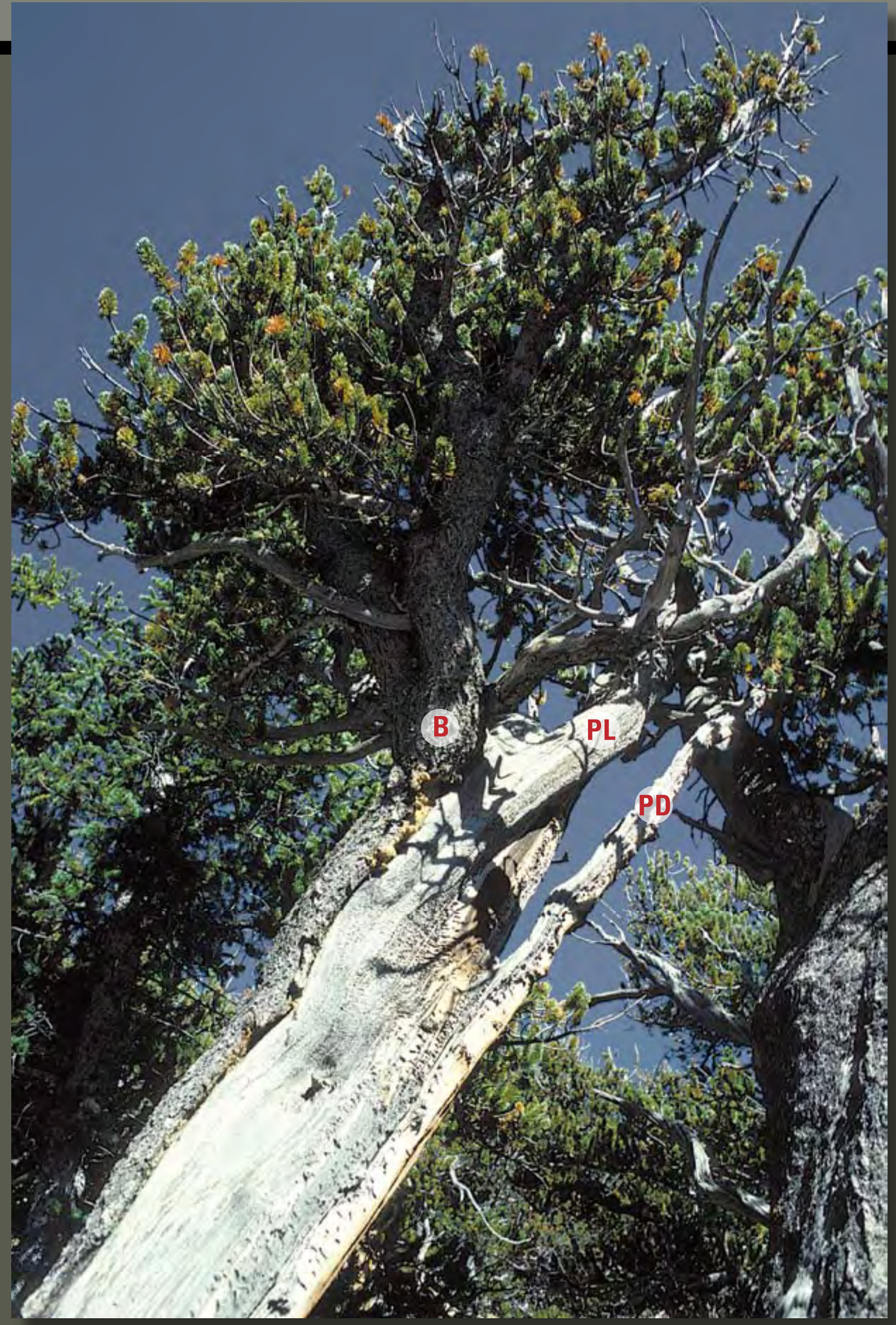




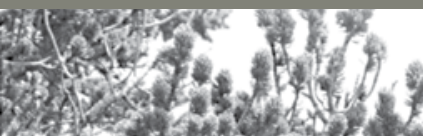

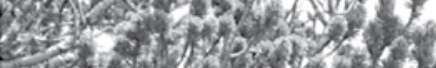

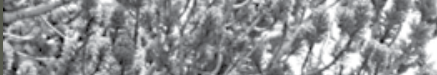
The rond

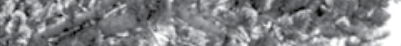

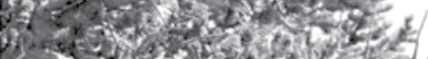

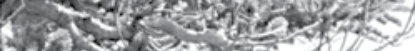

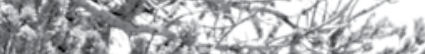

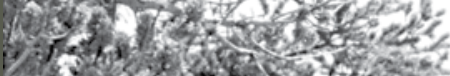

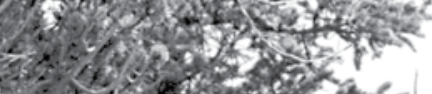
-3. 2 - 2 Hon ${ }^{2}$

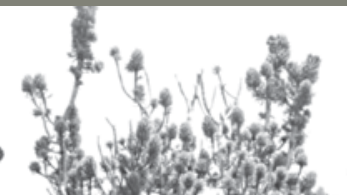
(1)

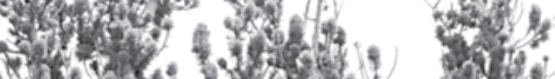
20.

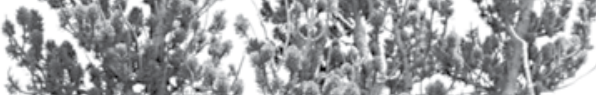

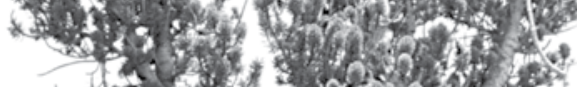

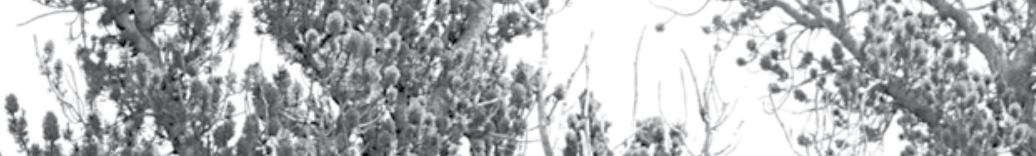

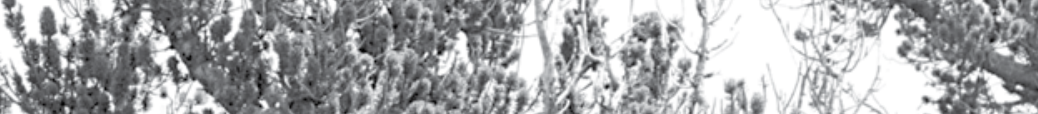

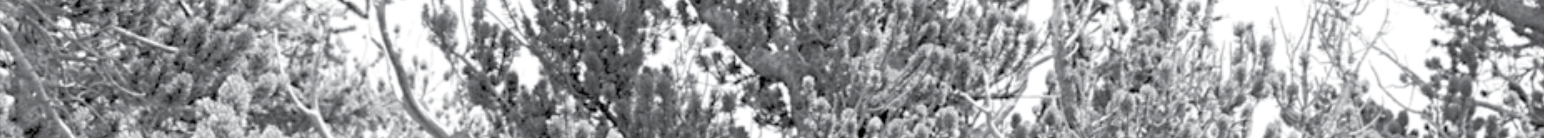

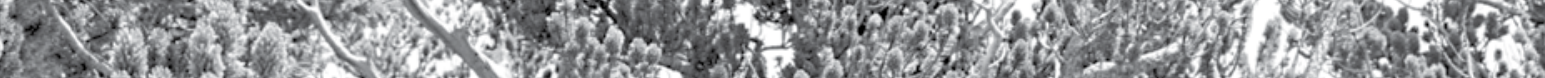

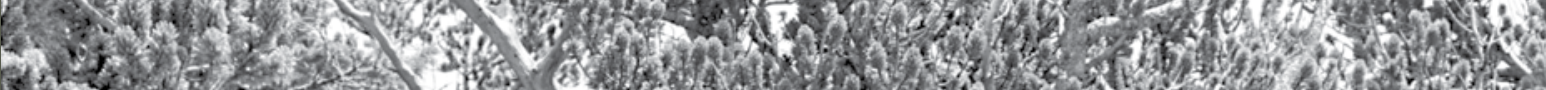

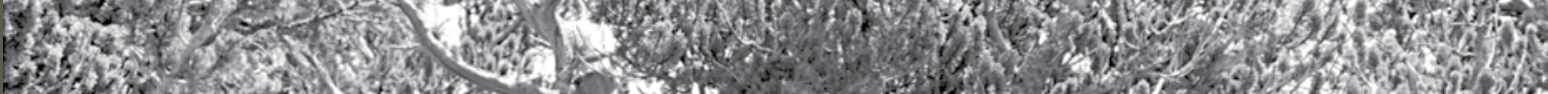

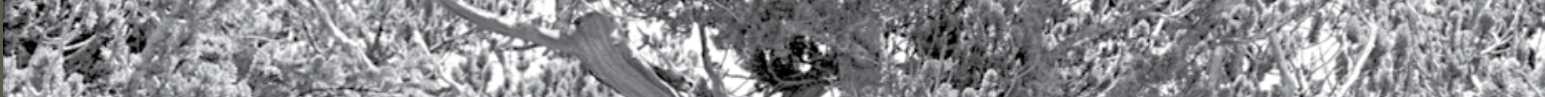

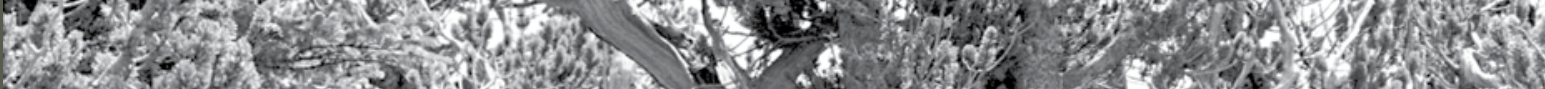

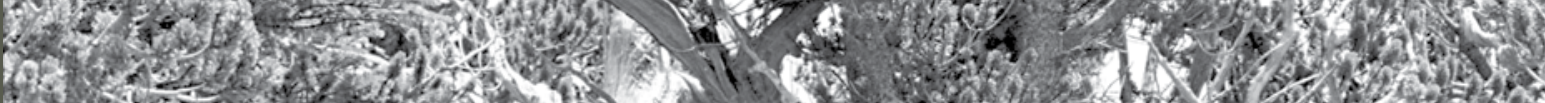

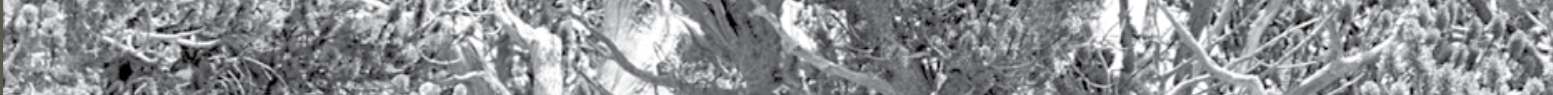
3.

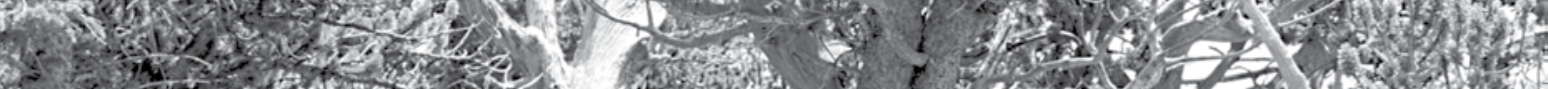

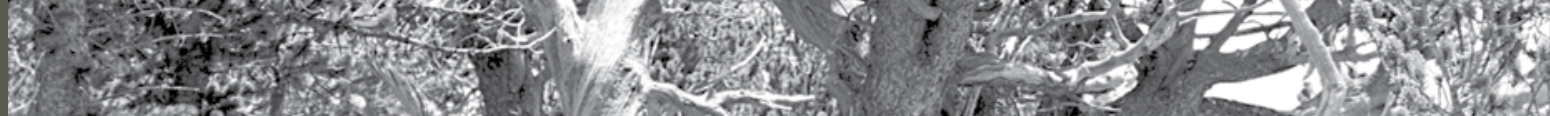

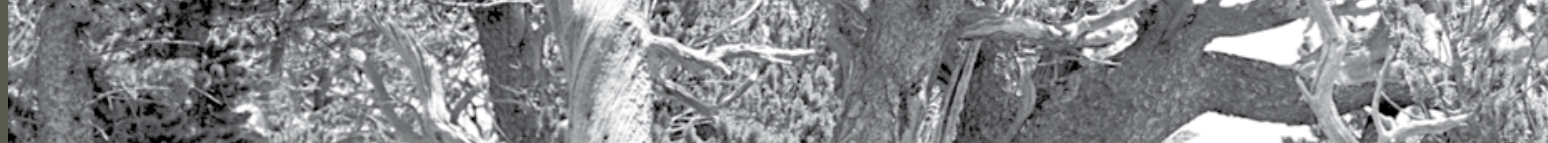

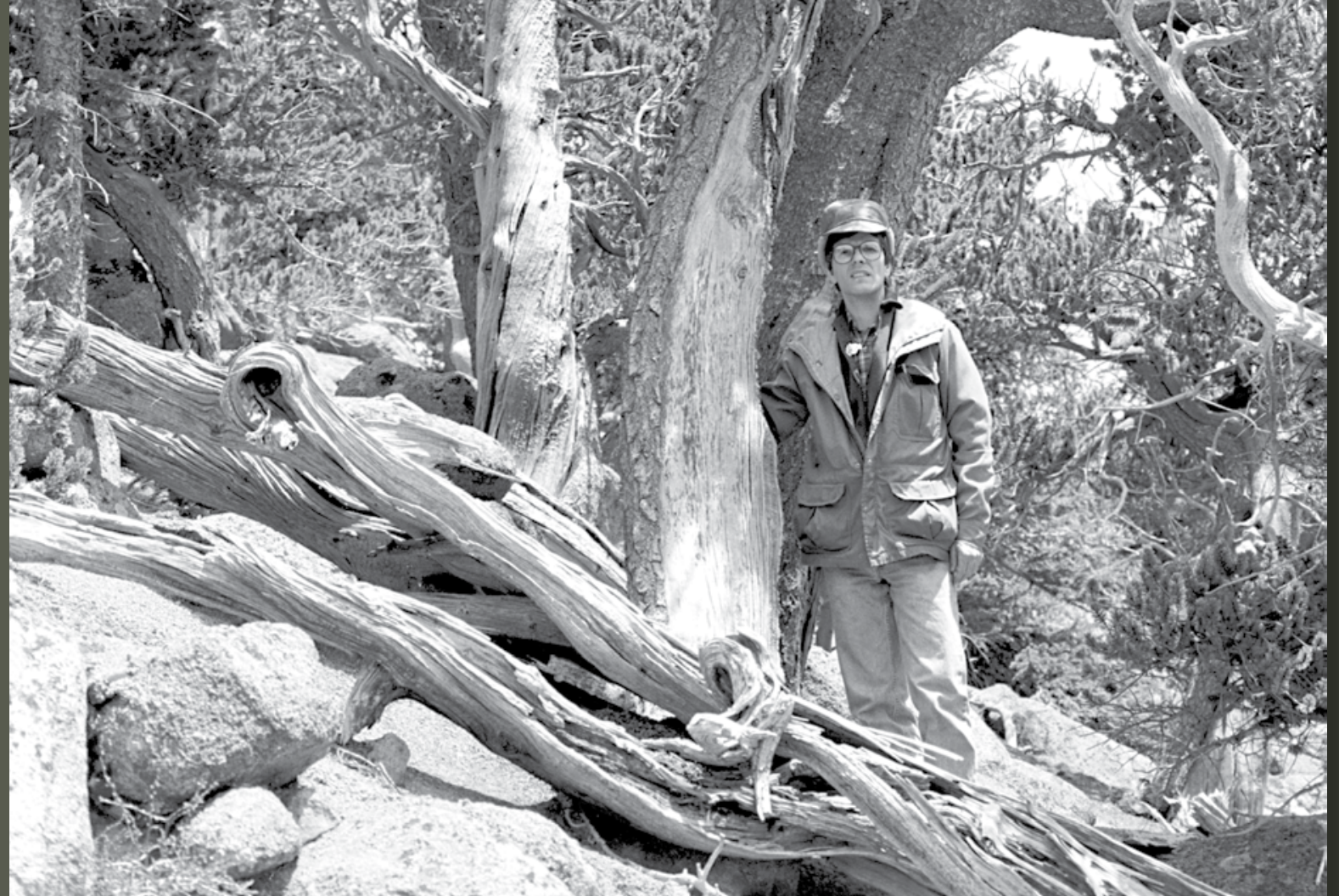




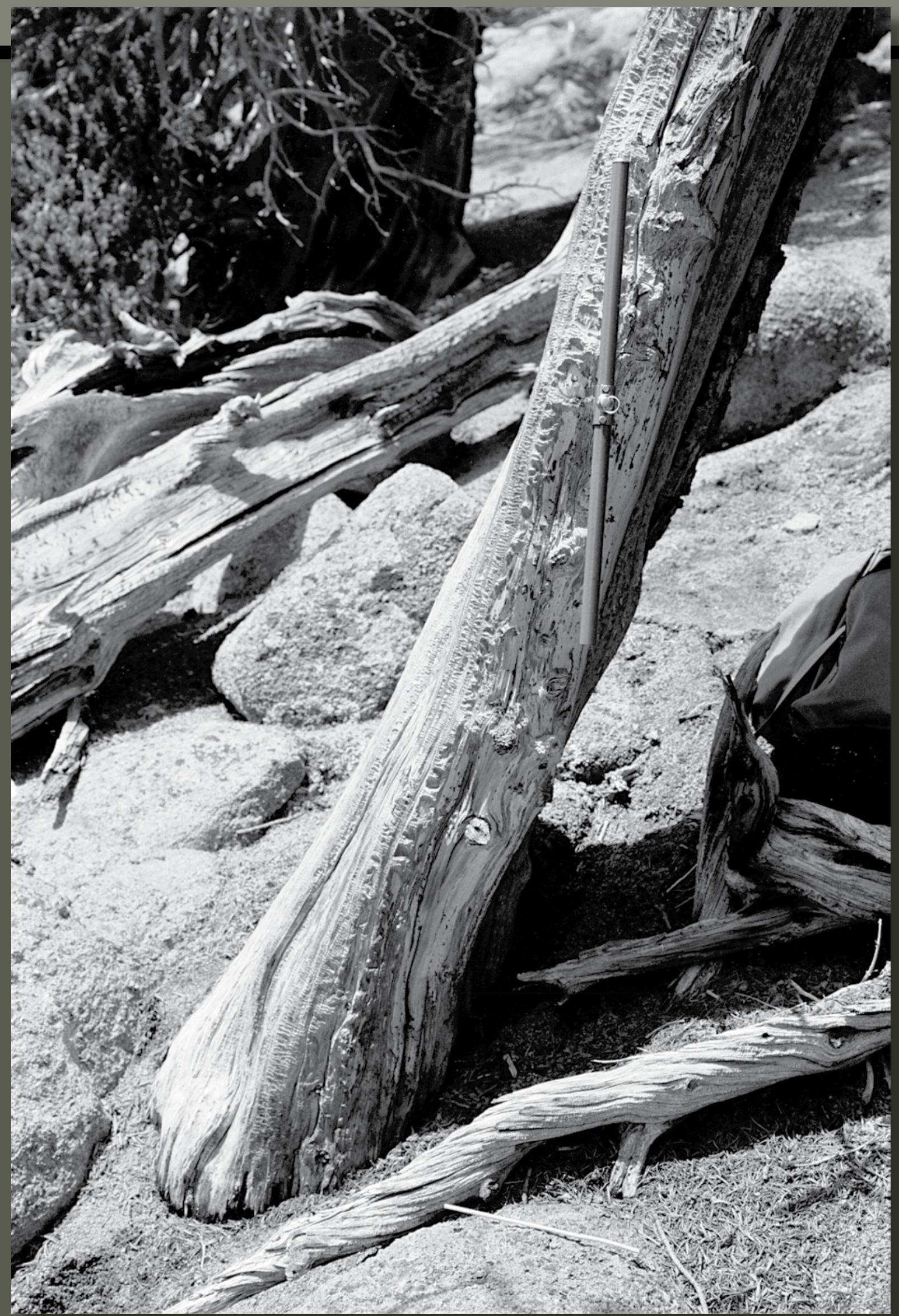




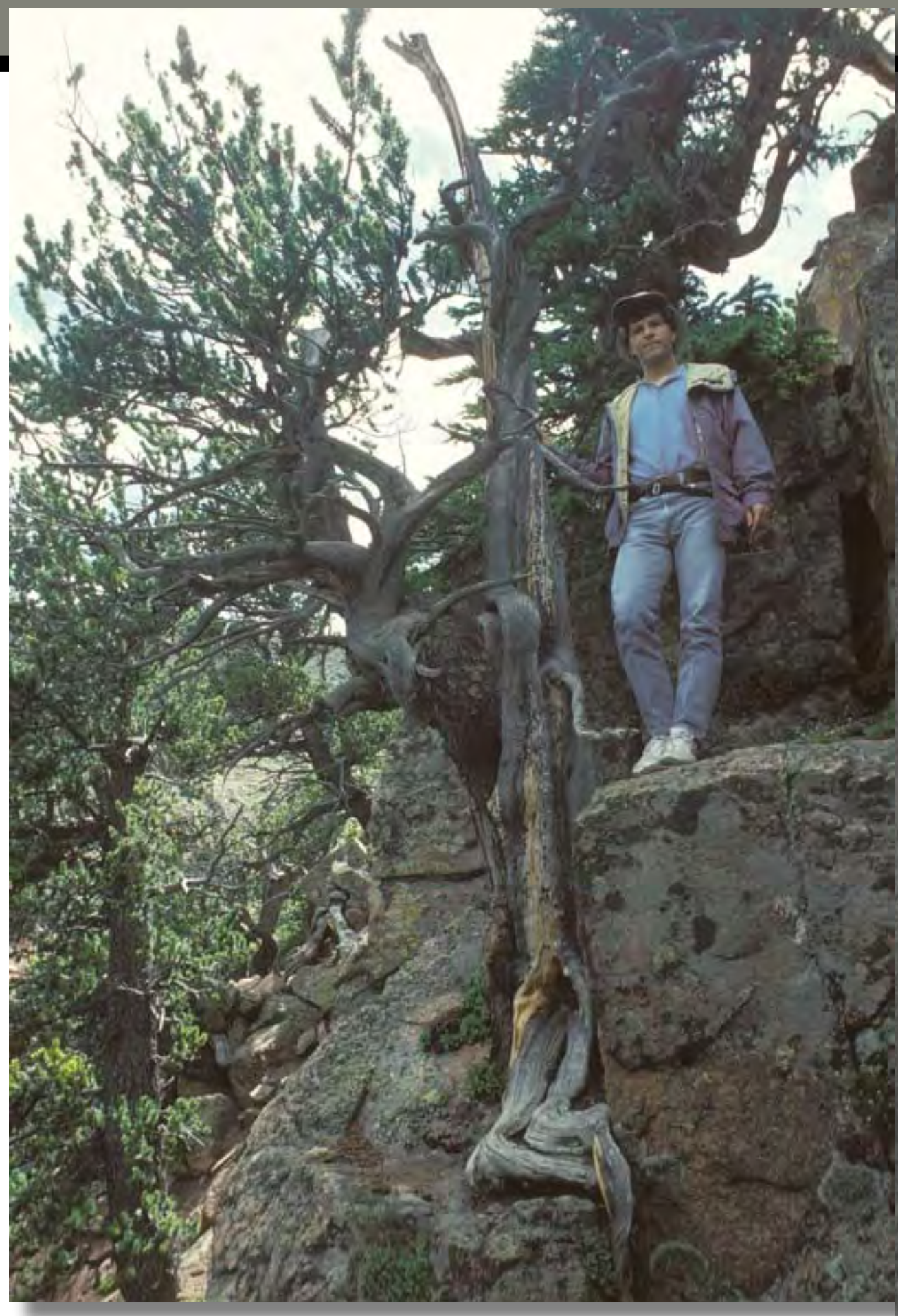

Figure 12. Living slab-form bristlecone pine about 1,410 years old. Tree $88-10$ has one living limb (first-order branch) attached to the trunk about 3-4 feet above ground. The long diameter is about 18 inches. The tree is about 15 feet tall, and it is growing on granite bedrock of Precambrian age. A close examination of the single living limb on the tree reveals a horizontal limb spike (not visible in this view) and a complex mass of higher order branches. The main bark strip is visible on the left side of the tree; note how it spirals over the top of the limb. The prominent pith spike has a few erosion-sculpted dead limbs. An inferred horizontal section view of the trunk is shown in figure 4. An Engelmann spruce (Picea engelmannii) is visible behind the person. The leafy green plant growing in bedrock cracks is James saxifrage (Telesonix jamesii). The granite bedrock is broken by a prominent fracture set that gives the rock a blocky appearance. (Photograph taken July 28, 1988.) 


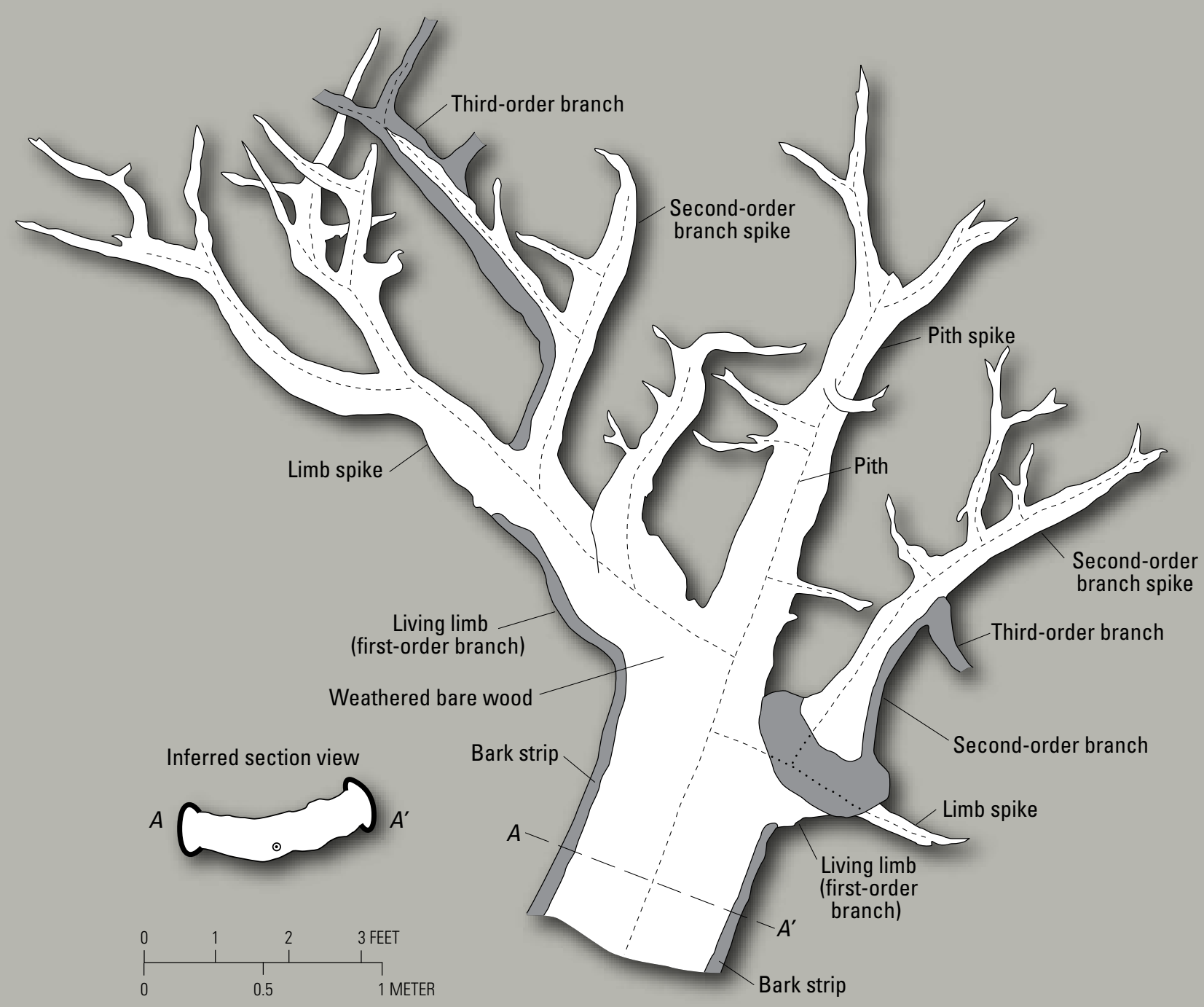

Figure 13. Interpretive and simplified sketch showing major structures of a living, opposite bark strips, slab-form bristlecone pine about 1,660 years old. Tree $91-65$ has two bark strips on opposite sides of the trunk; the bark strip on the left connects to one living limb, and the bark strip on the right connects to two living limbs (only one limb is shown for clarity). Tree is about 15 feet tall and is tilted downslope. Note that the limbs (excluding second-order and higher order branches) are essentially horizontal structures. Compare to figure 15 where the limbs (excluding second-order and higher order branches) are vertical structures. Also note how the bark strip on the right side of the tree almost completely encircles the second-order branch. The inferred section for this tree is diagrammatic and is not as accurately drawn as the sketches in figure 4. South Park area. 


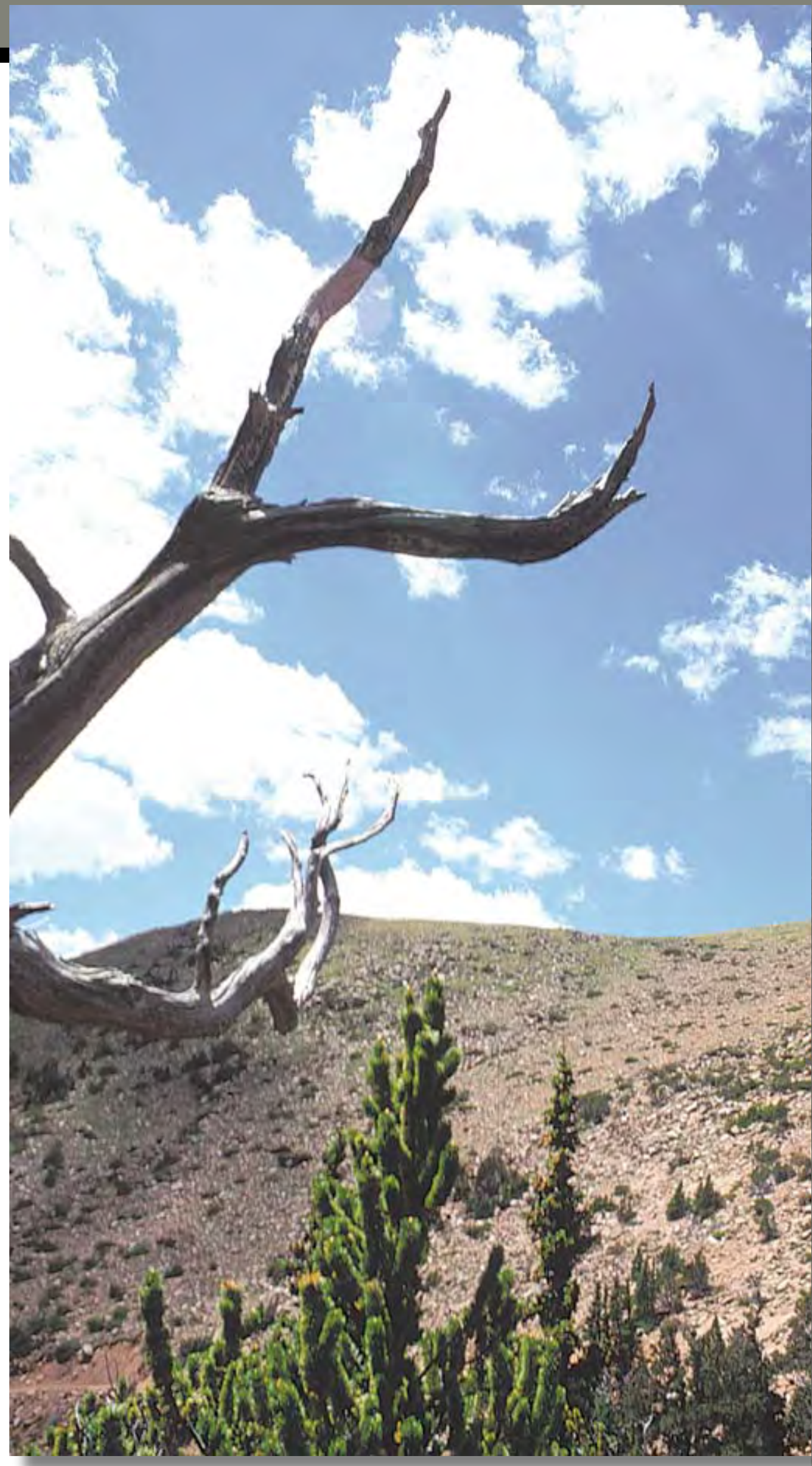

View from a bristlecone pine and Engelmann spruce grove to a distant northeast- to east-facing slope that has scattered small trees and krummholz near upper treeline. The top of the distant granitic ridge is at an altitude of about 12,200 feet. (Photograph taken probably July 1996. Southern Front Range.) 
Figure 14. (This page and facing page) A, Two living bristlecone pines that are twisted slabs. Tree $69-7$ in foreground is about 1,080 years old and has about $180^{\circ}$ of counterclockwise spiral twist. Tree 69-4, in the left background is about 960 years old and also has about $180^{\circ}$ of counterclockwise spiral twist. Erosion-sculpted pith spikes are present on both trees. Each tree has one bark strip and one living limb. Red increment borer handle is about 18 inches long. The extensive lichen coverings on the granite boulders and little or no erosion at the base of each tree are evidence for long-term stability and only slight erosion of the boulder-rich, thin granitic soil in this area. Prominent, low, green-leafed plant (with a few magenta flowers here and there) is James saxifrage (Telesonix jamesii). (Photograph taken July 30, 1988. Southern Front Range.) $\boldsymbol{B}_{\text {, Interpretive and simplified }}$ sketch of tree 69-7 showing the major structures of the tree.

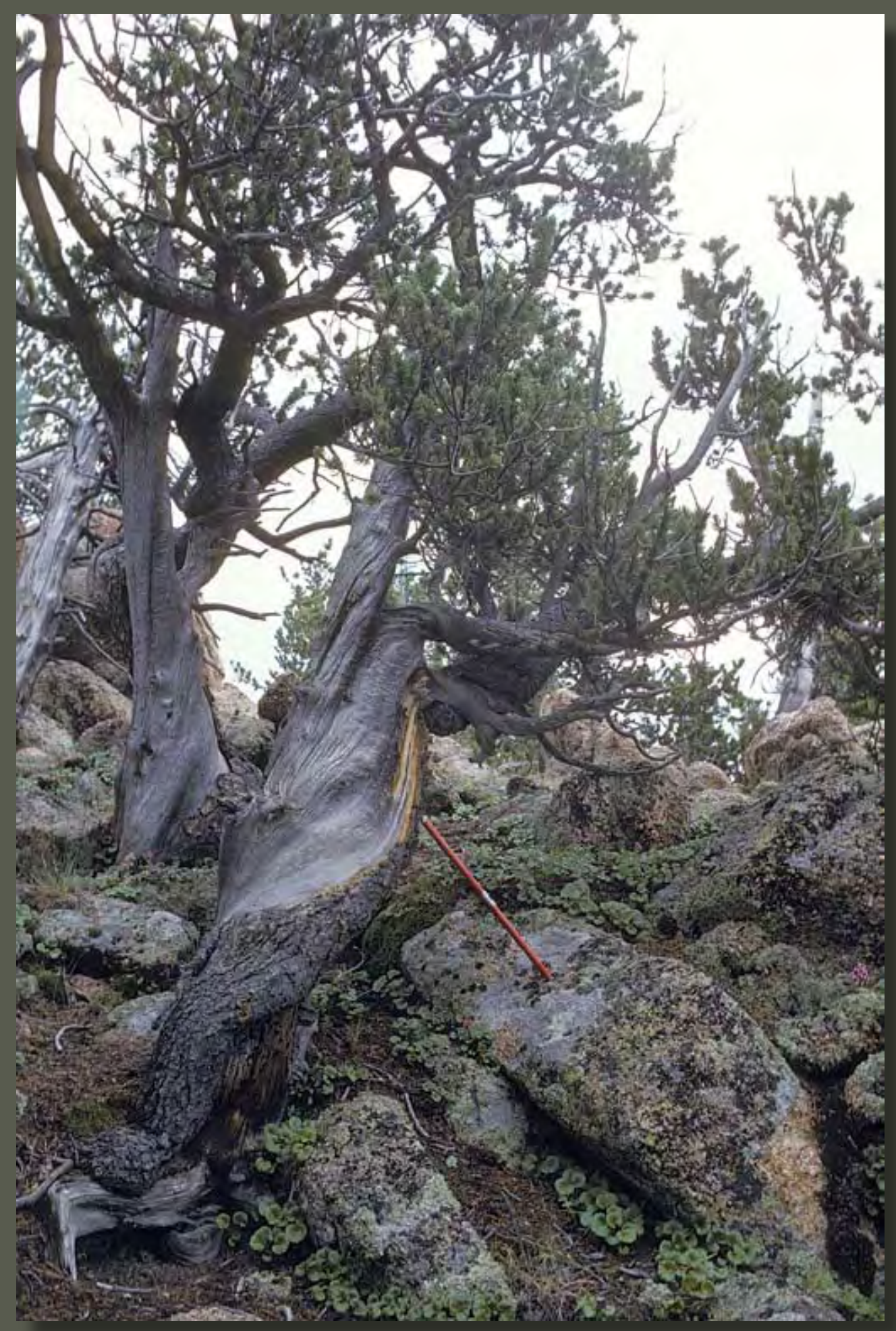

A 
W.

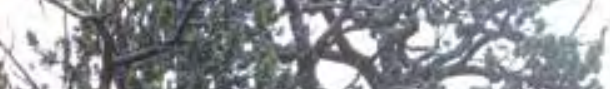

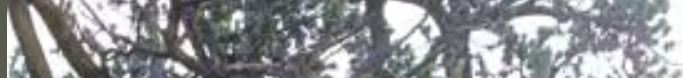

6. 2,3 , th

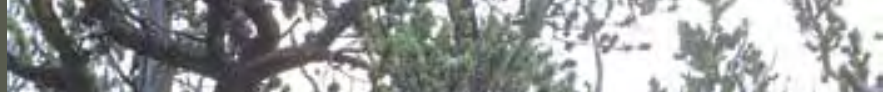

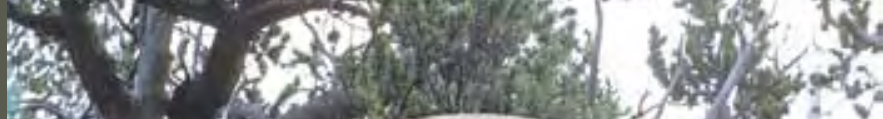
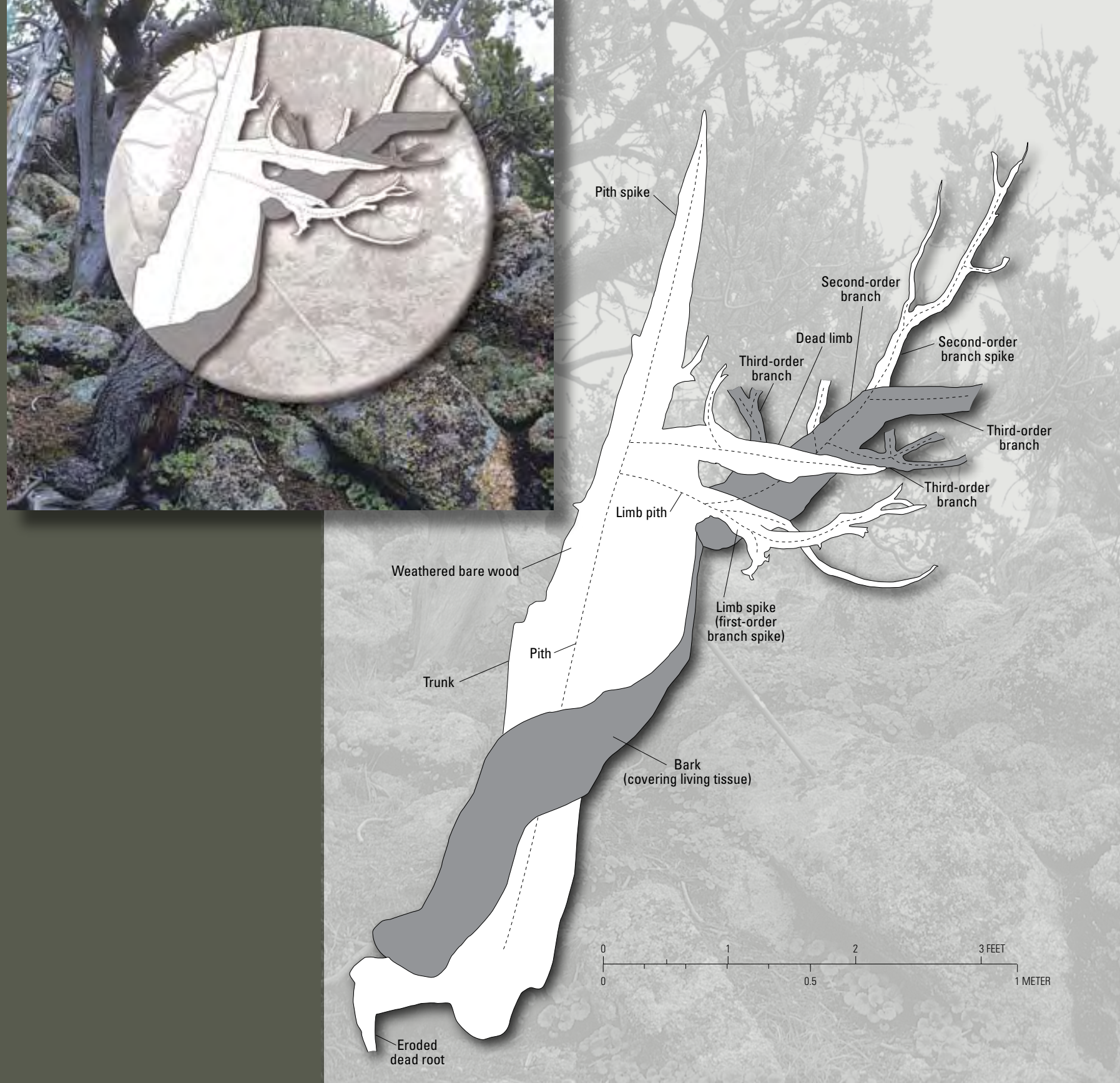
Figure 15. (This and facing page) $\boldsymbol{A}$, This multi-stem living bristlecone pine is on a ledge on a granite cliff, and it is about 1,030 years old. The two main stems are actually limbs (first-order branches) that became the main vertical structures of the tree after the top of the original main stem died early in this tree's life. One of the limbs is dead, but the limb on the right has two living second-order branches. Note how the two main limbs bow out at their juncture with the trunk - evidence of their probable origin as limbs. (Photograph taken February 1969. Southern Front Range.) B, Interpretive and simplified sketch showing the major structures of the tree. The upper parts of the two main limbs have been shortened slightly in order to show the entire tree and to show details of the lower half of the tree.
A

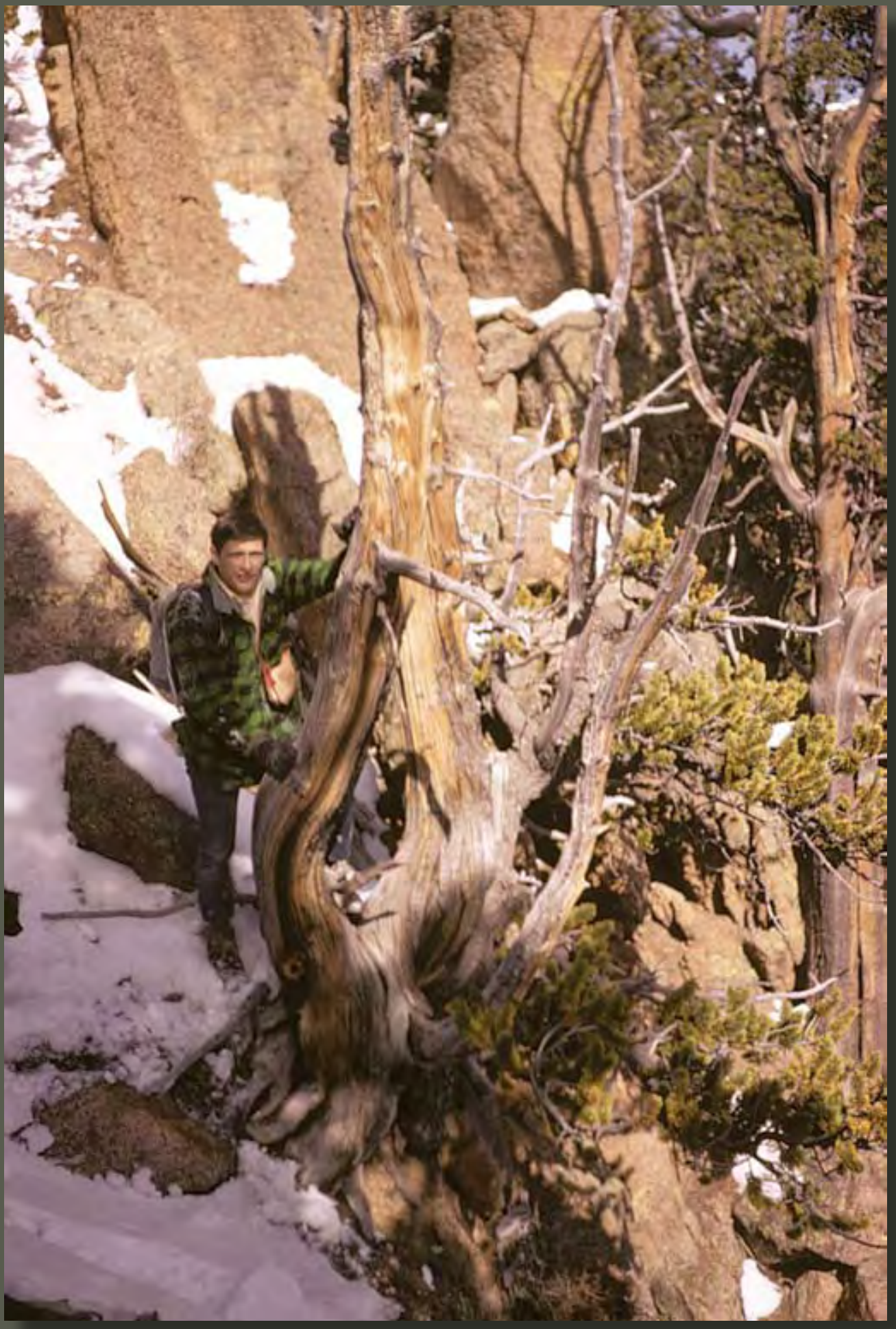


Limb spike

(first-order branch spike)

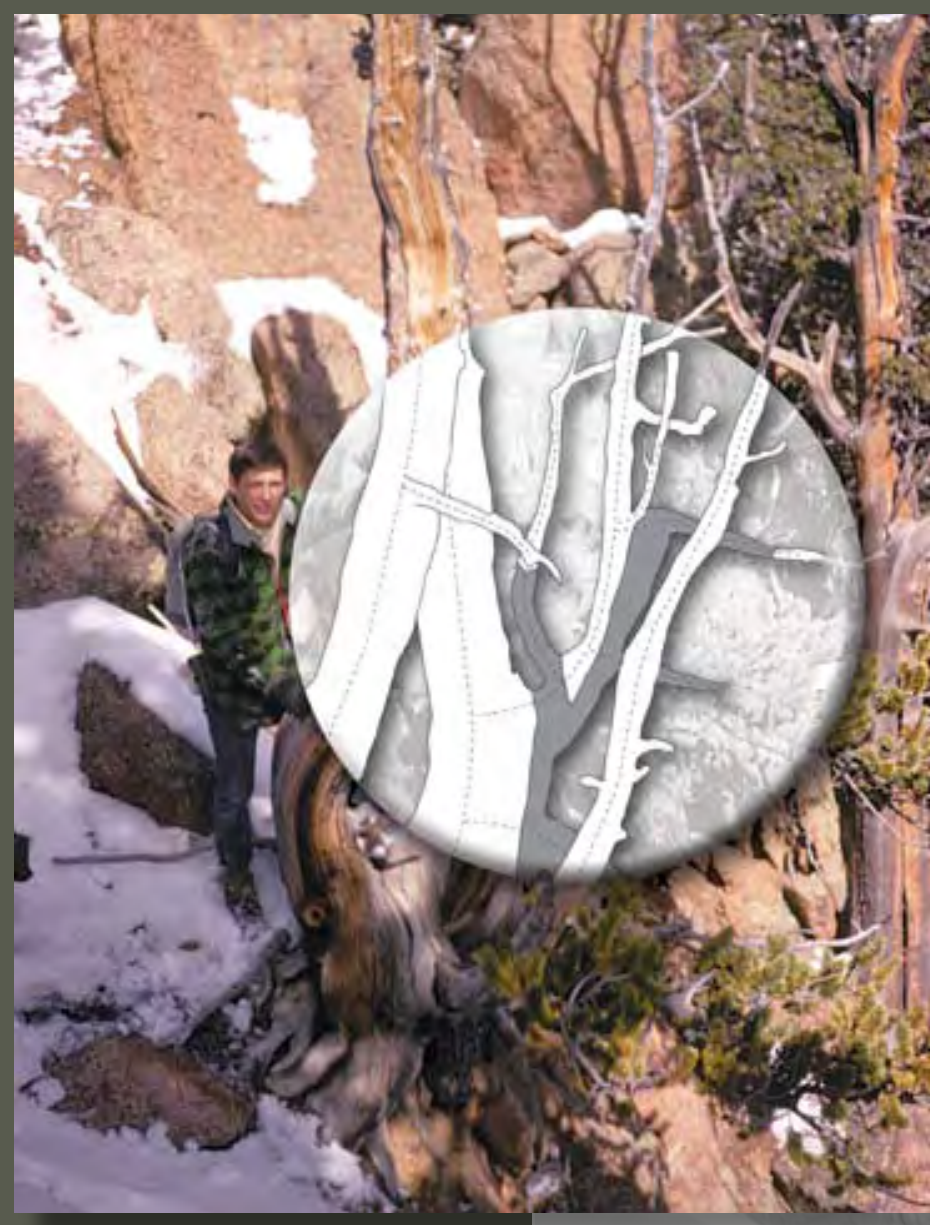

Limb spike

(first-order branch spike)
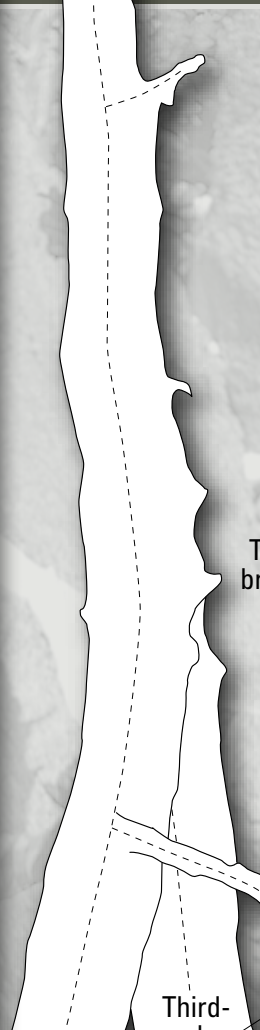

branch spike

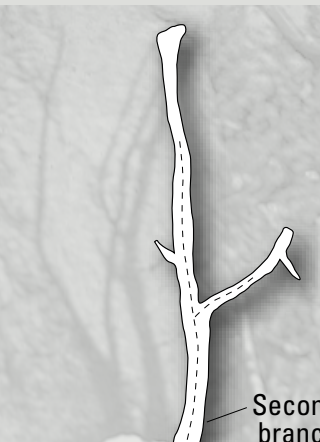

Second-order

branch spike

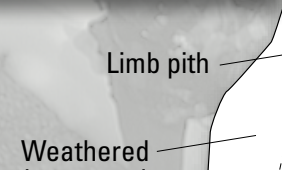
bare wood

Dead limb 


\section{Eroded Dead Limbs}

Most dead limbs are either eroded stubs on the trunk or are eroded flush with the trunk (fig. 17). However, some ancient trees have remnants of large dead limbs that are highly erosion sculpted (see figs. 9 and 10). Some trees have one or more limbs that have died recently, within the past one or two centuries - many small, dead branches remain on such limbs. The amount of erosion of each dead limb seems to be dependent upon how long the limb has been dead, the size of the limb, and how exposed the tree is to prevailing erosive winds.

\section{Living Limb Attachment Height}

In this study, the living limb attachment height is the vertical distance between the ground surface and where a living limb attaches to the tree trunk. Specifically, the limb attachment point is where the pith of the limb merges with the pith of the trunk (see figs. $8-16)$. However, the measurement of attachment height is usually approximate, because it is often difficult to determine precisely where the pith and limb pith are located (for example, see fig. 12) and because the ground surface on the upslope side of a tree on a steep slope is higher than the downslope side. In such a situation, where a tree is growing on a steep slope, the ground surface is defined for this report as the midpoint of the ground surface between the upslope and downslope sides of the tree.

For bristlecone pines 1,000-2,500 years old, the height of attachment was measured or visually estimated for 69 living limbs. The average height of attachment is 6 feet, the minimum is 1 foot, and the maximum is about 16 feet (tables $6 A$ and $6 B$ ).

Table $\mathbf{6 A}$. Average, minimum, and maximum attachment heights of living limbs on bristlecone pines $1,000-2,500$ years old.

[Total number of limbs is 69 . Heights were measured using a steel tape or were visually estimated. Average is rounded to the nearest foot. See "Methods" section for an explanation of the accuracy of height measurements and estimates]

\begin{tabular}{|c|c|c|}
\hline $\begin{array}{c}\text { Average attachment height } \\
\text { (feet) }\end{array}$ & $\begin{array}{c}\text { Minimum attachment height } \\
\text { (feet) }\end{array}$ & $\begin{array}{c}\text { Maximum attachment height } \\
\text { (feet) }\end{array}$ \\
\hline 6 & 1 & 16 \\
\hline
\end{tabular}

Table 6B. Ranges of attachment heights of living limbs on bristlecone pines 1,000-2,500 years old.

[Total number of limbs is 69 . Heights were measured using a steel tape or were visually estimated. See "Methods" section for an explanation of the accuracy of height measurements and estimates]

\begin{tabular}{l|lllll}
\hline Attachment height (feet) & $1-2$ & $2.1-4$ & $4.1-8$ & $8.1-12$ & $12.1-16$ \\
Number of limbs & 6 & 20 & 32 & 9 & 2 \\
\hline
\end{tabular}




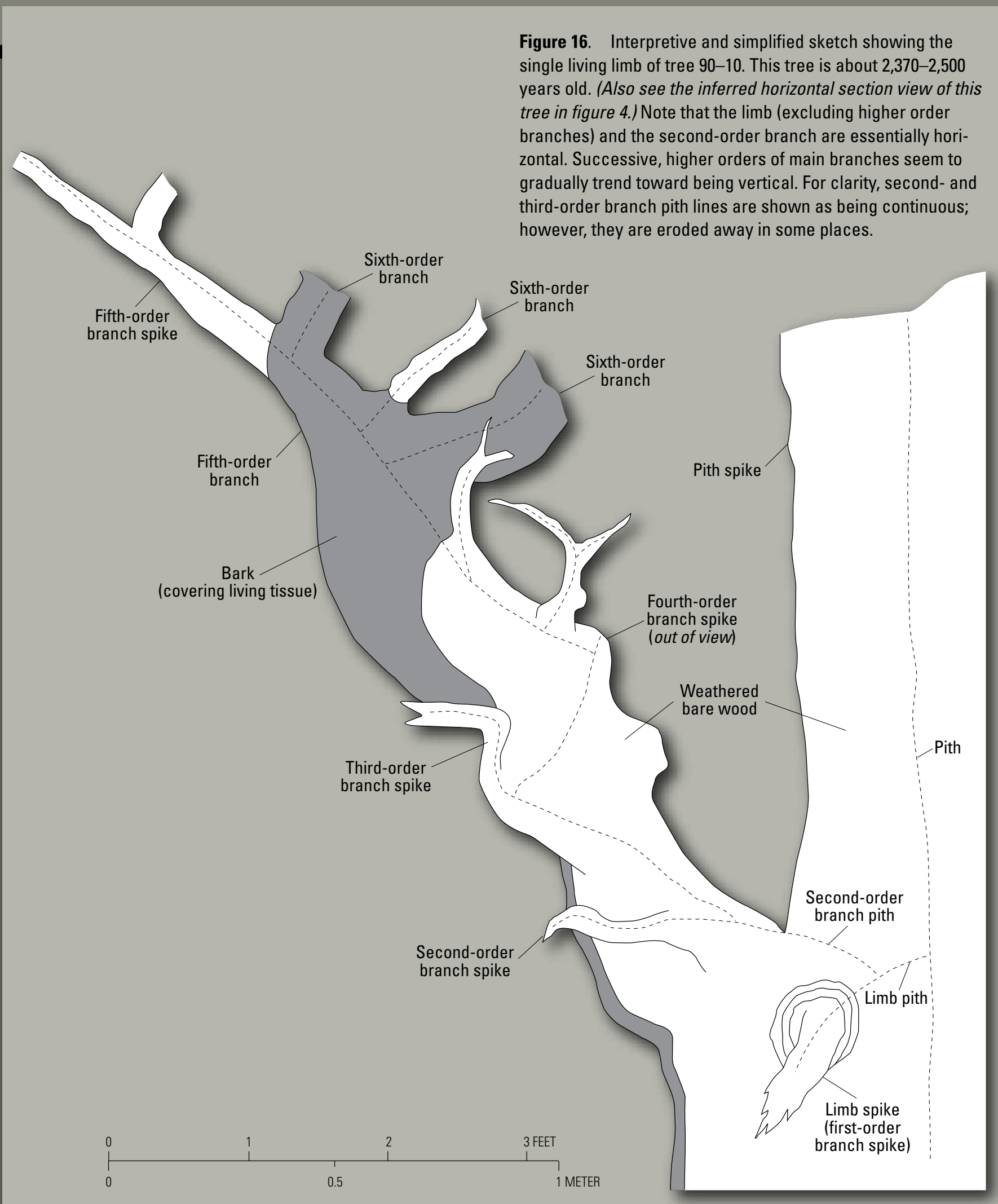


A

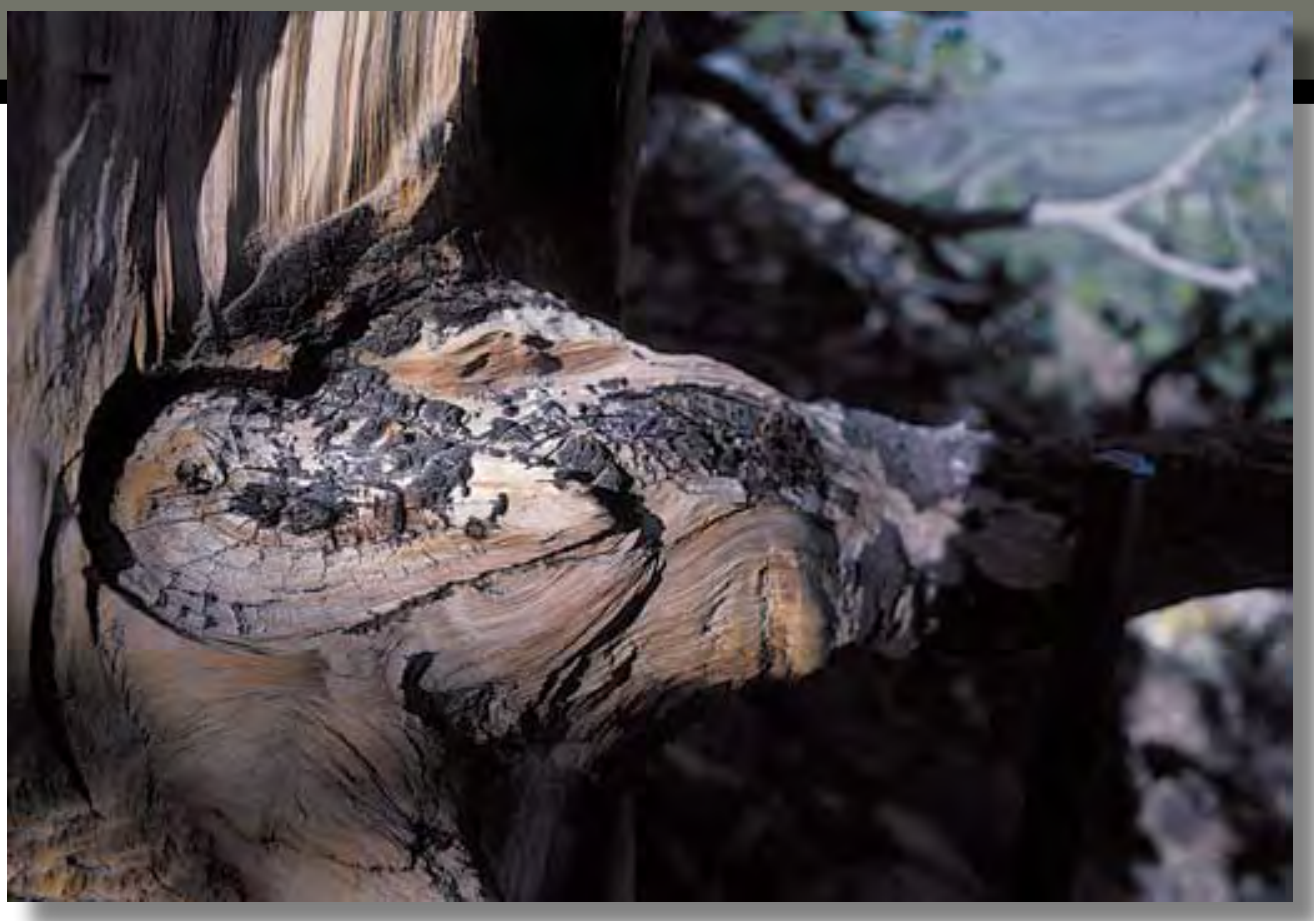

Figure 17. Eroded dead limbs (first-order branches) on the trunks of two bristlecone pines. $\boldsymbol{A}$, Tree $90-4$ (about 1,870 years old). This limb has been dead for many centuries. (Photograph taken September 1, 1990. South Park area.) B, Edge-on view of the slab-form trunk of tree $69-2$, which is about 1,200 years old; thickness of slab in this view is about $6-7$ inches. Long diameter (not visible in this view) is about 17 inches. The eroded knots on the trunk are all that remain of once-living limbs (first-order branches). (Photograph taken July 30, 1988. Southern Front Range.)

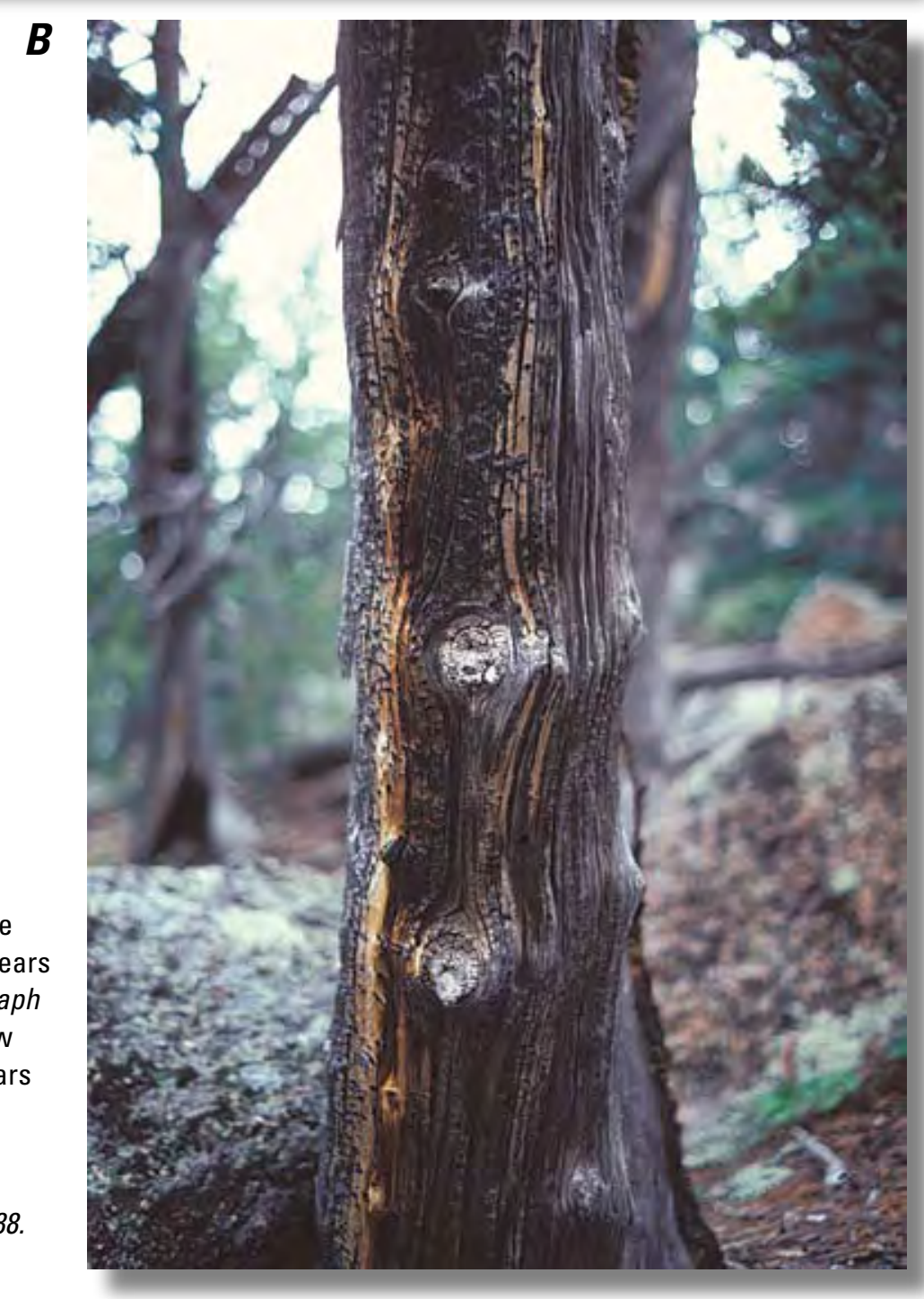




\section{Strip-Bark Growth on Trunks and Limbs}

Most of the sampled 1,000- to 2,500-year-old Pinus aristata have the "strip-bark" growth habit (Schulman and Ferguson, 1956; Schulman, 1958; LaMarche, 1969), which, over the long lifespans of these trees, has caused the trunks of the trees to grow only along a narrow segment of each tree's circumference (fig. 4). (A few of the trees do not have stripbark growth; however, they still have significant cambial dieback on their trunks, exposing large areas of bare wood.) As little as 5-10 percent of the circumference of some bristlecone pines is covered by bark (fig. 4). Such growth is characterized by one or more strips of bark that generally maintain the same width from the base of the tree up to where the strip(s) connect to one or more living limbs. Bark strips as narrow as about 2-3 inches were observed on some of the trees (table 7). Trees with such narrow bark strips seem to be barely clinging to life. Such a narrow bark-strip width seems to be at the very minimum for existence and appears to be rarely sustainable over many centuries. Bark-strip widths of about 15 inches are the average for 1,000- to 2,500-year-old trees in this study (table 7). A few trees more than 1,000 years old have anomalously wide bark strips-as much as 48 inches wide (table 7). An example of the development of strip-bark growth in an approximately 1,000-year-old slab-form bristlecone pine is shown in figure 18. At some point in the life of some bristlecone pines, the width of the bark strip becomes relatively stable for many centuries to considerably more than a millennium, which results in slab-form trunks that have remarkably uniform thicknesses (see tree 88-8 in fig. 4).

Cambial dieback due to wind-induced dessication and scouring by wind-driven ice and soil seems to be the precursor or beginning of strip-bark growth for most bristlecone pines (LaMarche, 1969; Schauer and others, 2001). However, other factors may also contribute to initiation of strip-bark growth: (1) the possible physiological inability of aging trees to maintain living cambium around the entire circumference of a tree whose circumference increases each year (Wright and Mooney, 1965; Schauer and others, 2001), (2) death of roots on the eroded downslope side of trees, which causes the death of cambial tissue on the downslope-facing side of the tree (LaMarche, 1969; this study), and (3) for at least some trees, damage to living cambium (with resultant dieback of cambium) caused by falling and tumbling rocks, gnawing by animals, forest fires, and lightning strikes. Some of these topics are discussed later in this report.

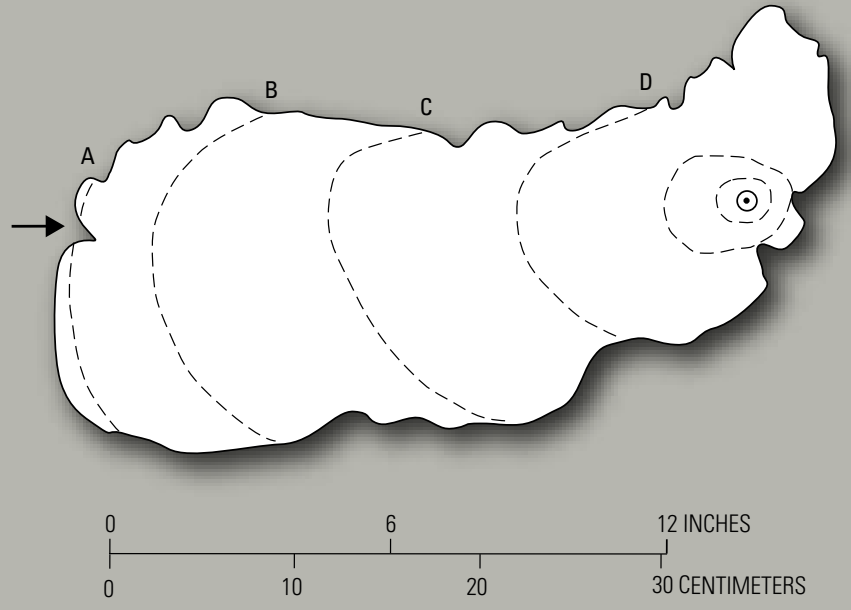

Figure 18. Horizontal section of the slab-form trunk of a dead bristlecone pine showing the extent of selected annual rings (dashed lines). The trunk does not have any bark. Annual rings $A, B, C$, and $D$ depict a relatively accurate picture of the extent of the bark strip and annual rings at those stages of the tree's life. Section is about 2 feet above the top of the basal root flare. Arrow points to a place where a part of ring $A$ has probably been removed by weathering. Ring widths of rings $A, B, C$, and $D$ are greatest near the midpoints of the arcs formed by the dashed lines; rings become progressively narrower toward the ends of the arcs. Note the asymmetry of the tree in its youth, as shown by the dashed lines that enclose the pith. The shape of the trunk is primarily a result of the "strip-bark" growth habit (Schulman and Ferguson, 1956; Schulman, 1958; LaMarche, 1969); however, the exposed wood surfaces of the trunk are also weathered by wind-driven ice and soil particles. Tree was approximately 1,000 years old when it died, probably several centuries ago. Tree was cut by firewood gatherers in the 1960s or 1970s. This drawing was made from a field sketch of the weathered surface of the saw cut. Note that gathering or cutting of dead bristlecone pines on National Forest lands is regulated by the USDA Forest Service. 
Eventually, the top surfaces of most (but not all) bristlecone pine limbs next to their juncture with the trunk develop cambial dieback (figs. $6 B$ and 8-16). In very old limbs, such cambial dieback progresses from the juncture with the trunk outward toward the end of the limb, as well as downward on the sides of the limb, leaving such limbs with exposed weathered wood along most of their top surfaces and sides (figs. 6B and 8-16). Even though such cambial dieback is a dying-off process, it enables the limb to maintain for centuries or millennia a bark strip on the underside of the limb (figs. 8-10) or side of the limb (fig. 15) that has supported a succession of branches. Likewise, some of the second-order and higher order branches also develop strip-bark growth (figs. 8-10, 13, 15, 16).

\section{The Number of Bark Strips and Living Limbs}

Of 39 living trees 1,000 or more years old, 30 each have a single bark strip, 8 each have two bark strips, and 1 has three bark strips (table 8 ).

In contrast to relatively young bristlecone pines about 40-100 years old that have as many as $71-100$ or more living limbs, bristlecone pines 1,000 or more years old have only 1 to 4 living limbs. Of 39 living trees 1,000 or more years old, 22 each have a single living limb, 9 have two living limbs, 7 have three living limbs, and 1 has four living limbs (table 8).

Of 39 living trees 1,000 or more years old, 19 each have only one bark strip and only one living limb (table 8). The other 20 trees, ranging in age from about 1,000 to 1,870 years, have different combinations of bark strips and living limbs (table 8). Each of the six oldest trees in this study, ranging in age from about 1,980 to 2,500 years, has only one bark strip and only one living limb.

Of 48 bark strips, 33 are each connected to a single living limb—or one living limb per bark strip (table 8). However, 13 of the bark strips are each connected to two, three, or four living limbs (table 8).

Three trees about 1,180,1,410, and 1,630 years old each have two separate bark strips on the lower trunk, but the bark strips merge about 8, 3.5, and 10 feet above the ground for each respective tree.

For trees 1,000 or more years old, most of the living limbs (first-order branches) and some of their successively higher order major branches have gone through a process of development and aging that includes production of higher order branches, dieback of the top (or distal end) of the branch, and cambial dieback (figs. 8-16), a process similar to the main stems of such trees.

\section{Location of Bark Strip}

There are 33 living trees 1,000 or more years old for which the location(s) of the bark strip(s) at the base of each tree was noted (table 9). Of these 33 trees, 26 each have a single bark strip on the upslope side of the tree, 3 each have a single bark strip on the downslope side, 2 each have one bark strip on the upslope side as well as another bark strip on the downslope side, and 2 trees each have a single bark strip growing parallel to the slope. 
Table 7. Widths of bark strips on bristlecone pines $1,000-2,500$ years old.

[Total number of measured bark strips is 54 . Measurements taken $1-4$ feet above ground.]

\begin{tabular}{ccc}
\hline $\begin{array}{c}\text { Average bark strip width } \\
\text { (inches) }\end{array}$ & $\begin{array}{c}\text { Minimum width } \\
\text { (inches) }\end{array}$ & $\begin{array}{c}\text { Maximum width } \\
\text { (inches) }\end{array}$ \\
\hline 15 & $2-3$ & 48 \\
\hline
\end{tabular}

Table 8. Number of bark strips and living limbs on bristlecone pines 1,000-2,500 years old.

[For example, the number of trees that have 1 bark strip and 1 living limb is 8 for trees that are 1,000-1,500 years old. The total number of trees that have 1 bark strip and 1 living limb in all age classes is 19 . Number of trees in this table is 39 ; they have a total of 48 bark strips and 65 living limbs]

\begin{tabular}{|c|c|c|c|c|c|c|c|c|}
\hline Number of bark strips & 1 & 1 & 1 & 1 & 2 & 2 & 2 & 3 \\
\hline Number of living limbs & 1 & 2 & 3 & 4 & 1 & 2 & 3 & 3 \\
\hline Number of trees $1,000-1,500$ years old & 8 & 3 & 2 & 1 & $2 *$ & 2 & 0 & 0 \\
\hline Number of trees $1,501-2,000$ years old & 6 & 3 & 2 & 0 & $1 *$ & 1 & 2 & 1 \\
\hline Number of trees $2,001-2,500$ years old & 5 & 0 & 0 & 0 & 0 & 0 & 0 & 0 \\
\hline Total trees & 19 & 6 & 4 & 1 & 3 & 3 & 2 & 1 \\
\hline
\end{tabular}

*Three trees about $1,180,1,410$, and 1,630 years old each have two separate bark strips on the lower trunk, but the bark strips merge about $8,3.5$, and 10 feet above the ground for each respective tree.

Table 9. Bark-strip location at the base of bristlecone pines 1,000-2,500 years old.

[Number of trees is 33]

\begin{tabular}{lrcccc}
\hline \multicolumn{1}{c}{ Age class of tree (years) } & $\mathbf{1 , 0 0 0 - 1 , 5 0 0}$ & $\mathbf{1 , 5 0 1 - 2 , 0 0 0}$ & $\mathbf{2 , 0 0 1 - 2 , 5 0 0 ~}$ & Total \\
\hline \multicolumn{1}{c}{ Bark-strip location } & 15 & 7 & 4 & 26 \\
\hline Upslope side of tree & 1 & 2 & 0 & 3 \\
Downslope side of tree & 1 & 1 & 0 & 2 \\
Upslope and downslope sides* & 0 & 1 & 1 & 2 \\
Parallel to slope & & &
\end{tabular}

*Each tree has two bark strips, one on the upslope side of the tree, the other on the downslope side. 


\section{Advantages of Having a Bark Strip on the Upslope Side of a Tree}

Most of the bristlecone pines 1,000 or more years old have a single bark strip that is on the upslope side of the tree (table 9). A bark strip on the upslope side of the tree generally indicates that the tree's point of ground attachment - the root system-is mostly on the upslope side of the tree. This arrangement probably serves to help anchor the upslope side of the tree and prevent the tree from falling downslope (fig. 19). The tendency for bristlecone pines to fall downslope instead of upslope or parallel to slope is supported by the following evidence: (1) 64 percent of living bristlecone pines 1,000-2,500 years old that are tilted are leaning downslope (sample size 14 trees) and (2) 67 percent of fallen dead bristlecone pines fell downslope (sample size 33 trees).

The upslope side of some bristlecone pines acts as a sediment dam (also noted by LaMarche, 1969), with sediment (soil, slopewash, colluvium, talus) on the upslope side dammed to a higher level than sediment on the immediately adjacent mountain slope. The upper surface of the dammed sediment on the upslope side of some trees is as much as about 4 feet higher than the ground surface on the downslope side, which is undercut by erosion (fig. 20). Such dammed sediment may prove beneficial for a tree because it:

(1) Holds moisture for the tree's roots. In addition, the dammed sediment on the upslope side of trees in this study is on the northwest, north, or northeast side of the trees, and such sediment probably is partly shaded during the day, which probably helps to conserve soil moisture.

(2) Prevents undercutting of the tree's roots by erosion.

(3) Serves to help anchor the upslope side of the tree to the mountain slope by providing a protective blanket of soil for the tree's roots to spread into adjacent mountainslope sediment and bedrock cracks. Such an upslope anchor serves to help prevent the tree from falling downslope (figs. 19 and 20).

(4) Provides a shorter distance from living roots to living branches as compared to roots on the downslope side of the tree.

In addition, for trees that have a bark strip on the upslope side of the tree, as each tree ages and increases its radius, the upslope side of the tree grows slowly upslope, probably decreasing the distance from the roots to the underside of the living limb(s). This distance is probably decreased further as downward radial growth of the bark strip on the underside of the limb slowly increases the long radius of the limb (see fig. $6 B$ ), which decreases the distance between the bottom of the limb and the roots.

The base of the trunk on the downslope side of many living bristlecone pines is undercut by erosion, exposing the roots of the trees (fig. 20; also noted by LaMarche, 1968, 1969). Such erosion eventually causes the death of roots and (or) increases the distance from living branches to living roots. The death of undercut roots and (or) the increase in the distance from the roots to living branches possibly causes a higher mortality rate for bark strips on the downslope sides of bristlecone pines as compared to bark strips on the upslope sides.

Figure 19. (Facing page) The upslope base of this living bristlecone pine is dead, so there are no living roots on that side of the tree to help anchor it to the mountain slope and prevent the tree from falling downslope. Note how the tree has nearly tipped over, pulling the dead roots out of the thin, gravelly granitic soil and lifting them into the air. (Photograph taken June 12, 1992. Southern Front Range.) 


\section{Slab Form}

Many ancient Pinus longaeva have trunks that look like slabs of wood, and researchers have for many years referred to such trees as having slab-like stems (Schulman, 1958; Wright and Mooney, 1965; LaMarche, 1969) or a "flattened slab-shaped stem form" (Fritts, 1976, p. 153). Similarly, most Pinus aristata in this study that are 1,000-2,500 years old have slab-like stems. In this report, a tree that has such a form is referred to as a slab or, alternatively, as having a slab form, slab trunk, slab-form trunk, or slab-like stem.

When the trunks of such trees are seen in inferred horizontal section view (see fig. 4), they have a slab-like form that has long, flat to bumpy sides; rounded to angular corners; and, on some trees, prominent lobes and depressions. The "strip-bark" growth habit (Schulman and Ferguson, 1956; Schulman, 1958; LaMarche, 1969), over the long lifespans of these trees, has caused the trunks of the trees to grow along a narrow segment of each tree's circumference (fig. 4), and such growth creates a trunk that has a long diameter and a long radius (fig. 21). The slab-form trees have long diameters that range from 10.5 to 48 inches and long radii that range from 9 to 30 inches (table 4).

The average long-diameter bearing of slab-form bristlecone pines on southeast-facing slopes is N. $10^{\circ}$ E., and for southwest-facing slopes it is N. $28^{\circ}$ E. (table 10 and figs. $22 \mathrm{~A}$ and B). The predominant north-northeasterly bearings are possibly the result of a combination of optimum (1) root growth and bark strip radial growth on the upslope side of the trees (with radial growth of bark strips toward the mountain slope), which creates stability and other advantages for the trees (see discussion in "Advantages of Having a Bark Strip on the Upslope Side of a Tree") and (2) radial growth of bark strips in a north-northeasterly direction (fig. 22C), which probably provides some protection of the bark strip from windinduced desiccation and scouring by wind-driven ice and soil from westerly, southwesterly, southerly, and southeasterly wind directions. Such wind directions are probably more common than other wind directions in Colorado (Doeskin, 2003; Schauer and others, 2001; also see discussion of wind directions in "Study Sites" section in this report). However, other factors, such as possible afternoon sun scalding (Schauer and others, 2001) or loss of soil moisture on the sunny east, southeast, south, southwest, and west sides of the trees, may also contribute to the fact that for many of the old trees, radial growth is on the relatively shady, north-northeast side of the trees.

The more easterly long-diameter bearings of trees on southwest-facing slopes (N. $28^{\circ}$ E.; table 10 and figure 22B) as compared to the bearings of trees on southeast-facing slopes (N. $10^{\circ}$ E.) could possibly:

(1) Be an indication of a more optimum radial growth direction toward the mountain slope; that is, a growth direction that is more perpendicular to the strike of the southwest-facing slopes. Such an optimum growth direction possibly creates maximum tree stability or other advantages for the trees (see discussion in "Advantages of Having a Bark Strip on the Upslope Side of a Tree").

(2) Provide the bark strips, many of which are on the northeast sides of the trees, with more protection from westerly and southwesterly winds, which are probably stronger on southwest-facing slopes as compared to southeast-facing slopes.

Most of the bark strips in this study display little or no spiral twist. Over the centuries, such a bark strip forms a straight, vertical slab of wood with little or no "twist" (figs. 8-13). Compare such trees to the twisted-slab form, which has a bark strip that partially spirals around the trunk of the tree (fig. 14).

A relatively thin bark strip, over the course of centuries, probably forms a relatively thin slab (see tree 93-55 in fig. 4). In contrast, a relatively thick bark strip, over the course of centuries, probably forms a thick slab (see tree 90-11 in fig. 4); such trees have a massive appearance. 


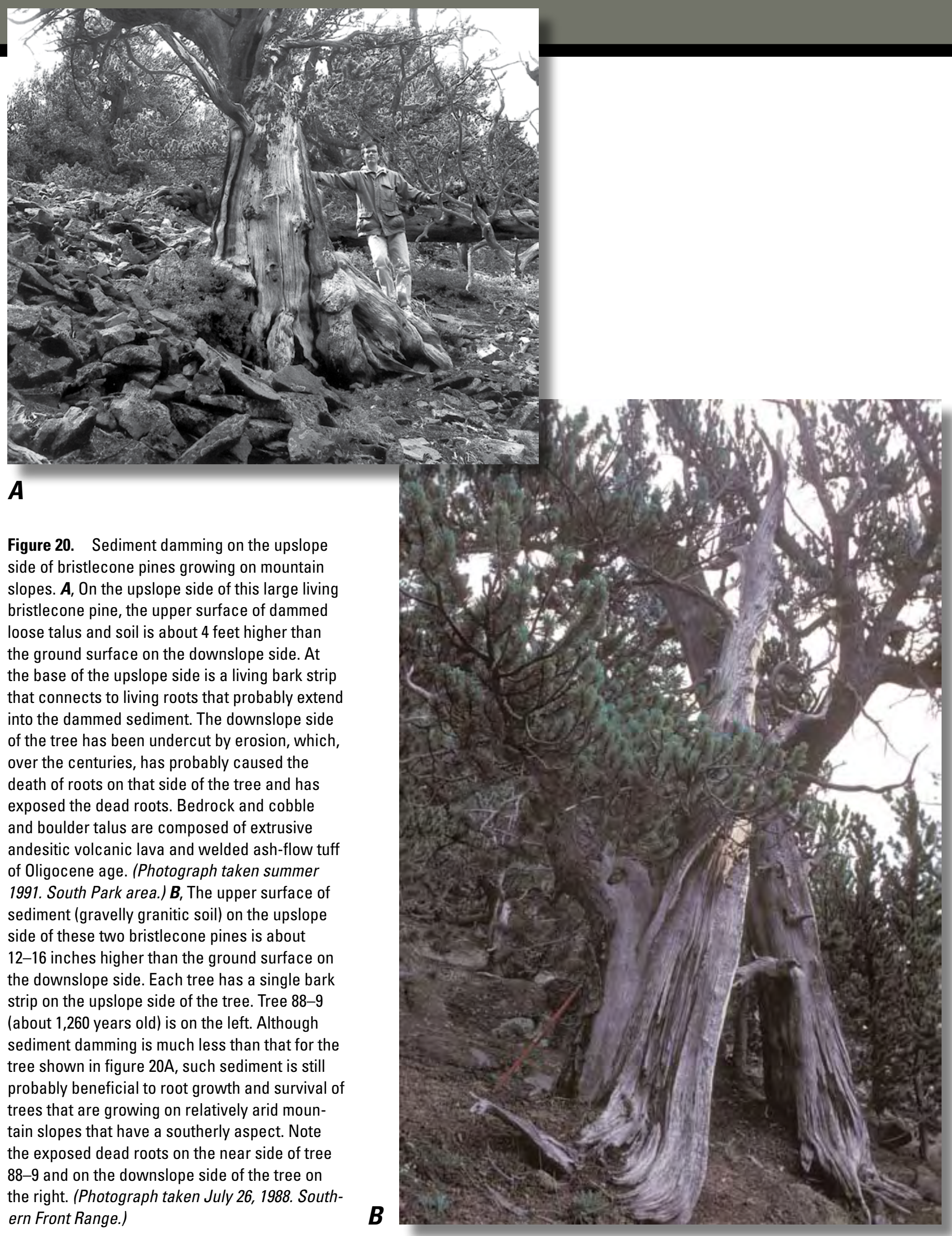




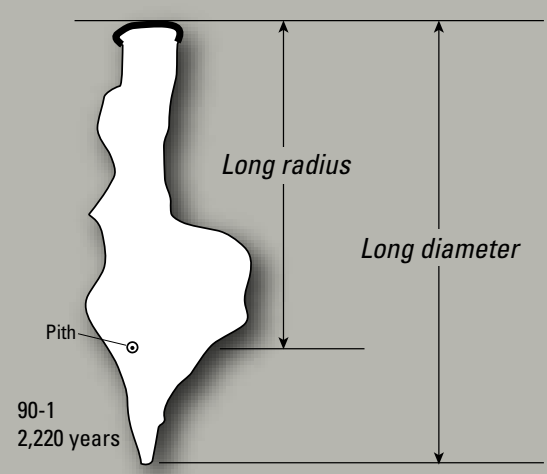

Figure 21. Inferred horizontal section view of a bristlecone pine showing long radius and long diameter.
The thickness of some slabs is remarkably consistent, with little variation (table 11). For example, tree 88-8 (about 1,210 years old) has a relatively uniform thickness of about 4-6 inches (see fig. 4). The thickness of other slabs is quite variable. Tree 90-1 (about 2,220 years old) has a slab thickness that varies from about 4 to 14 inches, and tree 68-3 (about 2,050 years old) has a slab thickness that varies from about 4 to 21 inches (figs. 4, 9, and 10).

The living limb attachment height (tables $6 A$ and $6 B$ ) determines the height of the slab-form part of the trunk of the trees. Compare tree 88-5 (fig. 8), which has a living limb attachment height of about 7 feet, to trees $90-1$ and 68-3 (figs. 9 and 10), which are shorter slabs because they have living limb attachment heights of about 4 and 3.5 feet, respectively.

\section{Opposite Bark Strips Slab}

Some of the slab-form trees have bark strips growing in opposite directions on opposite sides of the tree (see trees 91-14 and 93-39 in fig. 4 and tree 91-65 in fig. 13). Each bark strip connects to only one or two living limbs (fig. 13). Such trees form visually striking slabs having long diameters of as much as 45 inches. Such a tree is referred to in this report as an opposite bark strips slab.

A few centuries ago, tree 68-3 (see figs. 4 and 10) probably was an opposite bark strips slab. However, one side of the tree died, and now the tree has only one bark strip. Tree 90-10 (fig. 4) probably has had a similar history. Because one side of such trees is dead, some researchers not familiar with this form might mistake the long diameter (or a large percentage of the long diameter) for the long radius. Such an error in measuring the long radius could lead to a preliminary visual age estimate that is greatly inflated. A careful visual examination of such trees is sometimes necessary in order to locate the pith. Once the pith is located, an accurate radius measurement can be made.

One unusual tree included in this classification has two bark strips on one side of the trunk and one bark strip on the opposite side of the trunk (tree 90-15, fig. 23). It is a large, massive slab-form tree that has a long diameter of about 42 inches. Each of the three bark strips (7, 11, and 29 inches wide) connects to a different living limb, and the attachment heights of the limbs are about 4, 5, and 6 feet, respectively.

Table 10. Average long-diameter bearings (LDB) for living slab-form bristlecone pines 760-2,500 years old. Also see figure 22.

[Compass bearings were made using a Brunton pocket transit. A southeast aspect indicates that the slope faces southeast. The strike of a slope is parallel to the elevation contour lines on a topographic map.]

\begin{tabular}{l|ccc}
\hline Aspect & $\begin{array}{c}\text { Southeast } \\
\left(\text { strike N. } 40^{\circ}-75^{\circ} \text { E. }\right)\end{array}$ & $\begin{array}{c}\text { Southwest } \\
\left(\text { strike N. } 50^{\circ}-70^{\circ} \mathrm{W} .\right)\end{array}$ & $\begin{array}{c}\text { Southeast plus southwest } \\
\text { Average LDB }\end{array}{\text { N. } 10^{\circ} \mathrm{E} .}^{\text {Number of trees }}$ \\
20 & N. $28^{\circ} \mathrm{E}$. & N. $17^{\circ} \mathrm{E}$. \\
\hline
\end{tabular}




\section{Long-Diameter Bearing of Trees on Southeast-Facing Slopes}

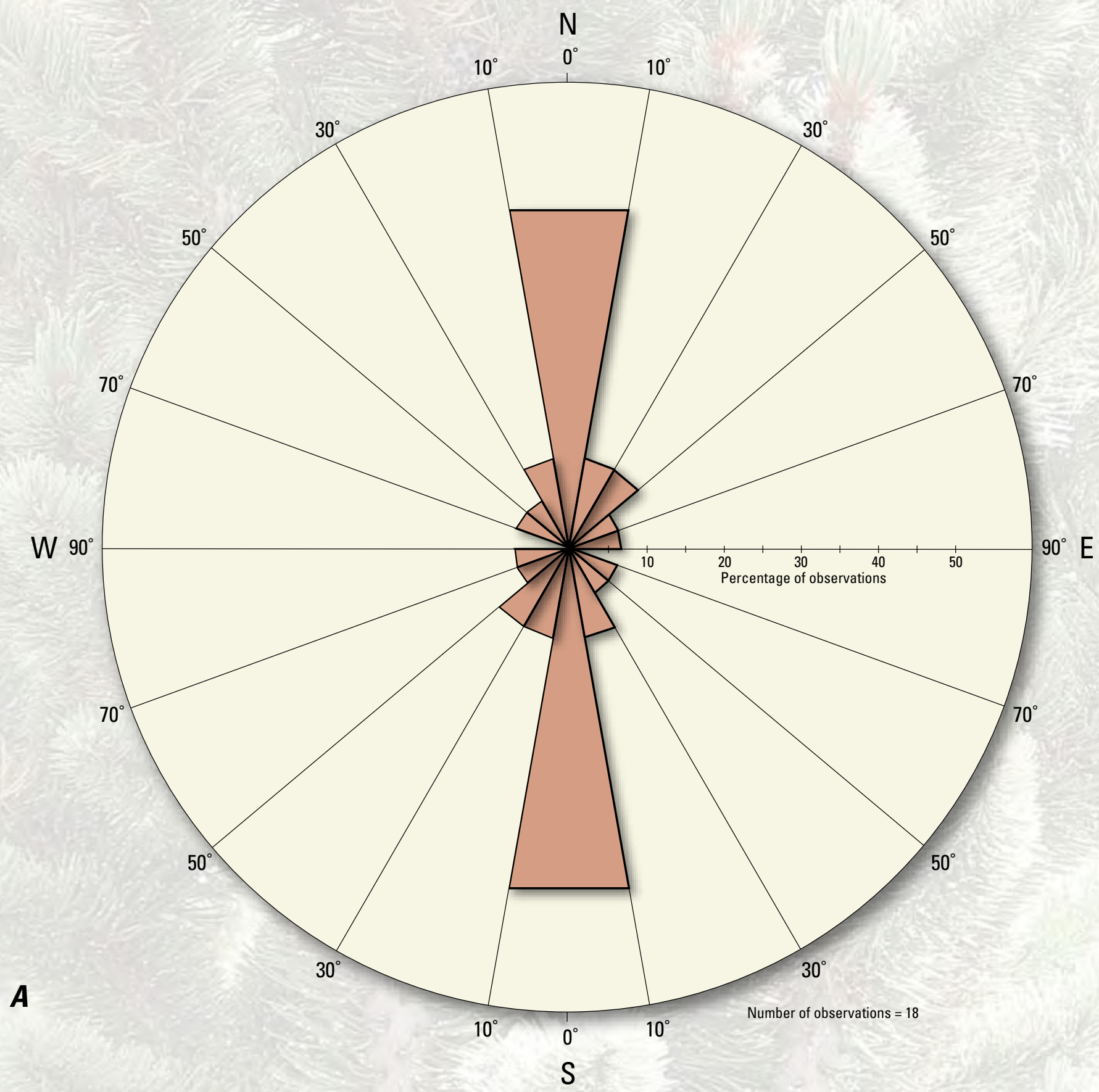

Figure 22. (Pages 57-59) Rose diagrams showing long-diameter bearings and bark-strip radial growth directions of 760- to 2,500-year-old slab-form bristlecone pines. $\boldsymbol{A}$, Long-diameter bearings for trees growing on southeast-facing slopes. Number of trees is 18 . $\boldsymbol{B}$, Longdiameter bearings for trees growing on southeast- and southwest-facing slopes. Number of trees is 30 . $\boldsymbol{C}$, Bark-strip radial growth directions at the base of trees that are on southeast- and southwest-facing slopes. Number of bark strips is 37 .

Southeast-facing slopes strike N. $40^{\circ}-75^{\circ} \mathrm{E}$. and southwest-facing slopes strike N. $50^{\circ}-70^{\circ} \mathrm{W}$. The strike of a slope is parallel to the elevation contour lines on a topographic map. Slopes at the study sites typically dip about $10^{\circ}$ to $60^{\circ}$. Compass quadrants are shown on the rose diagrams. 
Long-Diameter Bearing of Trees on Southeast- and Southwest-Facing Slopes

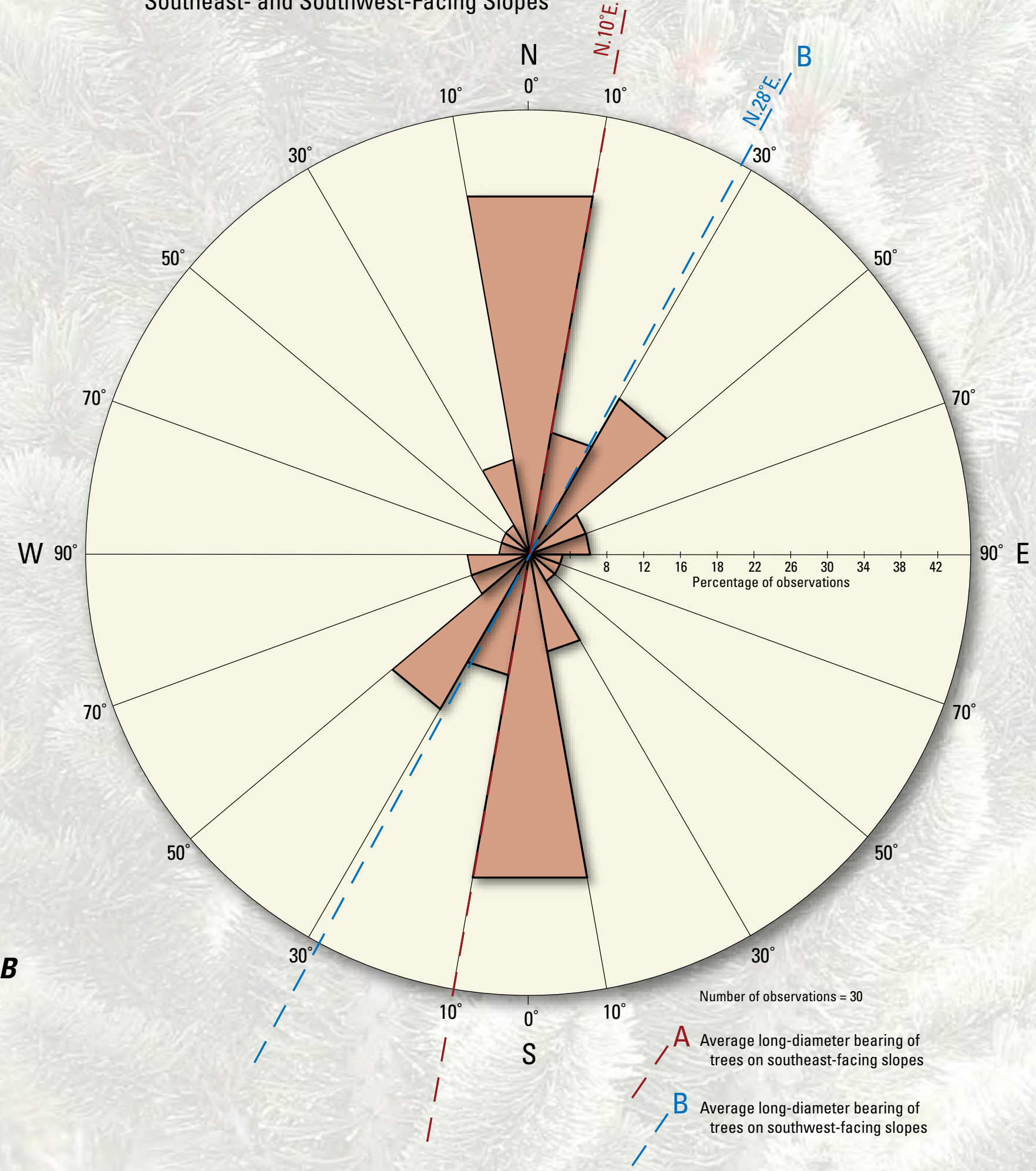




\section{Bark-Strip Radial Growth Direction}

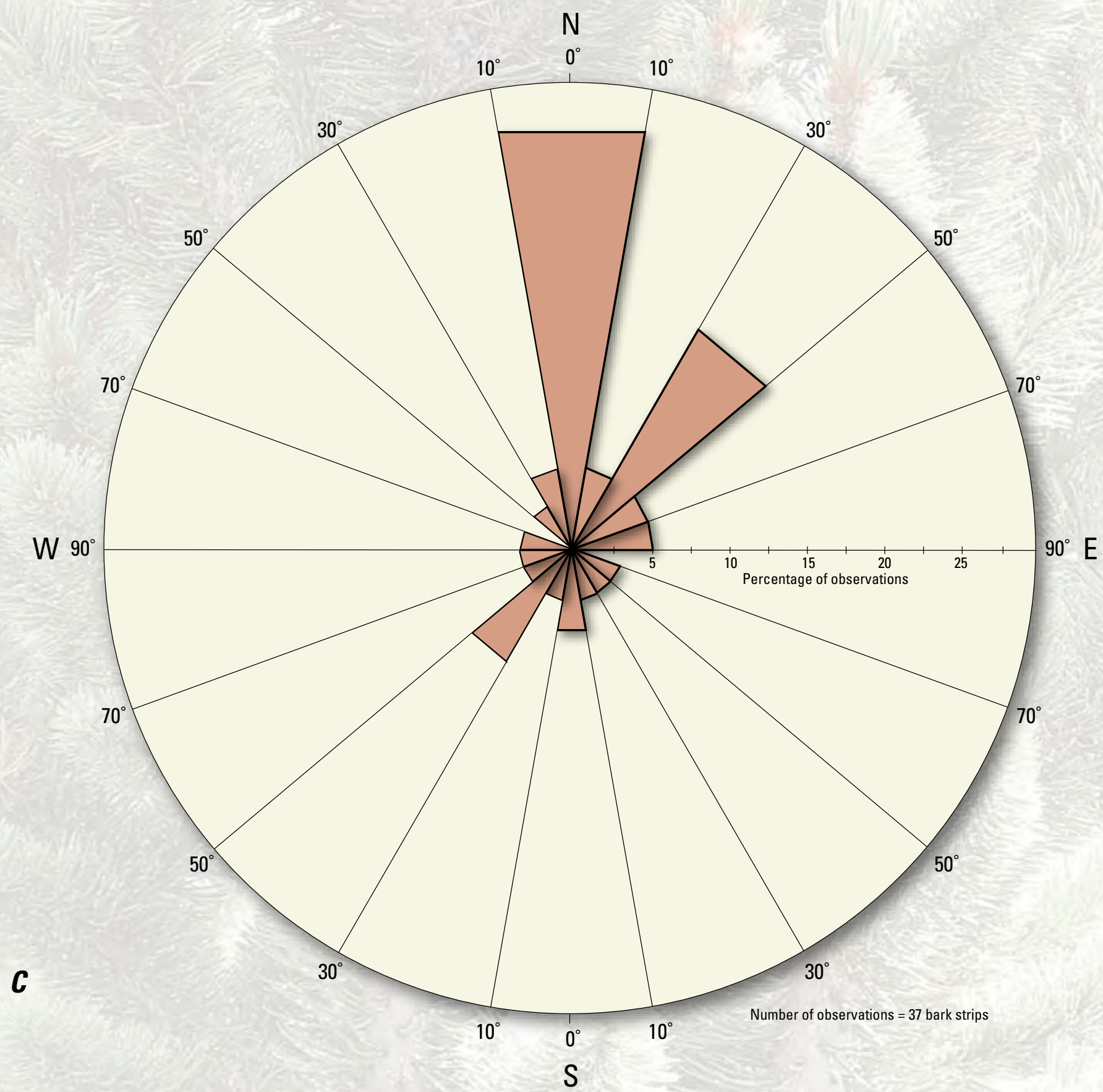




\section{Twisted Slab (or Spiral Slab)}

An uncommon form is a twisted slab (fig. 14; also see Appendix). This form has a single bark strip that forms a partial spiral (it could also be called a partial helix) around the trunk of the tree. Over many centuries of growth, the bark strip lays down a prominent spiral ridge of wood. The name of this form is derived from a combination of how the tree looks in long-axis view and in inferred horizontal section view. When the trunk of each tree is seen in long-axis view, the bark strip spirals to the right [counterclockwise] - up from the ground surface, forming a partial spiral around the trunk to where it meets a single living limb. When each of these trees is seen from above, the bark strip spirals counterclockwise from the ground surface, up around the trunk to where it meets the single living limb on each tree. When the lower trunk of each tree is seen in inferred horizontal section view, the trunk has a slab form (similar to a typical slab), and the twisted form is not readily apparent.

Three of the four twisted slabs in this study are growing on a southern Front Range site; two of them are within 10 feet of each other (see fig. 14). The fourth twisted slab was found at a site in the Sawatch Range. A few other twisted slabs were observed (but not sampled) at the study sites. At one Front Range site, an old limber pine (1,000+ years old) was observed to have the twisted-slab form.

Spiral bark strips on the twisted-slab form of Pinus aristata twist in the same direction and at about the same angles as spiral grain in relatively young trees that are not twisted slabs. This suggests that all such trees are displaying the same phenomenon (spiral grain).

\section{Multi-Stem Form}

One of the trees about 1,030 years old, as well as some younger trees in this study, have a multi-stem form. Such a tree form has (1) two or more vertical main stems, (2) a short main stem that produces two or more large vertical limbs (see fig. 15), or (3) one or more vertical main stem(s) that produce one or more vertical limb(s). In each case, the multiple main stems and (or) limbs dominate the form of the tree. The stems or limbs usually originate low on the trunk of the tree and extend vertically (see fig. 15). For some trees, this form might be the result of:

(1) Death of the upper stem (apical leader shoot as well as some to much of the stem below) of a young tree, resulting in two or more pre-existing, small, young limbs elongating upward to become vertical "main stems." Such vertical limbs can bow out at their juncture with the trunk, attesting to their probable origin as limbs (see fig. 15).

(2) Loss of apical dominance in a young tree, whereby growth of the current-year lateral shoots equals or surpasses the growth of the current-year apical leader shoot. Such competing shoots become multiple apical leader shoots, and they eventually develop into multiple main stems.

(3) Two or more individual trees that sprout close to each other and whose bases eventually "fuse" together.

Caching of Pinus aristata seeds by Clark's nutcracker (Nucifraga columbiana), red squirrels (Tamiasciurus hudsonicus), and possibly other birds and animals may lead to two or more individual trees sprouting close to each other. Clark's nutcracker is known to gather and cache seeds of Pinus longaeva in the Great Basin (Lanner, 1988). Nutcrackers were seen on numerous occasions at most of the study sites here in Colorado, which suggests that they may be gathering and caching Pinus aristata seeds. In September 1995, red squirrels were seen busily gathering unopened but mature bristlecone pine cones at altitudes of 11,500-11,900 feet at one of the southern Front Range sites. The highly resinous cones caused the faces and front paws of the squirrels to be liberally coated with resin. 


\section{Tilted Trees}

There are 14 living trees 1,000 or more years old for which the amount of tilt was recorded. They tilt from about $5^{\circ}$ to $75^{\circ}$ from vertical; most of them (64 percent) lean downslope. Tilting of some of the trees is probably caused by the slow downslope movement (creep) of surficial materials on the steep mountain slopes. However, at some places on the South Park site, the tilting of some of the bristlecone pines is caused by landslide movement. The evidence for landslide movement consists of gravity slumping and open tension fractures in colluvium at the site. A few of the tilted trees at a southern Front Range site have become tilted due to being partly undermined by collapse of the granite bedrock that makes up the steep mountainside. Such rockfalls have dislodged and killed some of the trees.

\section{Young Branches on Old Trees}

Each year, bristlecone pines add new needles and branches when terminal buds renew apical shoot growth at the start of the growing season. However, some of the bristlecone pines seem to have sprouted new growth from some of the old branch nodes on their trunks (see fig. 3) and on old branches. This may be vital to the survival of bristlecone pines, because such a mechanism enables the high-altitude trees to add new branches that shorten the distance from needle-bearing branches to roots, a highly advantageous adaptation in an environment where the highest and distal young branches on such trees may be at the limit of survival due to winter desiccation and other growth-limiting factors.

Young needle-bearing branches of Pinus aristata are usually erect and point upward (ascendant). However, some of the very young, flexible branches on some of the trees are pendulous; that is, they hang downward, similar to the pendulous branching typical of Pinus longaeva, as described by Bailey (1970).

Bailey (1970) found that young branches on Pinus aristata commonly retain green needles for 10-15 years, and very rarely for 20 years. In this study, a check of some of the small branches on three of the trees that are more than 1,000 years old revealed needle retention of 10-15 years (one branch 22 years), 14 years, and 16-18 years.

Table 11. Approximate thicknesses of slab-form bristlecone pines $1,000-2,500$ years old.

[Listed below are slab thickness measurements for 17 trees. Approximate thickness measurements are made perpendicular to the long axis of the inferred horizontal section of the slab-form trunk (see figure 4). Note that a range is shown for trees that have a variation in slab thickness. Measurements taken 1-4 feet above ground]

\begin{tabular}{cl}
\hline Age class (number of trees) & \multicolumn{1}{c}{ Thickness (inches) } \\
\hline $1,000-1,500$ years old (9 trees) & $4-4.5,5,4-6,5-9,7-9,8-11.5,9-12,10-14,20$ \\
$1,501-2,000$ years old ( 3 trees) & $4.5-12,6-8,10-15$ \\
$2,001-2,500$ years old (5 trees) & $4-21,5-8,4-14,4-17,4-25$ \\
Average thickness of all 17 trees & about 10 \\
\hline
\end{tabular}




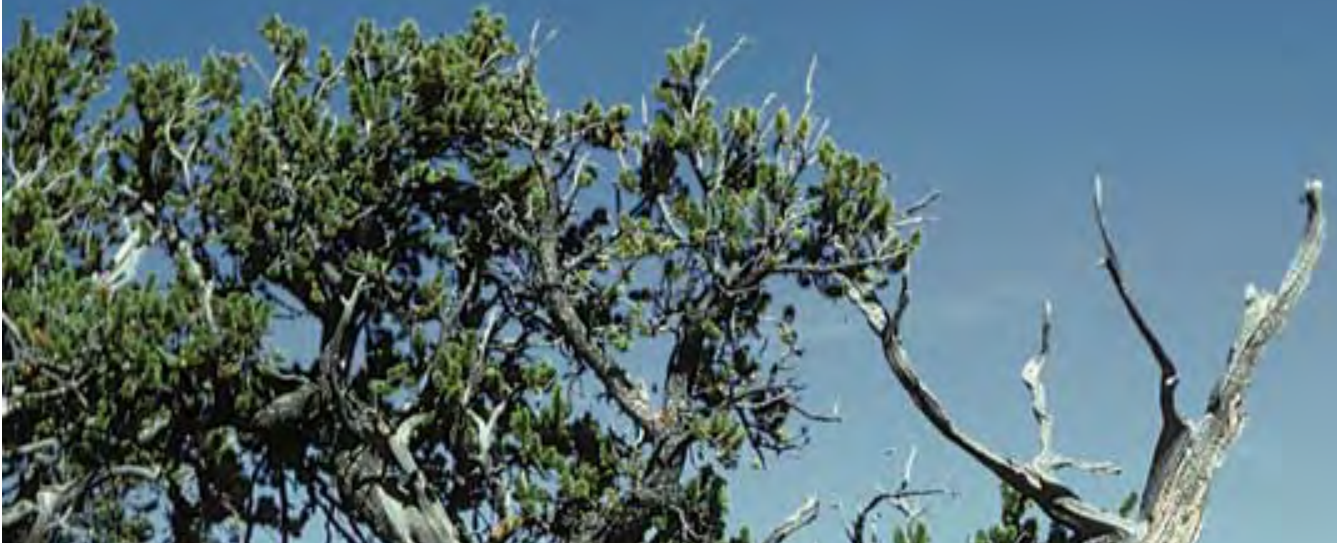

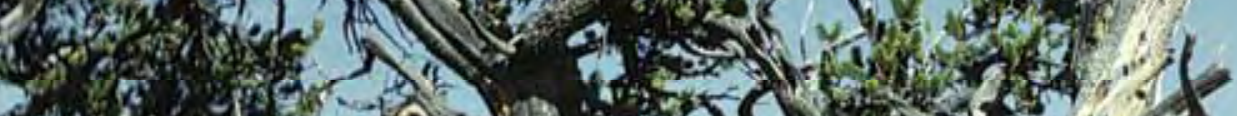

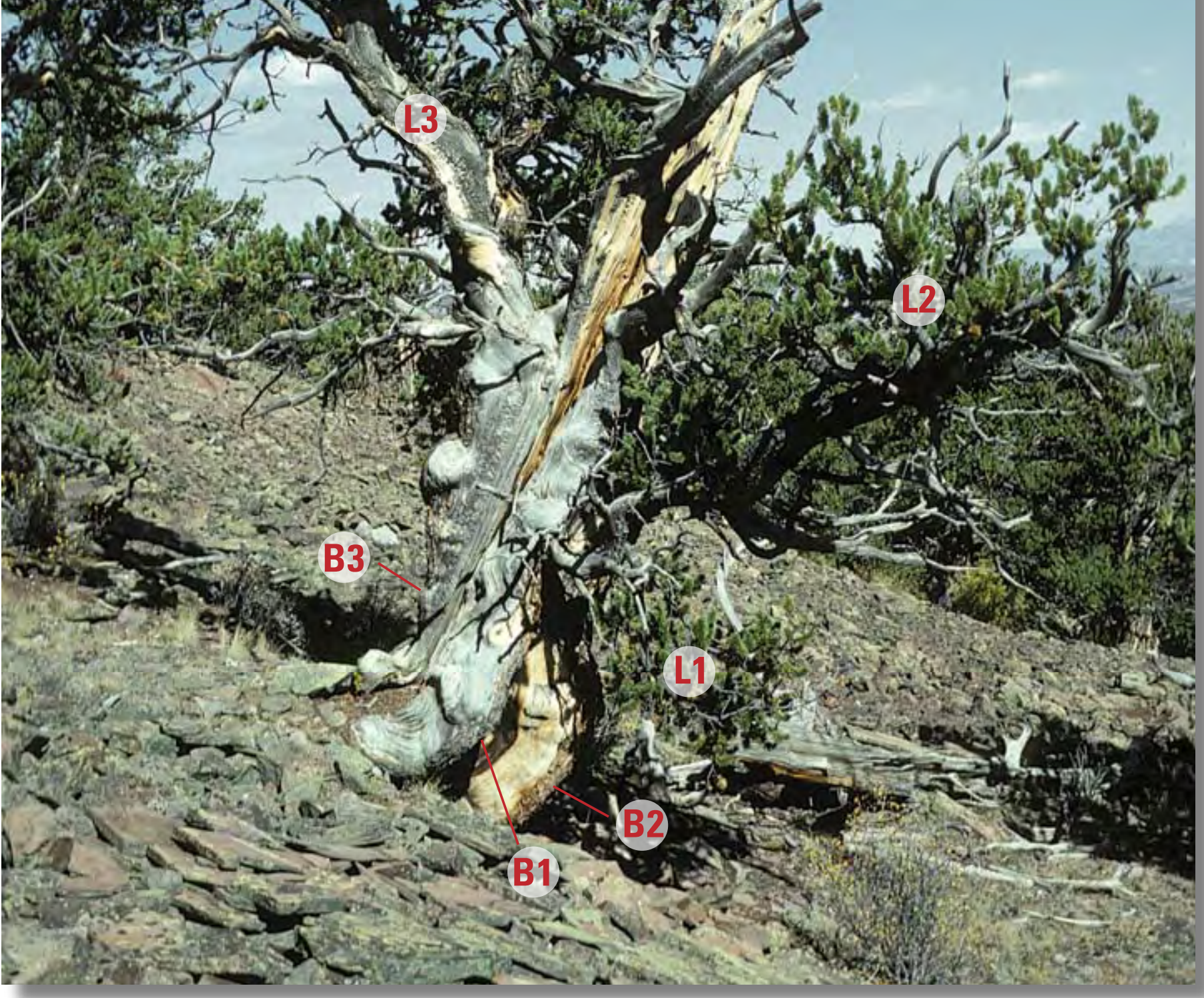




\section{Some Examples of Trees that are Exceptions to Predominant Growth Trends}

Counter to predominant growth trends shown in table 9 and fig. $22 C$ are two trees that have bark strips that have radial growth in a southerly, downslope direction and one tree that has radial growth in a southerly direction that is parallel to the strike of the slope (trees 88-10, 68-R4, and 68-3 in fig. 4; tree 68-R4 is dead, but the once-present bark strip was on the south side of the tree). These trees are on a southeast-facing steep slope composed of solid granite bedrock and stable granite-boulder talus. These substrates are very stable and have low erosion rates as evidenced by:

(1) Extensive lichen coverings on the substrates (see fig. 12). Lichen coverings are not present or are weakly developed on less stable and more erodible substrates such as loose talus, thin gravelly soil, and friable granite bedrock that most of the other trees grow on.

(2) Tree 68-3 has little or no erosion (with little or no undercutting of roots) on the downslope side (or any other side) of the tree.

(3) The trunk of tree $88-10$ is straight and not tilted (fig. 12), suggesting that the tree has been firmly anchored for more than a thousand years.

Solid bedrock and stable boulder talus possibly offer these trees advantages, such as low substrate erosion and greater tree stability, which equal or exceed the advantages of having a bark strip on the upslope side of such trees. The relatively low erodibility of these substrates probably prevents undercutting of the trees' roots and enables survival of bark strips and roots at the base of the trunk at locations other than the upslope side of the trees. The stability of such substrates probably enables the trees to remain stable (not fall over) regardless of where the bark strips and roots are located.

Other factors might contribute to the growth trends of these three trees. For example, the lower trunk on the dead north side of tree 68-3 has encroached upon two large granite boulders. Such encroachment possibly inhibited or stopped growth in that direction because the boulders might have presented physical obstacles that the tree could not surmount. The other two trees may have suffered impact damage to the upslope side of their trunks from boulders that tumbled down the steep slopes above the trees; such damage may have stopped growth on the upslope side of those trees. However, even if such factors are true, the relatively low erodibility of the substrates probably has contributed to the survival of these trees' bark strips and roots at the base of the trunk at locations other than the upslope side of the trees, and the greater stability of the substrates has enabled the trees to remain stable (not fall over) regardless of where the bark strips and roots are located.

Also counter to predominant growth trends shown in table 9 and fig. $22 \mathrm{C}$ are trees 91-38 and 91-14 (fig. 4). The single bark strip on tree 91-38 and one of the bark strips on tree 91-14 have radial growth in a southeasterly and southerly downslope direction, respectively. At the downslope base of both trees are large boulders that have prevented soil erosion and undercutting of the roots on the downslope side of these two trees, which may explain why the bark strips on the downslope side of the trees have survived.

A few additional trees were observed to have growth trends counter to predominant trends shown in table 9 and fig. 22C. Cursory examinations of those trees revealed no obvious reasons why they have growth trends that differ from predominant trends.

Figure 23. (Facing page) This living bristlecone pine (tree 90-15) is a large, massive, opposite bark strips slab-form tree that has a long diameter of about 42 inches. It has three bark strips that are 7,11 , and 29 inches wide (labeled B1, B2, and B3, respectively); one of the bark strips is on one side of the trunk and the other two are on the opposite side. Each bark strip connects to a different living limb (labeled L1, L2, and L3, respectively), and the attachment heights of the limbs are about 4, 5, and 6 feet, respectively. Bedrock and cobble and boulder talus are composed of extrusive andesitic volcanic lava and welded ash-flow tuff of Oligocene age. (Photograph taken October 6, 1990. South Park area.) 


\section{Selected Types of Injuries that Possibly Cause Growth-Form Changes or Death in Bristlecone Pines}

\section{Damage Caused by Lightning Strikes}

ome bristlecone pines have evidence of recent to old lightning damage. Such evidence usually consists of a 1- to 4-inch-wide unhealed to healed scar extending from high up on the tree to the base of the trunk. Relatively fresh, unhealed scars are partially or completely denuded of bark and cambial tissue. A nearly continuous vertical split or crack is present in the underlying wood in the center of some of the scars. Visible in the exposed wood in the trunks of some old trees are old lightning scars that are either partially or completely healed. The partially healed lightning scars suggest that such wounds can initiate cambial dieback in bristlecone pines.

Some trees have extensive damage due to lightning strikes. In July 1988, evidence for a lightning strike was observed on a bristlecone pine that stood out as the highest point on the top of a granite bedrock spur at a southern Front Range site. The tree had not burned, but the main living limb had been split apart and partly shattered. The tree was still alive, but it was obviously heavily damaged and it was not clear whether the main limb (the tree had only a few living limbs) on this tree would survive. A few of the tall, dead limber pines (Pinus flexilis) and Engelmann spruce (Picea engelmannii) at a nearby site seem to have been killed when they were struck by lightning and had burned. They were reduced to standing burnedout hulks; however, fire had not spread to nearby shorter bristlecone pines, some of which are more than 1,000 years old. The shorter stature of the 1,000+ year-old living bristlecone pines as compared to the other tree species at this particular site may have helped protect them from lightning strikes.

In 1968, I witnessed a lightning strike to a tree at an altitude of about 10,500 feet on a mountain near Pikes Peak. After the storm had passed, the minutes-old wound on a previously healthy limber pine (Pinus flexilis) was inspected. The wound was several inches wide and extended in a relatively straight line from near the top of the tree to the base of the trunk. Along the wound, the trunk was denuded of bark and cambial tissue, and fresh, white xylem wood along the wound had a prominent, mostly continuous, vertical split or crack. The probable steam explosion (caused by the lightning-heated water in the moist phloem, cambium, and xylem) probably caused the vertical split or crack and had blown off pieces of wood and overlying bark. Pieces and strips of bark and slivers of fresh wood several inches long were scattered on the ground near and at some distance (as much as about 50 feet) from the tree. At the base of the tree, where the wound met the ground, the soil was disturbed and a few rocks as large as about 3 inches in diameter were moved several inches. None of the branches on this tree appeared to be damaged. This lightning wound was nearly identical in appearance and dimensions to the lightning scars observed on the trunks of some bristlecone pines.

(Facing page) Weathered dead branches of a bristlecone pine were once bristling with living green needles. Wildflowers make a brief appearance during the cool mountain summer. (Photograph taken July 6, 1990.) 
Figure 24. Impact wound to the bark strip of a living bristlecone pine (tree 89-2; about 1,980 years old). This wound probably was caused by a boulder that rolled down the steep slopes above this tree. (Photograph taken in June or early July 1989. Southern Front Range.)

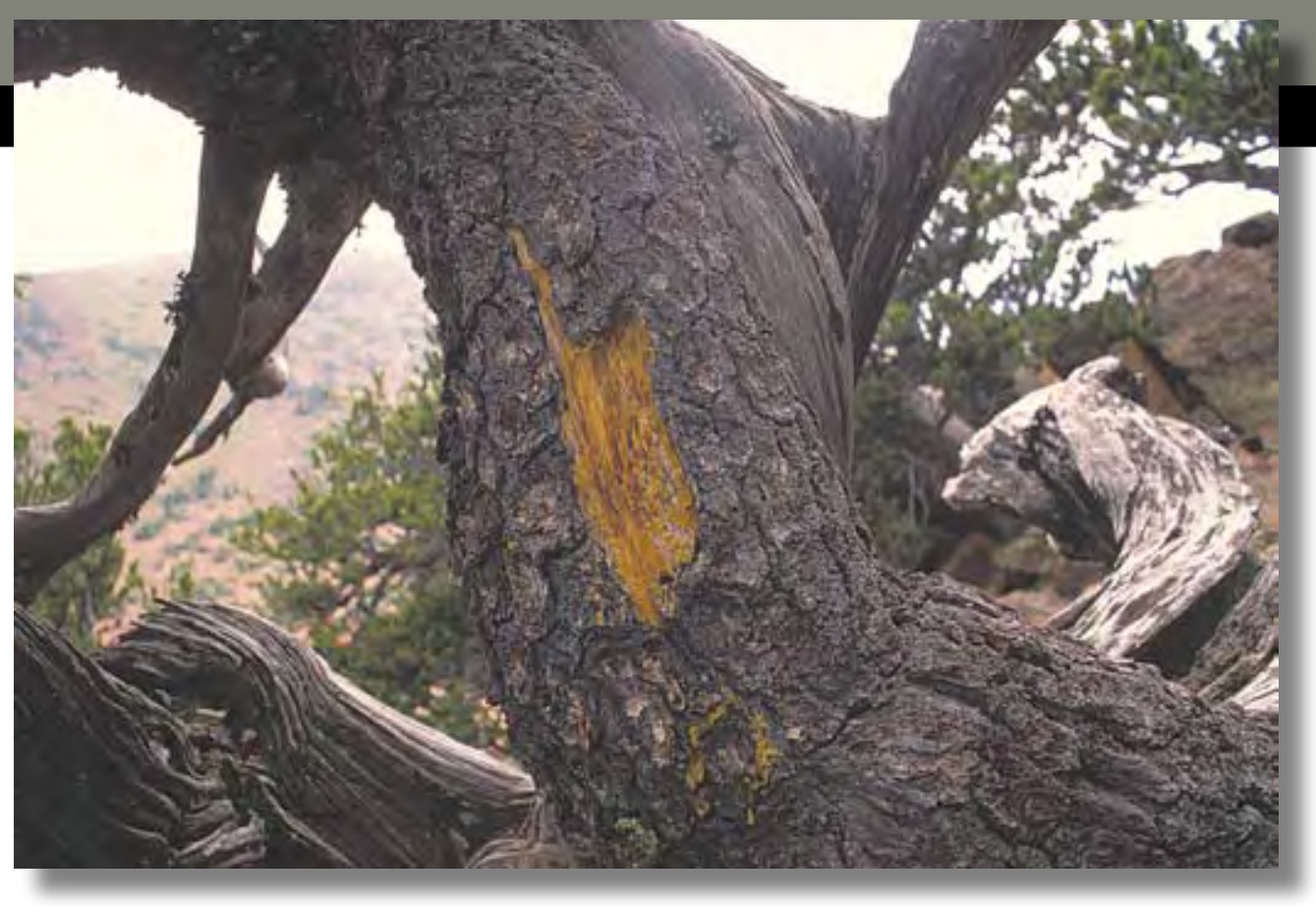

Figure 25. Impact wound, probably caused by a tumbling boulder, to the upslope side of a living bristlecone pine. At the wound, the bark, cambium, and part or all of the underlying xylem wood was crushed and torn away. No evidence of healing is present at the wound. Bark below and to the left of the wound is loose and falling off. The entire upslope part of the tree (bark strip and branches) is dead. The bark strip on the downslope side (not in view) of the tree is unharmed. Tree is on a talus slope beneath bedrock cliffs. (Photograph taken June 29, 1991. South Park area.)

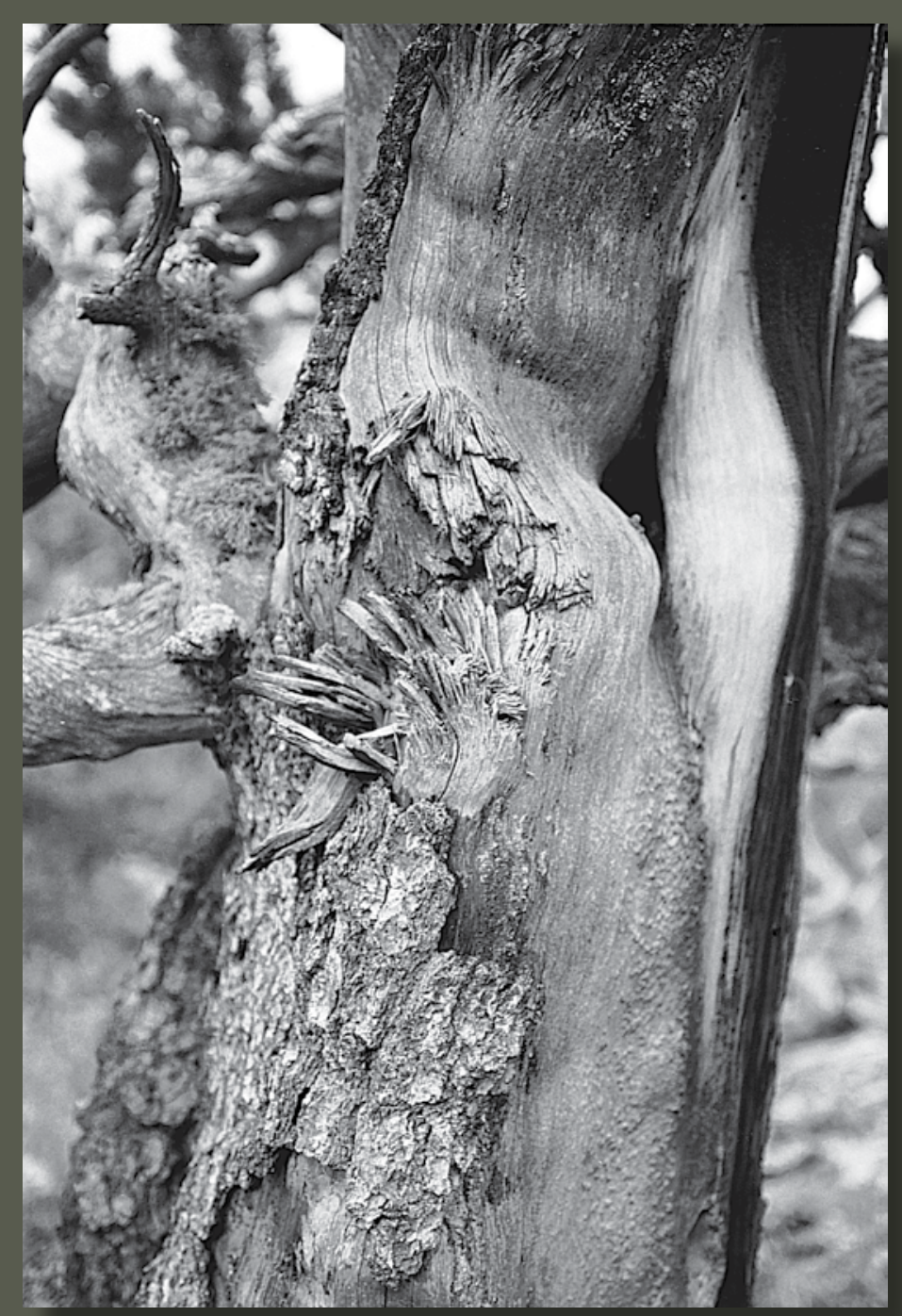




\section{Damage Caused by Falling and Tumbling Rocks}

Some bristlecone pines have minor to severe impact damage to the upslope side of their trunks. Such trees are usually located on steep, rocky slopes, steep talus slopes, or below bedrock cliffs. Damage to such trees usually consists of an area of bark and underlying cambial tissue 1-6 inches across that is torn off the lower 3-4 feet of the trunk. These wounds usually have little or no splintered wood and are usually found on relatively young bristlecone pines whose trunks are otherwise fully covered with bark. However, old living trees, such as tree 89-2 (about 1,980 years old), were occasionally found to have such wounds (fig. 24). Most wounds were observed to range from recent and unhealed to old and partly healed. I witnessed an occurrence of such damage when a rock about 6 inches in diameter tumbled about 20 feet down a steep $\left(30^{\circ}-40^{\circ}\right)$ slope and hit the upslope side of the bark-enclosed trunk of a young bristlecone pine, shaking the tree and tearing off a 5- by 5 -inch patch of bark and underlying cambial tissue about a foot above the ground.

A few trees have severe impact damage that consists of small to large areas of bark and underlying cambial tissue that are torn off, and the underlying wood is severely splintered and shattered. Some of these wounds show no evidence of healing. On one tree the unhealed impact wound apparently caused the death of the entire upslope side of the tree (fig. 25). Prior to this wound, this tree had two living bark strips, one on the downslope side of the tree and one on the upslope side of the tree. Such a tree offers evidence that impact damage can greatly affect the future growth forms of some bristlecone pines.

A few old bristlecone pines were observed to be killed outright, such as an old bristlecone pine in the South Park area, which was crushed and partly buried by a large boulder about 8-10 feet in diameter that had tumbled down from bedrock cliffs.

Most of the oldest bristlecone pines are growing in microsites that have little evidence of falling and tumbling rocks, a factor that is probably conducive to longevity of bristlecone pines. However, even old trees in areas that appear to be mostly safe from such hazards apparently do occasionally succumb to damage from a rolling boulder. For example, a standing dead tree (tree 68-R4; fig. 4), cores from which contain the ring sequence from 101 B.C. to A.D. 1431, appears to have been killed by a rolling boulder that broke off a 4-inch-diameter chunk of wood and adhering living bark strip near the base of the tree. 


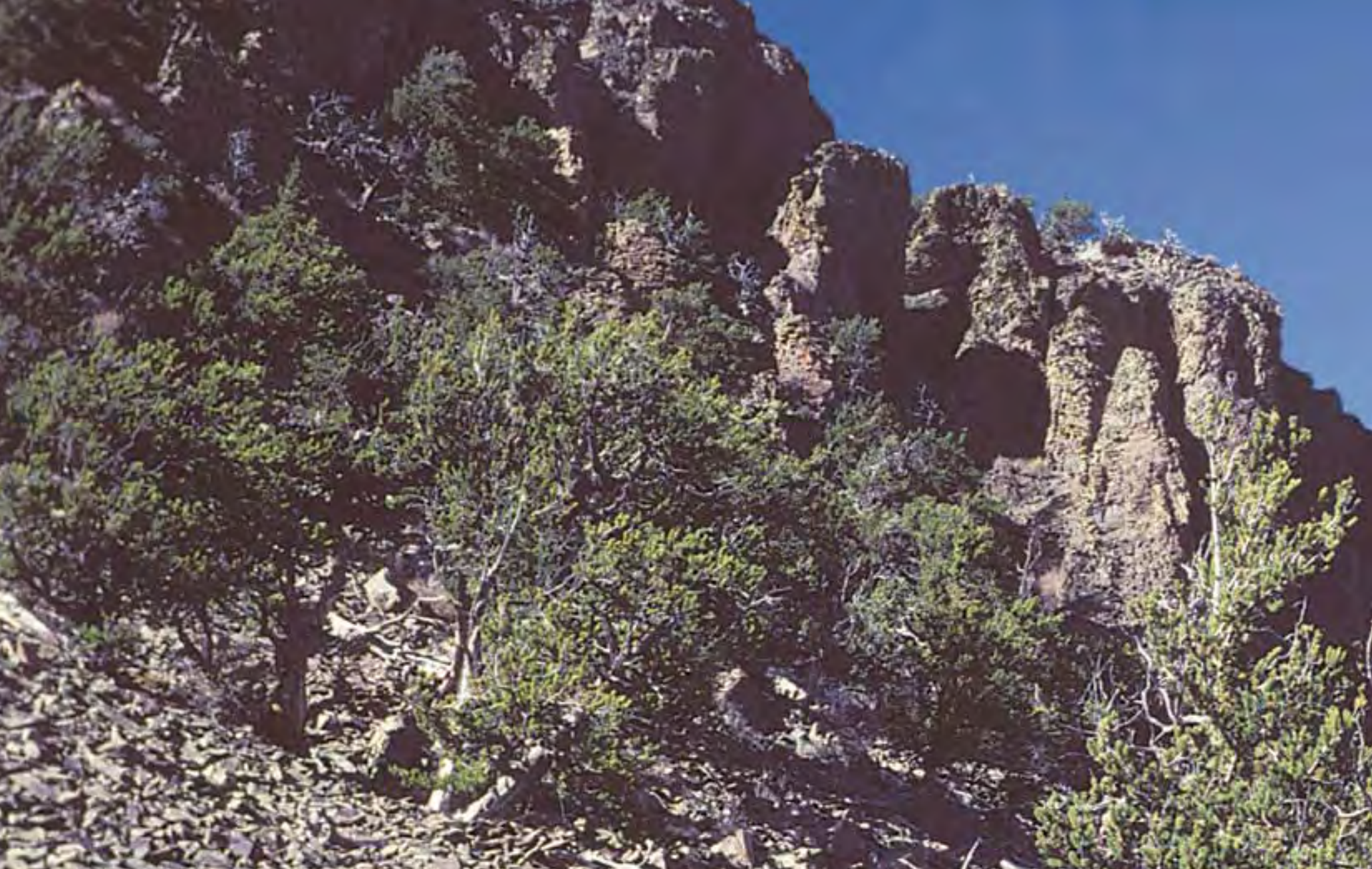
trat

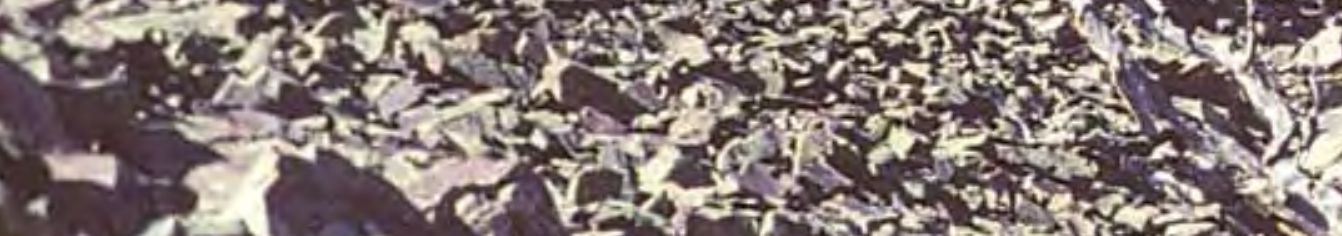

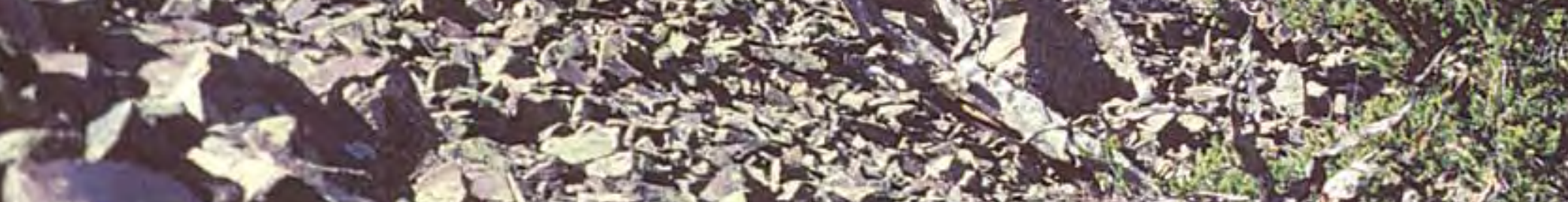

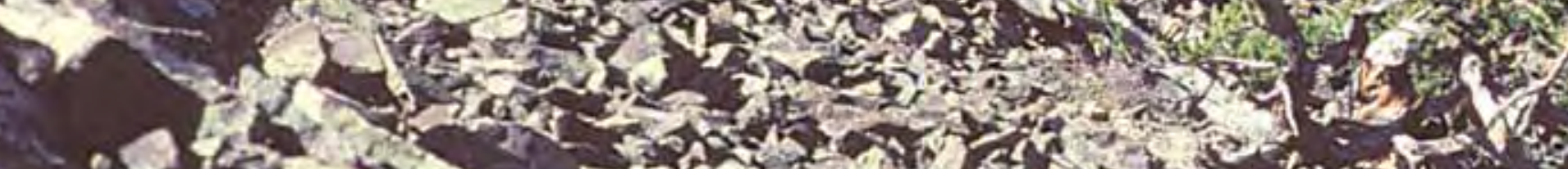

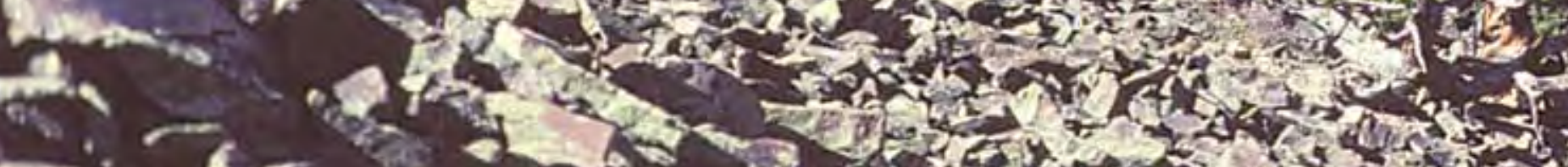

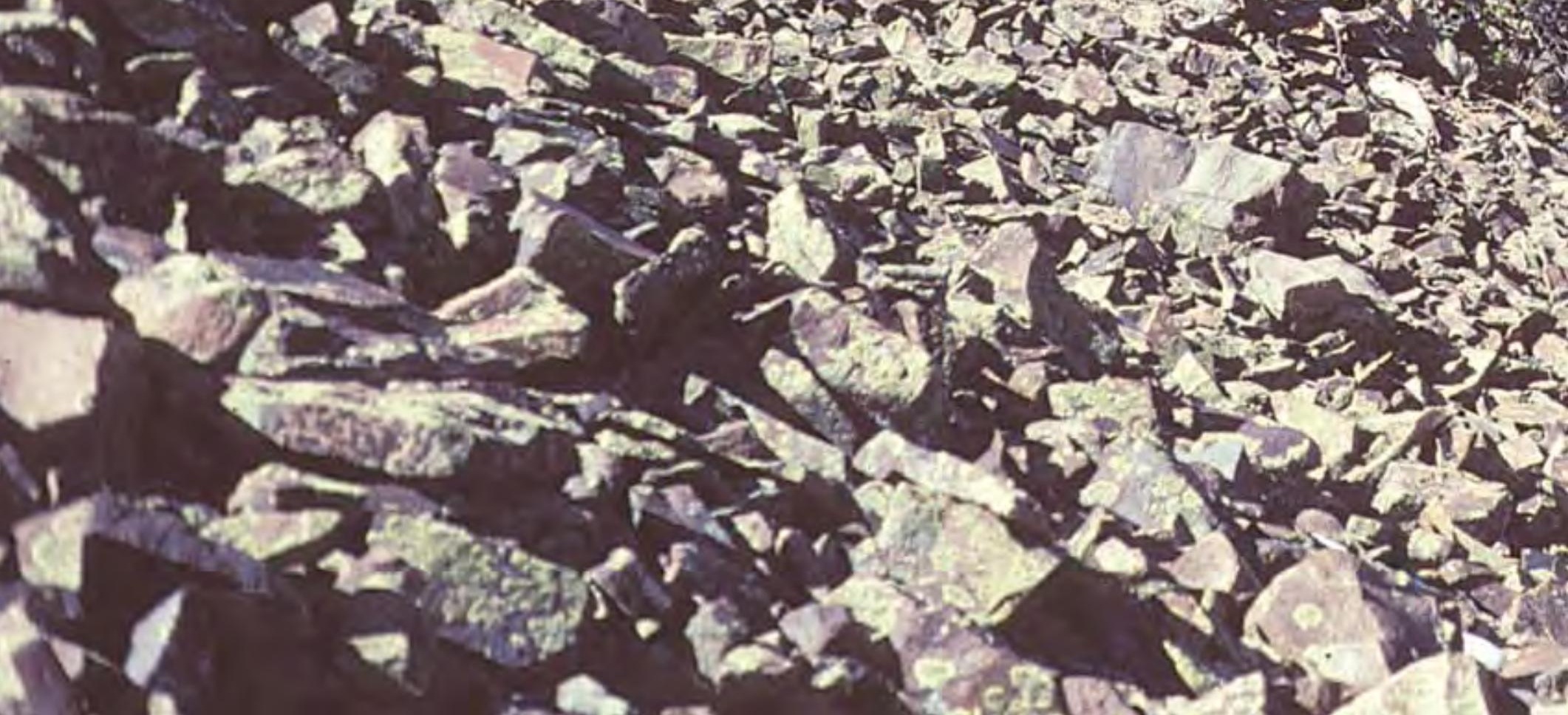


Bedrock cliffs and steep cobble and boulder talus slopes of a bristlecone pine site in central Colorado. Such sites have treacherous footing and are dangerous for hikers. The sites are also hazardous for bristlecone pines. Rocks dislodged from the bedrock cliffs, as well as an occasional tumbling boulder on the steep talus slopes, can kill or wound young to old bristlecone pines (see figs. 24 and 25). (Photograph taken October 30, 1990.)
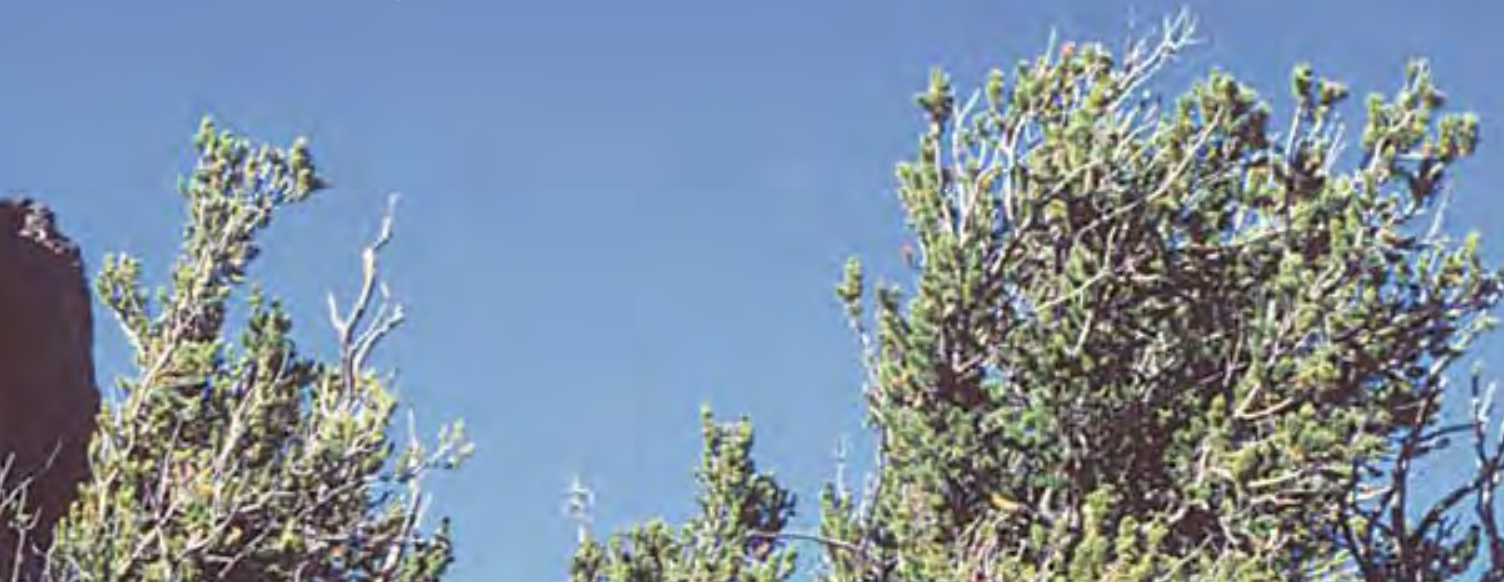

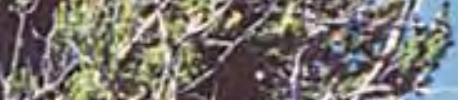

(2)

4. 30 .

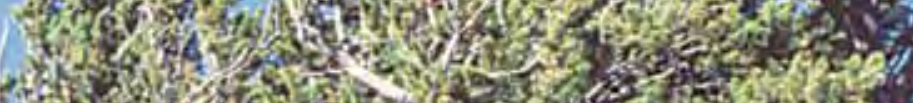

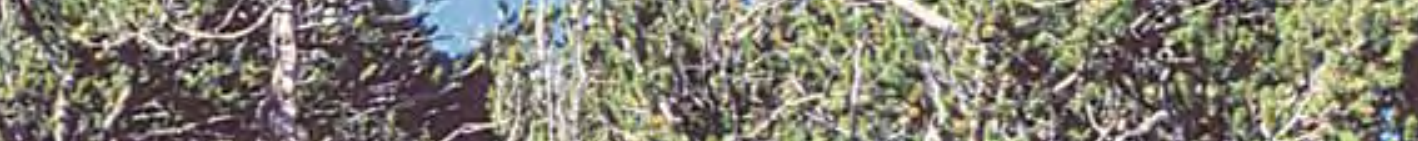

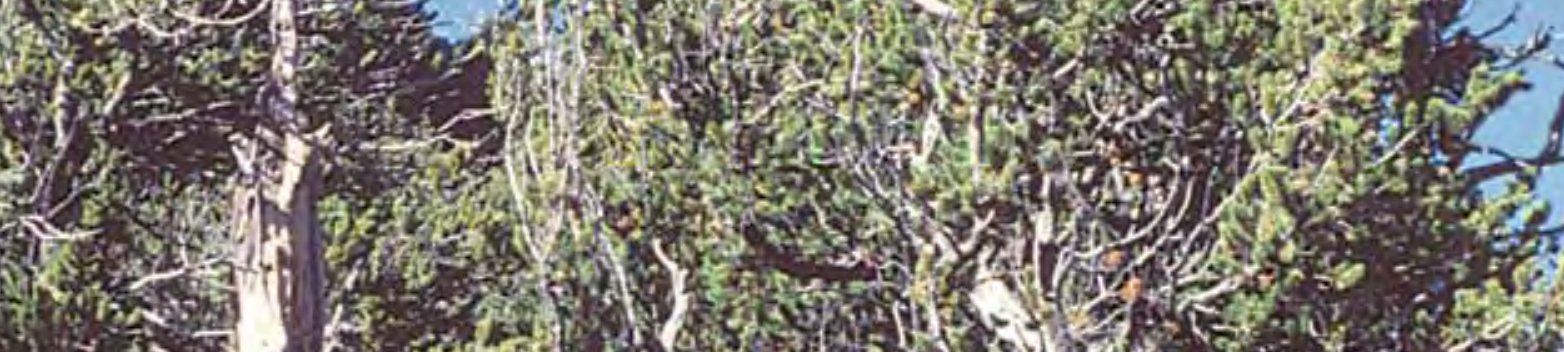

2

7.5.

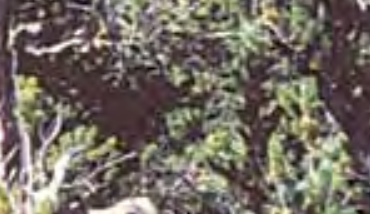

(3)

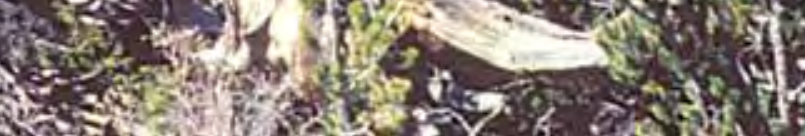

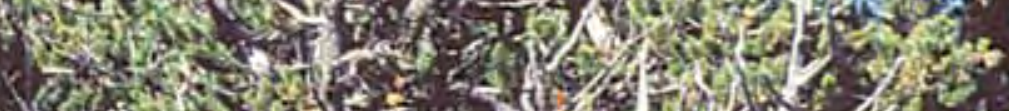

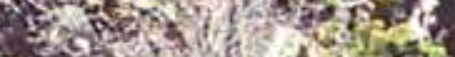

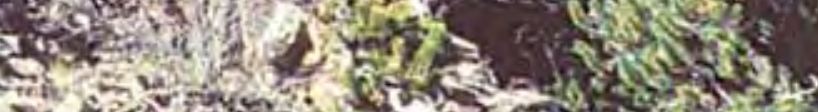

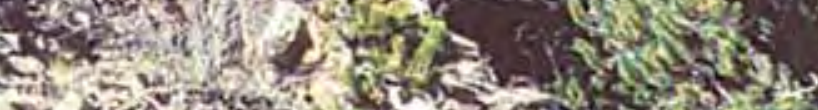

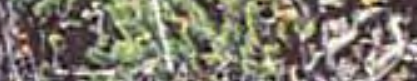

1.

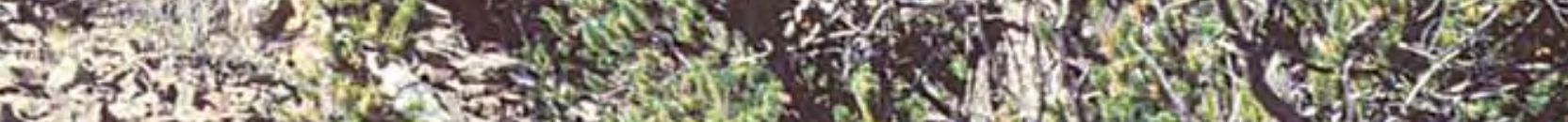

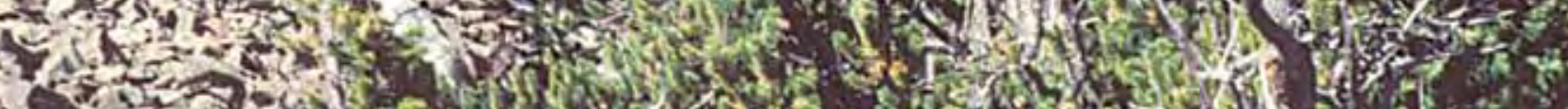

15. 2 .

\{. $340 \%$

pos? 5.

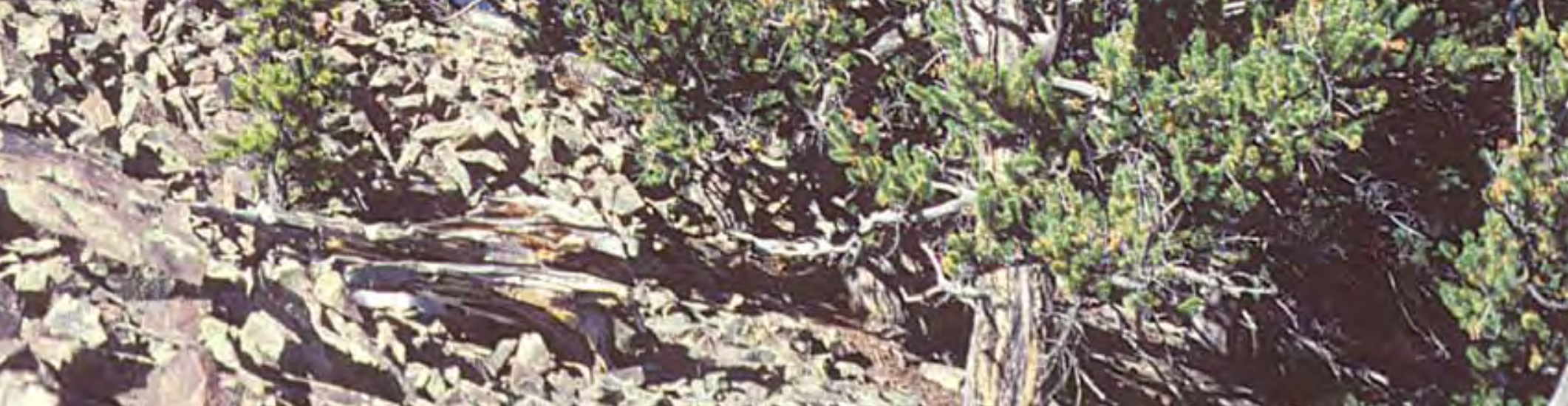




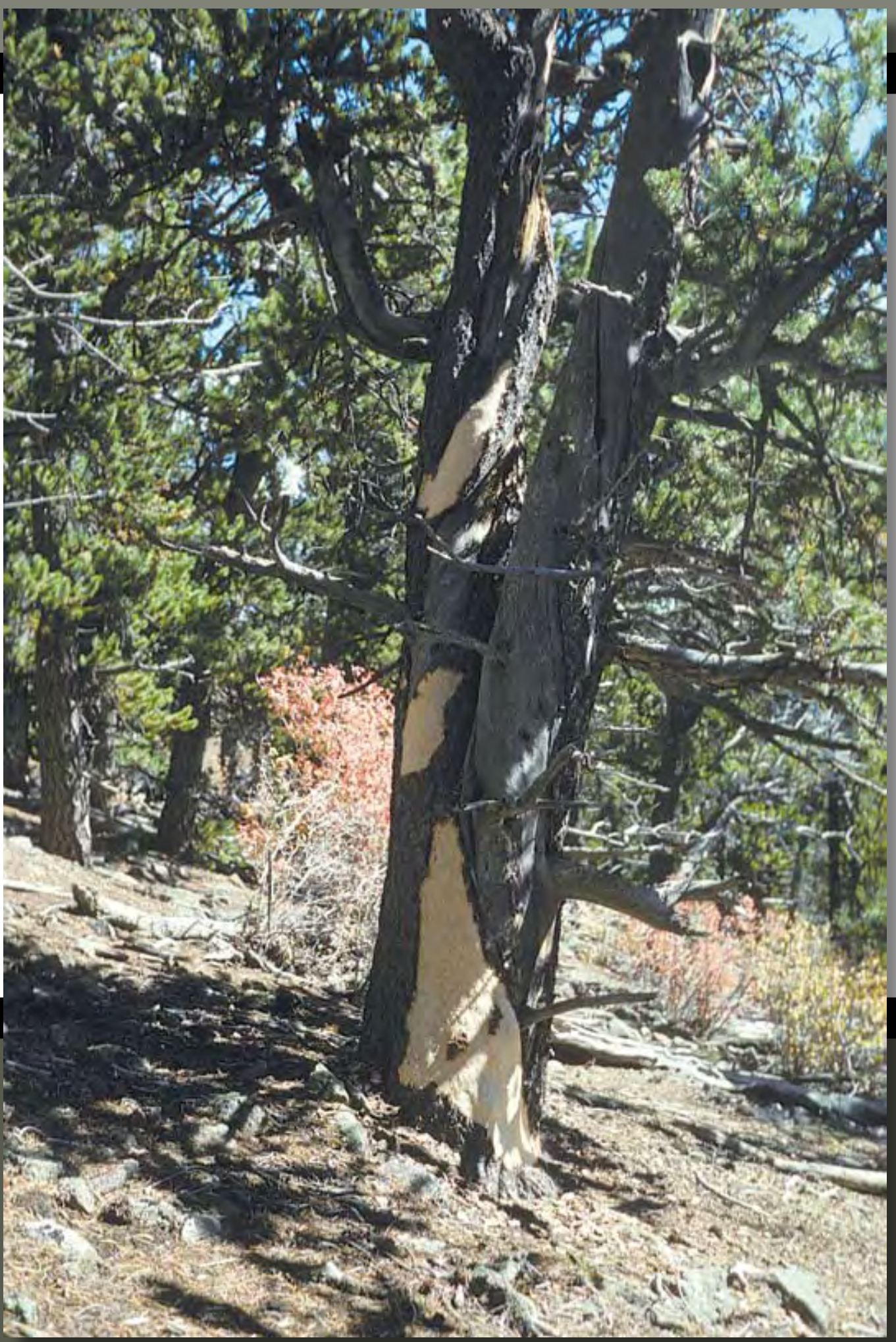

Figure 26. Porcupine damage to living multi-stem (two main stems) bristlecone pine. Bark and underlying cambium have been stripped from three large areas on this tree. Such damage will probably alter the eventual form of this tree and also may cause further loss of living bark-covered tissue as well as cause the death of large branches. This tree exhibited the most severe porcupine damage observed in this study. Only a small area of trees on this site was observed to have recent or old porcupine damage. Shrubs that have turned red and yellow in the background are mountain gooseberry (Ribes montigenum). (Photograph taken October 6, 1990. South Park area.) 


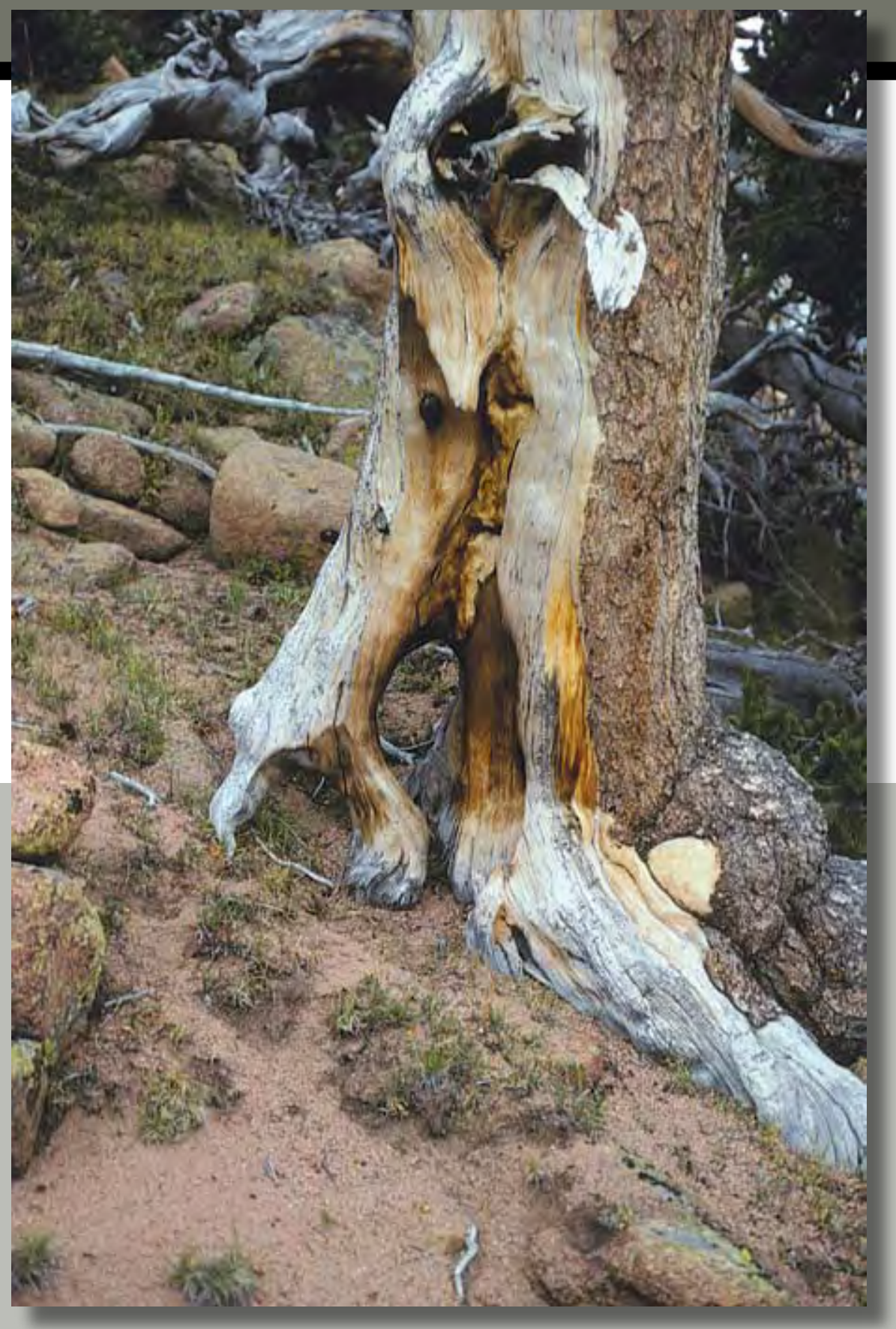

Figure 27. Fire damage to the trunk of a living bristlecone pine at an altitude of about 11,850 feet, southern Front Range. This tree is at the uppermost part of a large "ghost forest" of bristlecone pines killed by a forest fire that occurred many years ago. Although this tree and several other nearby trees survived, the fire appears to have killed living cambial tissue on the trunk of this tree and on some of the other nearby trees, and some living branches on the trees may also have been killed. (Photograph taken September 14, 1995.)
Heights of trees about 20 to $<1,000$ years old (feet)

Heights of trees $\geq 1,000$ years old (feet)

Bark on lower trunk

Average diameter (circular trunk; inches)

Average long radius (slab trunk; inches)

Average long diameter (slab trunk; inches)

Presence of crown dieback

Presence of cambial dieback Maximum number of living limbs Maximum number of bark strips 


\section{Conclusions}

he life stages of young to old bristlecone pines in this study are punctuated by subtle to striking changes in the trees' growth-form characteristics (fig.

28). Observations of variations in growth-form characteristics reveal that each bristlecone pine, especially each ancient tree, is unique in easily quantifiable ways. In addition, each tree possesses a unique aesthetic quality.

The long lifespans of these trees reveal a long-term growth response or adaptation to the substrate on/in which they grow. The response of these trees to the erodibility and stability of the substrate affects certain growth-form characteristics and probably greatly influences whether the trees survive into old age.

Cambial dieback due to wind-induced dessication and scouring by wind-driven ice and soil seems to be the precursor or beginning of strip-bark growth for most bristlecone pines, as suggested by other researchers. Evidence at the bristlecone pine sites in this study supports that finding. However, observations made in this study suggest that as most bristlecone pines growing on steep mountain slopes get older, the erodibility and stability of the substrate on which the trees grow become major factors that help determine the eventual location of the bark strip at the base of each tree as well as the radial growth direction of the bark strip(s) on each tree.

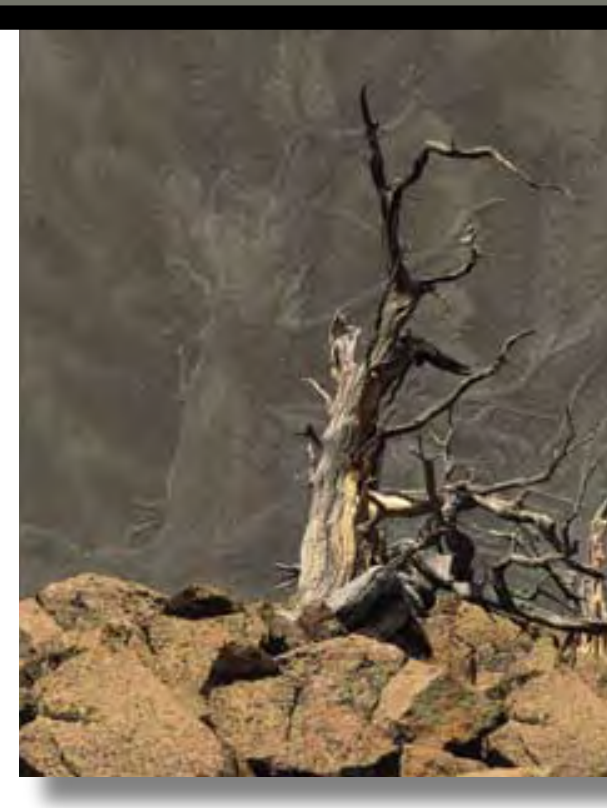

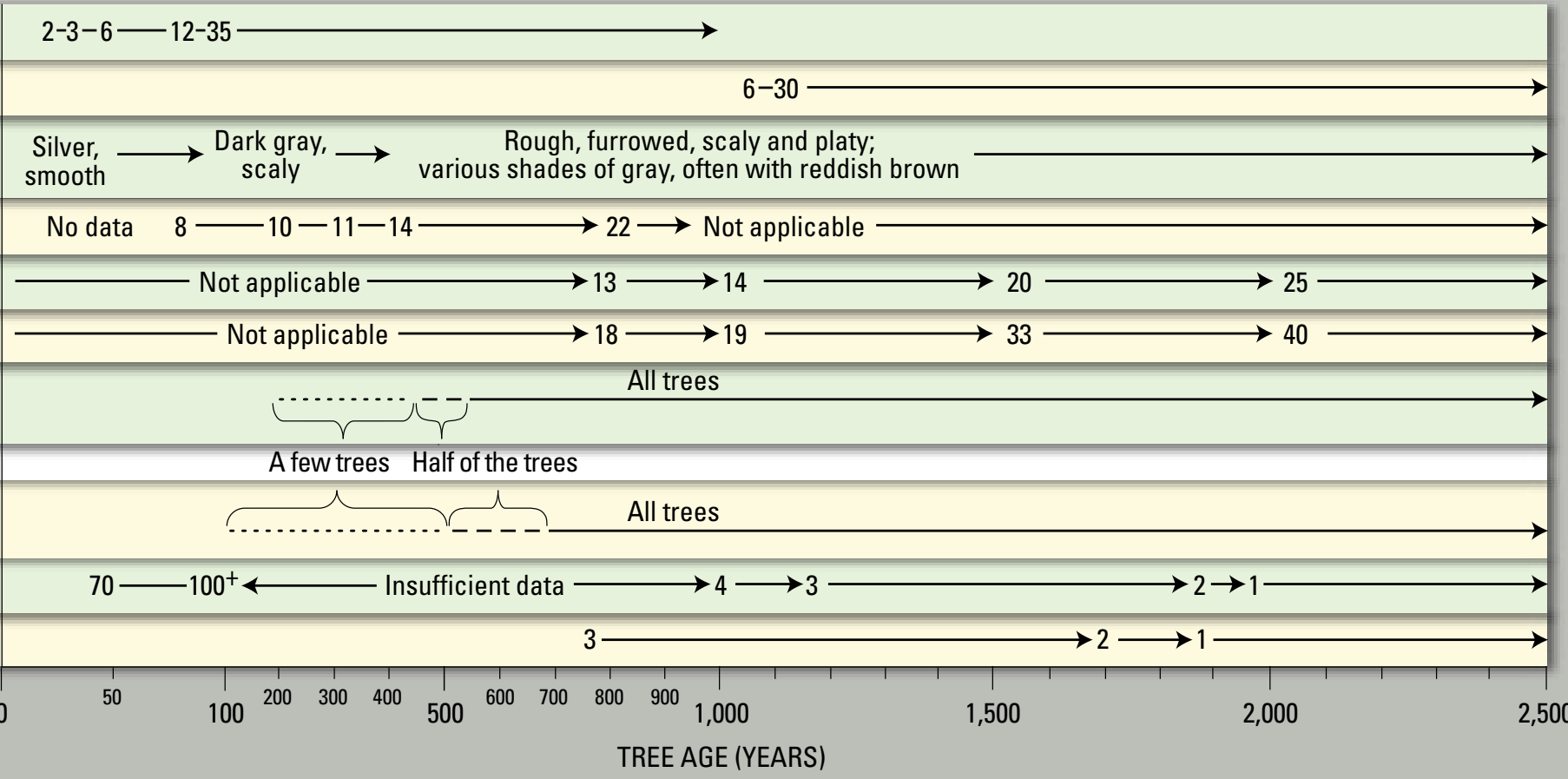

Figure 28. Timeline summarizing selected growth characteristics of bristlecone pines in this study. Most of the studied trees are in the interior of bristlecone pine groves on steep, midslope sites that face southwest, south, and southeast at altitudes ranging from about 10,800 to 12,100 feet. Averages for diameter, long radius, and long diameter are for age classes listed in tables 3 and 4 . 


\section{Acknowledgments}

any people made publication of this report possible, and I am very grateful to them. I extend my appreciation to Terry D'Erchia, Randall G.

Updike, Thomas J. Casadevall, Warren C. Day, Pamela S. Haverland,

Cheryl A. Morris, Stanley L. Ponce, Carol A. Quesenberry, and Edward J. Swibas for their support and encouragement. I sincerely thank Carol Quesenberry for the wonderful design and layout of this book and for expertly drafting most of the figures. Carol's book design and treatment of the illustrations and photographs surpass my loftiest hopes for this book. I thank the following reviewers who helped improve this manuscript: Paul Cararra (USGS), Jeff Lukas (University of Colorado, INSTAAR), and Mary Kidd (USGS). I have drawn much inspiration from my personal contacts with $\boldsymbol{D r}$. C.W. Ferguson and Dr. V.C. LaMarche. Dr. Ferguson was very kind and gracious in his help and encouragement during my communications with him. In 1969, it was quite gratifying for me to work with Dr. LaMarche when I led him to one of the bristlecone pine sites I had found. I thank Lorna Carter and Diane Lane for their advice during early drafts of this report and Alice and Joe Springfield, who drafted most of the inferred sections in figure 4. The following people also contributed to the production of this publication: Mari Kauffmann and Margaret (Margie) Montoya. I appreciate the support and encouragement of Warren Rasmussen; Fred Myers; Jerry, Betty, and Lynn Brunstein; Liz Rees; and the USDA Forest Service staff who allowed me to study bristlecone pines on National Forest lands.

(Facing page) Living and dead bristlecone pines among large boulders of Precambrian granite in the Colorado Front Range. (Photograph taken July 1989.) 


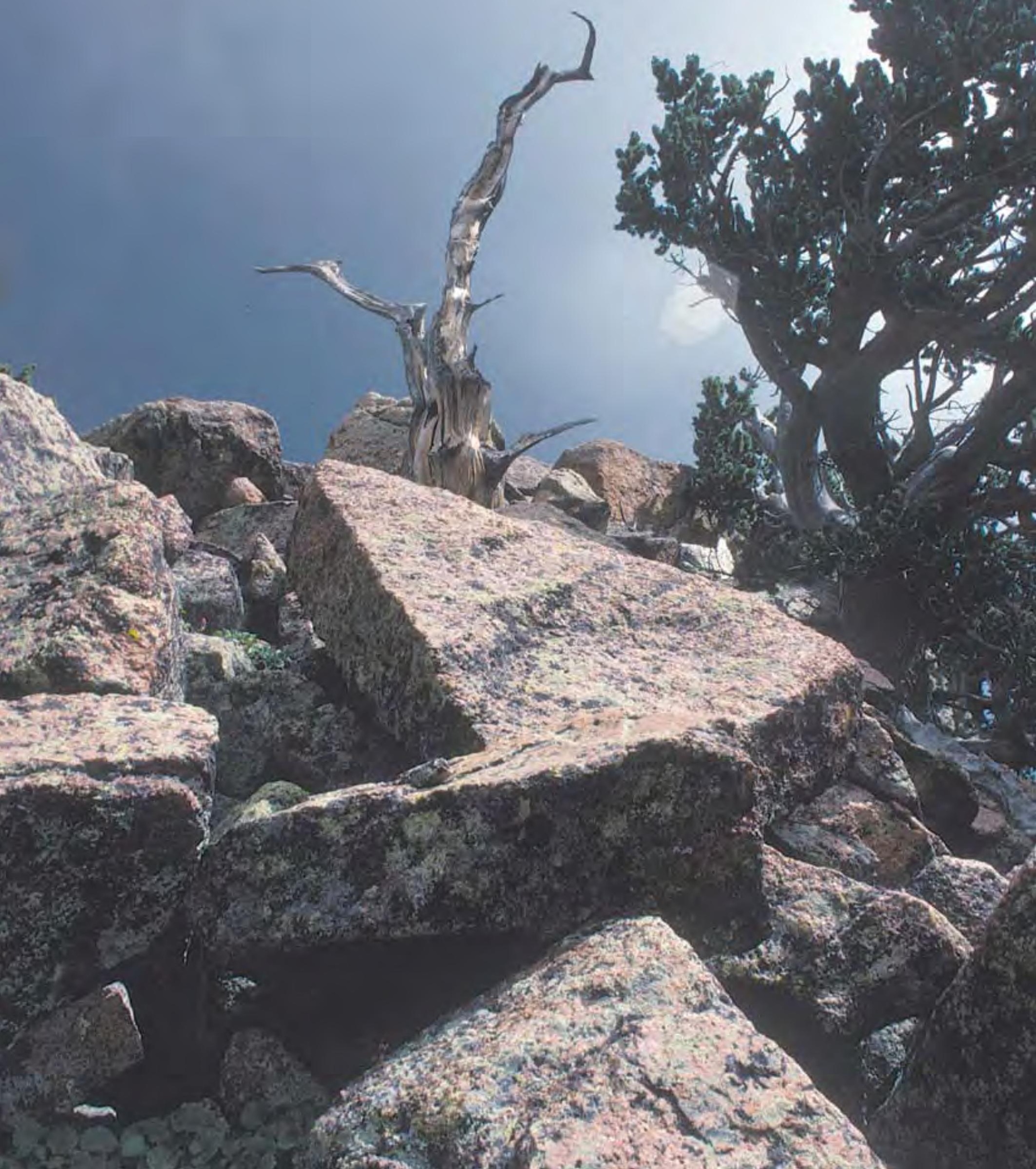




\section{Selected References}

Bailey, D.K., 1970, Phytogeography and taxonomy of Pinus subsection Balfourianae: Annals of the Missouri Botanical Garden, v. 57, p. 210-249.

Baker, W.L., 1992, Structure, disturbance, and change in the bristlecone pine forests of Colorado, U.S.A.: Arctic and Alpine Research, v. 24, p. 17-26.

Brown, C.L., McAlpine, R.G., Kormanik, P.P., 1967, Apical dominance and form in woody plants-a reappraisal: American Journal of Botany, v. 54, no. 2., p. 153-162.

Brunstein, F.C., 1995, Bristlecone pine frost-ring and light-ring chronologies, from 569 B.C. to A.D. 1993, Colorado: U.S. Geological Survey Open-File Report 95-63, 25 p.

Brunstein, F.C., 1996, Climatic significance of the bristlecone pine latewood frost-ring record at Almagre Mountain, Colorado, U.S.A.: Arctic and Alpine Research v. 28, no. 1, p. 65-76.

Brunstein, F.C., and Yamaguchi, D.K., 1992, The oldest known Rocky Mountain bristlecone pines (Pinus aristata Engelm.): Arctic and Alpine Research, v. 24, p. 253-256.

Cline, M.G., 1997, Concepts and terminology of apical dominance: American Journal of Botany, v. 84, no. 8, p. 1064-1069.

Currey, D.R., 1965, An ancient bristlecone pine stand in eastern Nevada: Ecology, v. 46, p. 564-566.

Doesken, N.J., Pielke, R.A., Sr., and Bliss, O.A.P., January 2003, Climate of Colorado: Colorado Climate Center Climatography of the United States no. 60, http://ccc.atmos. colostate.edu/climateofcolorado.php (accessed June 2006)

Drew, L.G., ed., 1974, Tree-ring chronologies of western America, IV, Colorado, Utah, Nebraska, and South Dakota: Chronology series 1, Laboratory of Tree-Ring Research, University of Arizona, p. 5-6.

Fritts, H.C., 1969, Bristlecone pine in the White Mountains of Califormia-Growth and ring-width characteristics: Tucson, University of Arizona Press, Papers of the Laboratory of Tree-ring Research 4, $44 \mathrm{p}$.

Fritts, H.C., 1976, Tree rings and climate: New York, Academic Press, 567 p.

Gedney, Larry, 1986, More on why tree trunks spiral: University of Alaska Fairbanks Geophysical Institute, Alaska Science Forum, Article 783, 3 p., available online at http:// www.gi.alaska.edu/ScienceForum/ASF7/783.html (accessed June 2006)

Kelly, P.E., Cook, E.R., Larson, D.W., 1992, Constrained growth, cambial mortality, and dendrochronology of ancient Thuja occidentalis on cliffs of the Niagara Escarpment: An Eastern Version of Bristlecone Pine?: International Journal of Plant Sciences, v. 153, no. 1, p. 117-127.

Krebs, P.H., 1972, Dendrochronology and the distribution of bristlecone pine in Colorado: $\mathrm{Ph} . D$. dissertation, Boulder, University of Colorado, $211 \mathrm{p}$.

Krebs, P.V., 1973, Dendrochronology of bristlecone pine (Pinus aristata Engelm.) in Colorado: Arctic and Alpine Research v. 5, no. 2, p. 149-150.

LaMarche, V.C., Jr., 1968, Rates of slope degradation as determined from botanical evidence, White Mountains, California: U.S. Geological Survey Professional Paper 352-I, p. 341-377.

LaMarche, V.C., Jr., 1969, Environment in relation to age of bristlecone pines: Ecology, v. 50, p. $53-59$. 
LaMarche, V.C., Jr., 1970, Frost-damage rings in subalpine conifers and their application to tree-ring dating problems, in Smith, J.H.G., and Worrall, J., eds., Tree-ring analysis with special reference to Northwest America: The University of British Columbia Faculty of Forestry Bulletin, v. 7, p. 99-100.

LaMarche, V.C., Jr., and Hirschboeck, K.K., 1984, Frost rings in trees as records of major volcanic eruptions: Nature, v. 307, p. 121-126.

LaMarche, V.C., Jr., and Stockton, C.W., 1974, Chronologies from temperature-sensitive bristlecone pines at upper treeline in western United States: Tree-Ring Bulletin, v. 34, p. 21-45.

Lanner, R.M., 1988, Dependence of Great Basin bristlecone pine on Clark's nutcracker for regeneration at high elevations: Arctic and Alpine Research v. 20, no. 3, p. 358-362.

Lavoie, Claude, and Payette, Serge, 1992, Black Spruce growth forms as a record of a changing winter environment at treeline, Quebec, Canada: Arctic and Alpine Research, v. 24 , p. $40-49$.

Olson, Rich, and Lewis, A.M., 1999, Porcupine ecology and damage management techniques for rural homeowners: Laramie, University of Wyoming College of Agriculture, Cooperative Extension Service, B-1073, 14 p.

Paulsen, J., Weber, U.M., and Körner, C., 2000, Tree growth near treeline: abrupt or gradual reduction with altitude?: Arctic, Antarctic, and Alpine Research, v. 32, no. 1, p. 14-20.

Phipps, R.L., 1985, Collecting, preparing, crossdating, and measuring tree increment cores: U.S. Geological Survey Water-Resources Investigations Report 85-4148, 48 p.

Ranne, B.M., 1995, Natural variability of vegetation, soils, and physiography in the bristlecone pine forests of the Rocky Mountains: Laramie, University of Wyoming, M.S. thesis, $68 \mathrm{p}$.

Ranne, B.M., Baker, W.L., Andrews, T., and Ryan, M.G., 1997, Natural variability of vegetation, soils and physiography in the bristlecone pine forests of the Rocky Mountains: Great Basin Naturalist v. 57, p. 21-37.

Salzer, M.W., 2000, Dendroclimatology in the San Francisco Peaks region of northern Arizona, USA: Tucson, University of Arizona, Ph.D. dissertation, 211 p.

Schauer, A.J., Schoettle, A.W., and Boyce, R.L., 2001, Partial cambial mortality in highelevation Pinus aristata (Pinaceae): Journal of Botany, v. 88, p. 646-652.

Schemnitz, S.D., 1994, Porcupines, in Hygnstrom, S.E., Timm, R.M., and Larson, G.E., eds., Prevention and control of wildlife damage: Lincoln, University of Nebraska, Cooperative Extension Division, Institute of Agriculture and Natural Resources, p. B81-B83.

Schoettle, A.W., 1994, Influence of tree size on shoot structure and physiology of Pinus contorta and Pinus aristata: Tree Physiology, v. 14, p. 1055-1068.

Schoettle, A.W., 2004, Developing proactive management options to sustain bristlecone and limber pine ecosystems in the presence of a non-native pathogen [white pine blister rust], in Shepperd, W.D., and Eskew, L.G., eds., 2004, Silviculture in special places; Proceedings of the National Silviculture Workshop; 2003 September 8-11; Granby, CO: Fort Collins, CO, U.S. Department of Agriculture, Forest Service, Rocky Mountain Research Station Proceedings RMRS-P-34. p. 146-155. 
Schubert, G.H., and Rietveld, W.J., 1970, Bristlecone pine-its phenology, cone maturity, and seed production in the San Francisco Peaks, Arizona: U.S. Department of Agriculture, Forest Service Research Note RM-180, 7 p.

Schulman, Edmund, 1954, Longevity under adversity in conifers: Science, v. 119, p. 396-399.

Schulman, Edmund, 1958, Bristlecone pine, oldest known living thing: National Geographic Magazine, v. 113, p. 355-372.

Schulman, Edmund, and Ferguson, C.W., 1956, Millenia-old pine trees sampled in 1954 and 1955, in Schulman, Edmund, Dendroclimatic changes in semiarid America: Tucson, University of Arizona Press, p. 136-138.

Skatter, Sondre, and Kucera, Bohumil, 1998, The cause of the prevalent directions of the spiral grain patterns in conifers: Trees-Structure and Function, v. 12, no. 5, p. 265-273.

Stokes, M.A., and Smiley, T.L., 1968, An introduction to tree-ring dating: Chicago, University of Chicago Press, $73 \mathrm{p}$.

Swetnam, T.W., Thompson, M.A., and Sutherland, E.K., 1985, Using dendrochronology to measure radial growth of defoliated trees: U.S. Department of Agriculture Agriculture Handbook 639, 39 p.

Trefil, James, 1986, Meditations at 10,000 feet-a scientist in the mountains: New York, Charles Scribner's Sons, 236 p.

Veblen, T.T., and Donnegan, J.A., 2004, Historical range of variability assessment for forest vegetation of the national forests of the Colorado Front Range, final report: U.S. Department of Agriculture Forest Service, $182 \mathrm{p}$.

Wardle, Peter, 1968, Engelmann spruce (Picea engelmannii Engel.) at its upper limits on the Front Range, Colorado: Ecology, v. 49, p. 483-495.

Wright, R.D., 1963, Some ecological studies on bristlecone pines in the White Mountains of California: Los Angeles, University of California, Ph.D. dissertation, 118 p.

Wright, R.D., and Mooney, H.A., 1965, Substrate-oriented distribution of bristlecone pine in the White Mountains of California: American Midland Naturalist, v. 73, p. 257-284.

Yamaguchi, D.K., and Brunstein, F.C., 1991, Special sanding films and sandpapers for surfacing narrow-ring increment cores: Tree-Ring Bulletin, v. 51, p. 43-46.

(Facing page) Upper stems of two young bristlecone pines. Note how the stems are clothed in green needles. The upper parts of young stems retain needles for 9 to 12 or more years. As the young stems grow taller, the lowest and oldest needles die and fall off. The numerous white resin specks on the green needles are characteristic of Rocky Mountain bristlecone pines. (Photograph taken September 9, 2005. Southern Front Range.) 


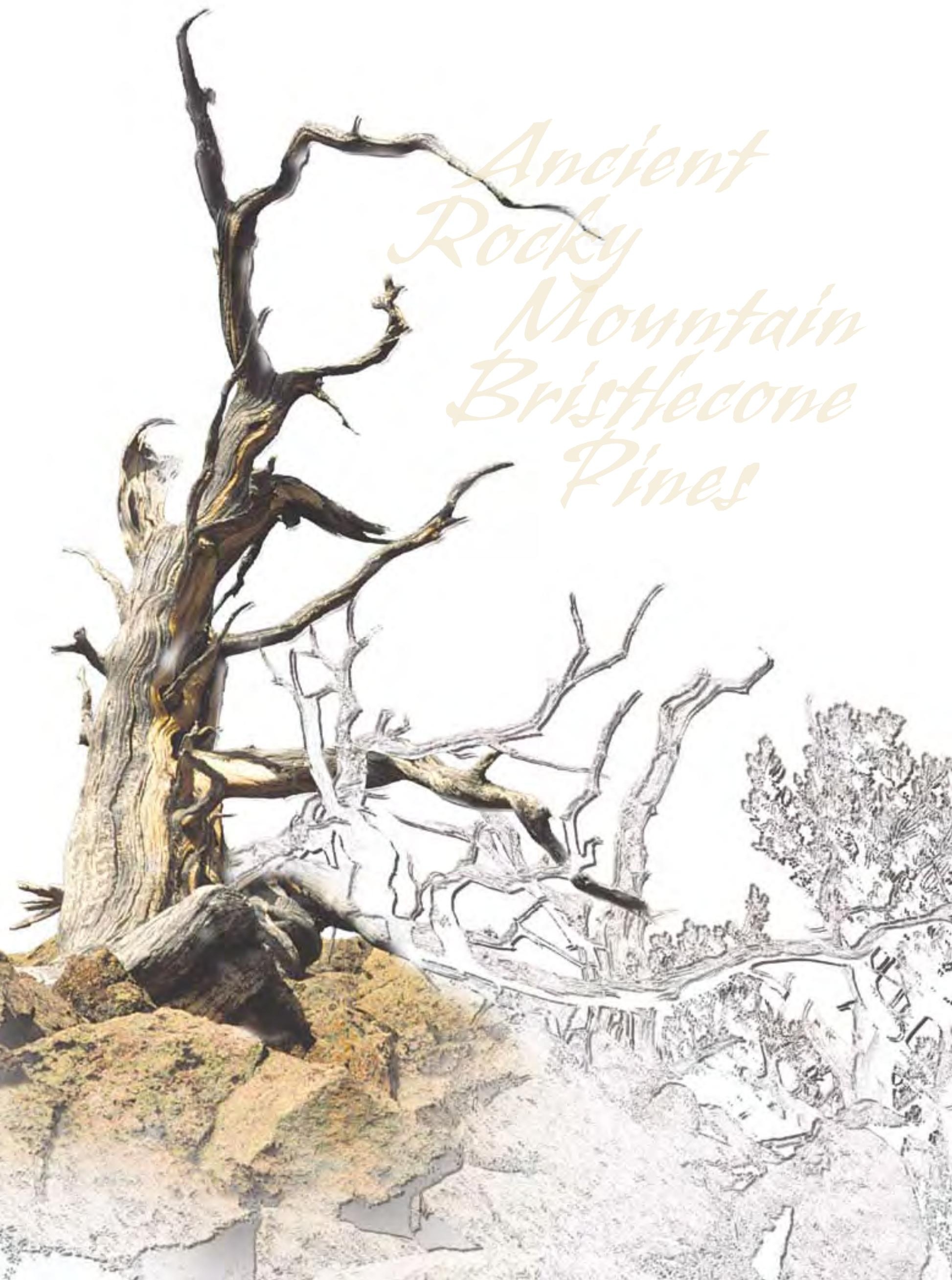




\section{Appendix}

\section{Brief Descriptions of Growth Forms of Rocky Mountain Bristlecone Pines in this Study}

[The following growth-form classification system is intended to be a general guide for classifying and describing the forms of bristlecone pines included in this study.]

\section{Growth Forms Based on Inferred Horizontal Section View of Trunk Above Basal Root Flare}

\section{Circular or Nearly Circular Trunk}

When the trunks of such trees are seen in inferred horizontal section view, they have a circular or nearly circular form. The trunk is usually bark-enclosed, but it can have some to extensive cambial dieback. If a bark strip is present, it sometimes partly spirals around the trunk and (or) spirals completely $\left(360^{\circ}\right.$ or more) around a limb. Trees that have these forms usually have full crowns; however, older trees (about 450 or more years old) that have these forms usually have crown dieback. Growth rate is usually faster on one side (usually leeward side) of even the young, bark-enclosed trees, causing slight asymmetry (pith can be slightly off-center; see trees 91-41AL and 93-17 in fig. 4). These are the most common forms for trees that are less than about 500 years old (see table 12). One sampled tree, which has a nearly circular trunk, is about 890 years old.

\section{Oval, Elliptical, Nearly Semicircular, or Semicircular Trunk}

When the trunks of such trees are seen in inferred horizontal section view, they have an oval, elliptical, nearly semicircular, or semicircular form. Some examples are tree 90-5, which is classified as having a nearly semicircular trunk; tree 95-11, which is classified as having either a nearly semicircular or nearly circular trunk; and trees 91-7 and 93-38, which might arguably be classified as having elliptical trunks or slab-form trunks (see fig. 4). Trees that have these forms have none to much cambial dieback and none to much crown dieback. The trunks of such trees do not have broad, flat (or flattish) slab-like sides, thus they do not fit into the slab-form category. If a bark strip is present, it sometimes partly spirals around the trunk and (or) spirals completely $\left(360^{\circ}\right.$ or more) around a limb. Age range of these forms is about 350 to less than 1,000 years.

\section{Irregular Trunk}

When the trunks of such trees are seen in inferred horizontal section view, they have an irregular form that prevents classifying such trees as other growth forms. Trees of this form have much cambial dieback and crown dieback. Trunks can be relatively small (tree 95-13 in fig. 4) to large and massive (tree 91-2 in fig. 4). When tree 91-2 (fig. 4) was much younger, it had two bark strips that were only a few inches apart. Over many centuries, the two bark strips grew outward, laying down two prominent ridges of wood that form a large $\mathrm{V}$-shaped trunk. Trees that have this form have one or more living bark strips. Age range of trees that have this form is about 760 to 1,850 years. 
Slab

When the trunks of such trees are seen in inferred horizontal section view, they have a slab-like form that has long, flat to bumpy sides; rounded to angular corners; and, on some trees, prominent lobes and depressions (see fig. 4 for numerous examples of this form). In inferred horizontal section view, the slab form's pronounced long axis is generally about 1.4 to 3 or more times greater than the average slab thickness; however, a few of the slab-form trunks have a section view that is nearly square.

Trees that have this form have one to three bark strips, but usually only one bark strip. The slab trunk is short to tall (1 to 16 feet) depending on the attachment height of living limbs on the trunk. The thickness of slabs can be thin to thick, uniform or variable (see figure 4 and table 11); average slab thickness of 17 trees is about 10 inches but ranges from about 4 to 25 inches (table 11). Some spiral twist creates a slightly twisted slab. The bark strip sometimes spirals partly or completely $\left(360^{\circ}\right.$ or more) around a limb. The age range of slab-form trees is about 760 to 2,500 years.

An uncommon form is the opposite bark strips slab, which has bark strips on opposite sides of the trunk that are growing in opposite directions. Each bark strip connects to one or two living limbs. Such trees form visually striking slabs having long diameters of as much as 45 inches. For examples of this form, see trees 91-14 and 93-39 in fig. 4 and tree 91-65 in figure 13. One unusual tree included in this classification has two bark strips on one side of the trunk and one bark strip on the opposite side of the trunk (tree 90-15 in fig. 23). The oldest opposite bark strips slab in this study is about 1,870 years old.

\section{Growth Form Based on Long-Axis View and Inferred Horizontal Section View of Trunk}

\section{Twisted Slab (also referred to as Spiral Slab)}

Trees that have this form have a single bark strip that forms a partial spiral (could also be called a partial helix) around the circumference of the trunk (fig. 14). Over the centuries, the spiral bark strip lays down a prominent, raised ridge of wood. This is not to be confused with younger trees that have a spiral bark strip but no prominent raised ridge of wood. The name of this form is derived from a combination of how the tree looks in long-axis view and inferred horizontal section view. When the trunks of such trees are seen in long-axis view, each tree's bark strip spirals to the right (counterclockwise)—up from the ground surface, forming a partial spiral around the trunk to where the bark strip meets the single living limb (see fig. 14). I have arbitrarily defined the twisted slab classification to include trees displaying about $90^{\circ}$ or more of counterclockwise spiral twist. When the lower trunks of such trees are seen in inferred horizontal section view, the trunk has a slab form (similar to a typical slab), and the twisted form is not readily apparent. The height of the twisted slab trunk is dependent upon the attachment height of the living limb on the trunk (all twisted slabs in this study each have only one living limb). Examples: tree 88-17 has counterclockwise spiral of about $225^{\circ}$; trees 69-4, 69-7, and 93-40 have counterclockwise spiral of about $180^{\circ}$. Ages of these four trees are about $1,170,960,1,080$, and 1,880 years, respectively. The bark strip sometimes spirals partly or completely $\left(360^{\circ}\right.$ or more $)$ around the limb. This is an uncommon growth form. 


\section{Growth Form Based on Long-Axis View of Tree}

\section{Multi-Stem (also Referred to as Forked or Eagle's Aerie)}

Such a tree form has (1) two or more vertical main stems (fig. 26), (2) a very short main stem that produces two or more large vertical limbs (see fig. 15), or (3) one or more vertical main stem(s) that produce one or more vertical limb(s). In each case, the multiple main stems and (or) limbs dominate the form of the tree. The stems or limbs usually originate low on the trunk of the tree, and they extend vertically (see figs. 15 and 26). Older trees can have one or more bark strips. At some sites, this is a relatively common form among trees that are less than about 500 years old. The oldest multi-stem tree in this study is about 1,030 years.

\section{Other Odd Forms}

A few trees were observed to have a pith spike projecting nearly horizontally, while the rest of the tree is erect. Such a growth form is caused by a tree that has fallen over or whose trunk has been broken near the base and fallen over, and then one of the limbs takes over as the vertical "trunk" of the tree.

The lower 3 feet of the trunk of one of the studied trees that is about 1,180 years old is a typical opposite bark strips slab. However, from about 3 to 8 feet above ground, one of its two bark strips makes a $180^{\circ}$ counterclockwise spiral partly around the trunk of the tree; the other bark strip has no spiral twist. The two bark strips merge at about 8 feet above ground where they connect to a single living limb.

\section{Krummholz}

Although this growth form was not a part of this study, a brief description is included for completeness. The krummholz growth form of bristlecone pine looks more like a low shrub than a tree. It can be found near upper treeline, which is the highest altitude at which erect, mature trees grow. The shrubby growth is about $1-4$ feet tall. Maximum age of this form is unknown.

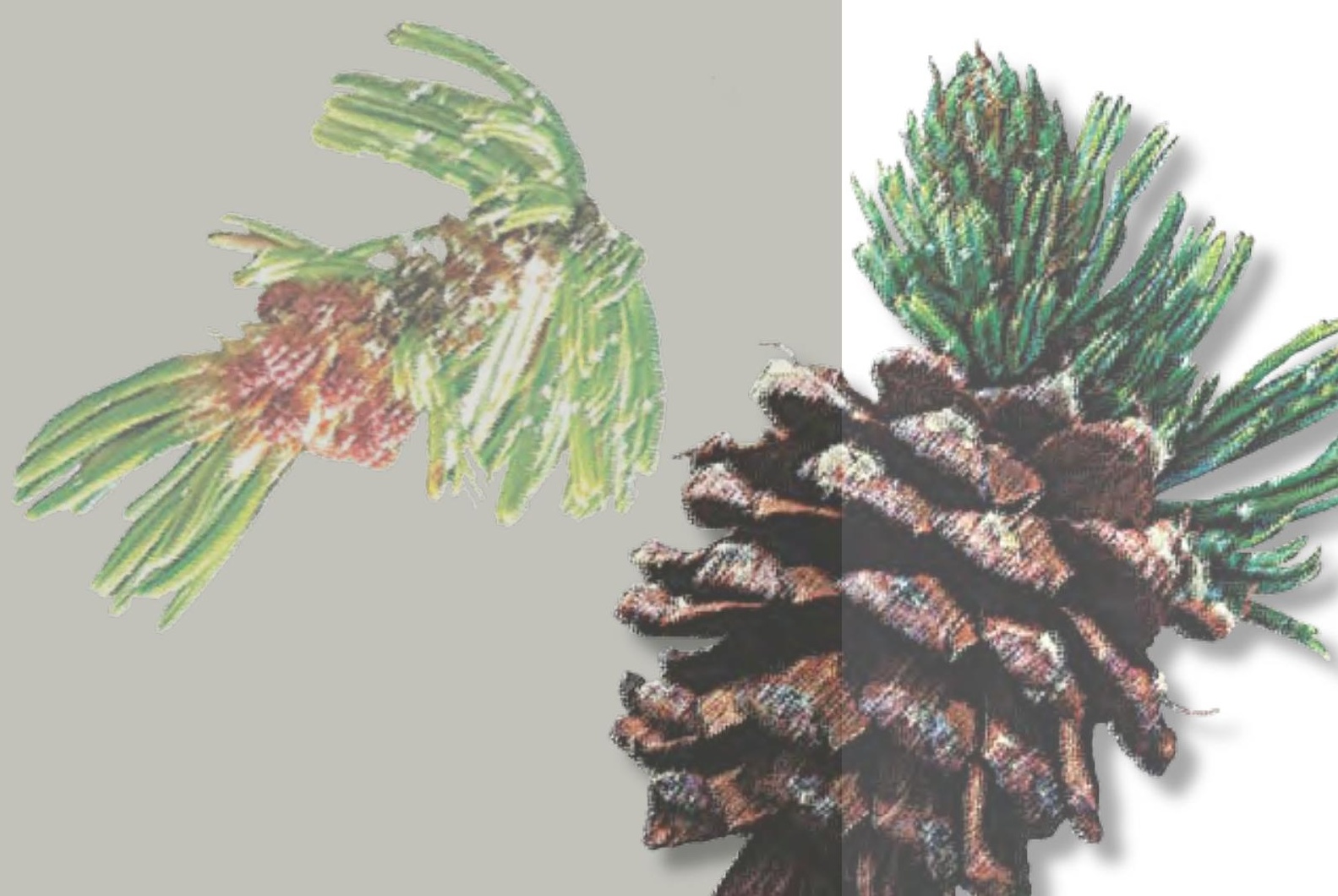


Krummholz form of bristlecone pine near the uppermost limit of bristlecone pine at about 11,950 feet altitude, southern Front Range. This example of shrubby growth clings close to the ground and is only 1-3 feet tall. (Photograph taken September 14, 1995.) 


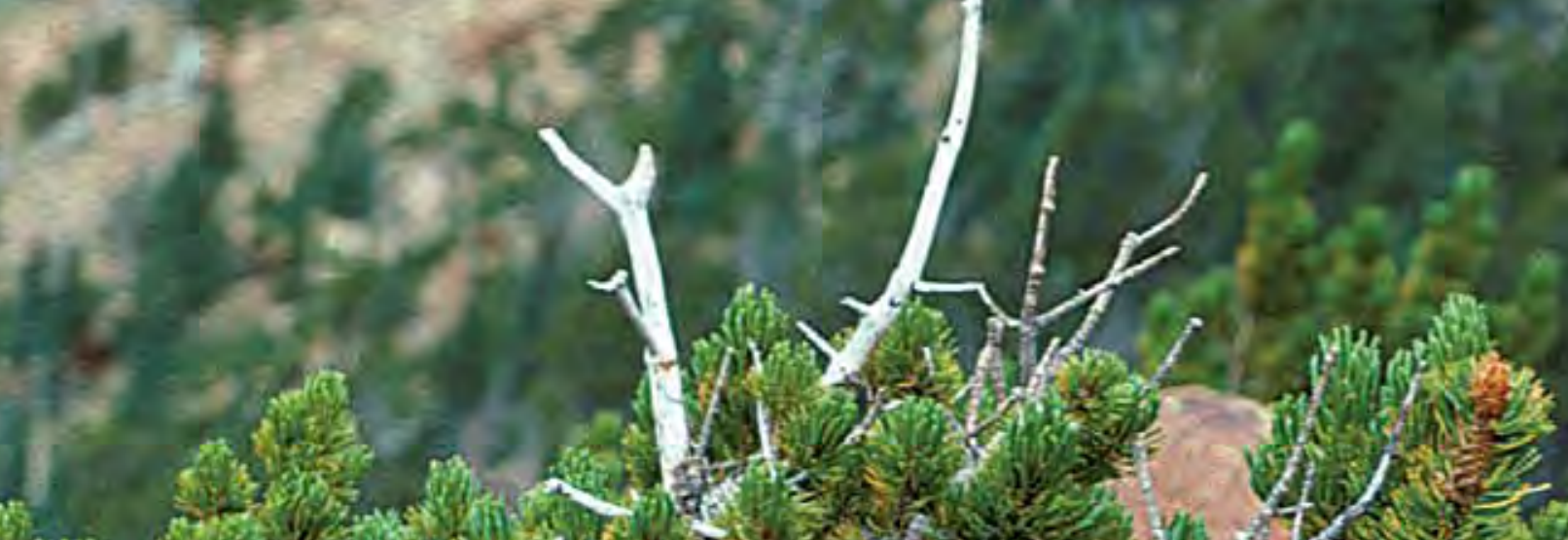

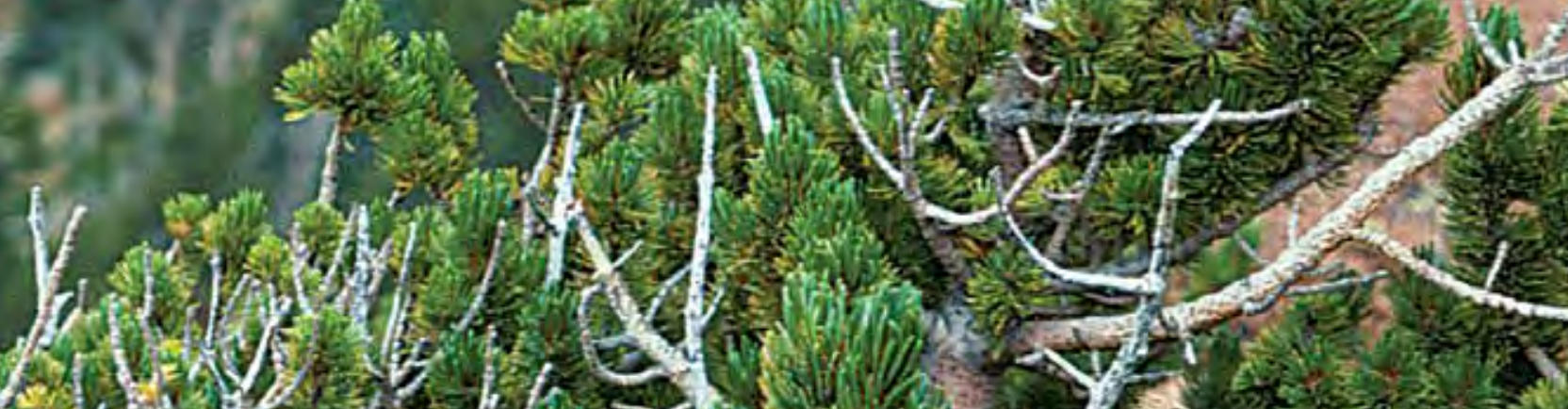

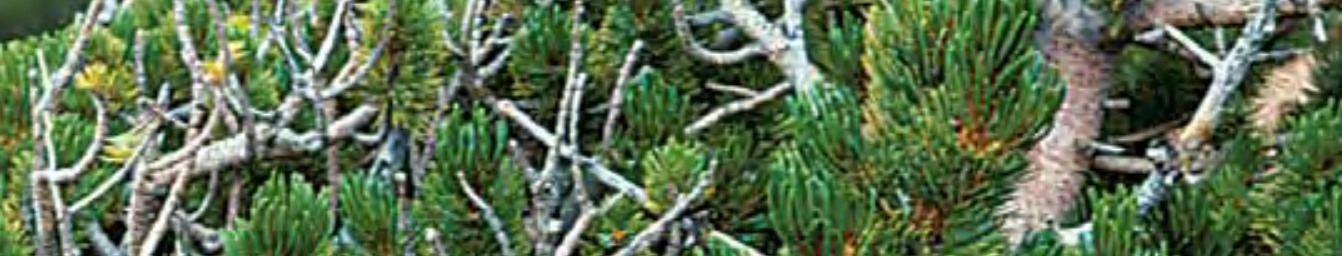

1.

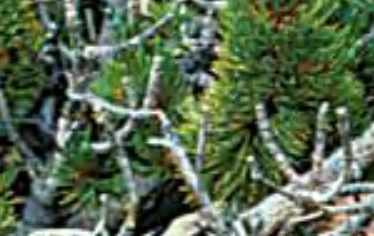

(2)

군

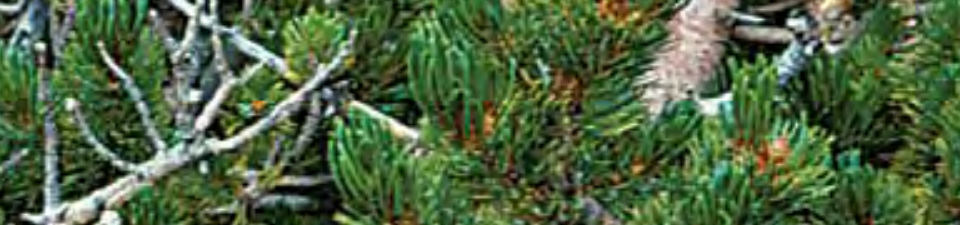

(4)

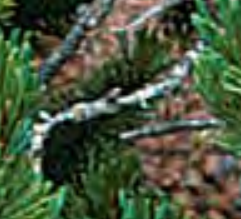

tis

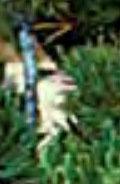

$$
x^{2} y^{2}
$$

(2) 25. 1.2.

it 2 2. 79 
Table 12. Field classifications of growth forms of 134 Rocky Mountain bristlecone pines in this study.

[The sample population shown in this table does not necessarily reflect the percentages of different tree forms at each of the tree sites. Some of the study sites do not have all of the growth forms described in this report. Numerous multi-stem trees that are less than about 500 years old are present at some bristlecone pine sites]

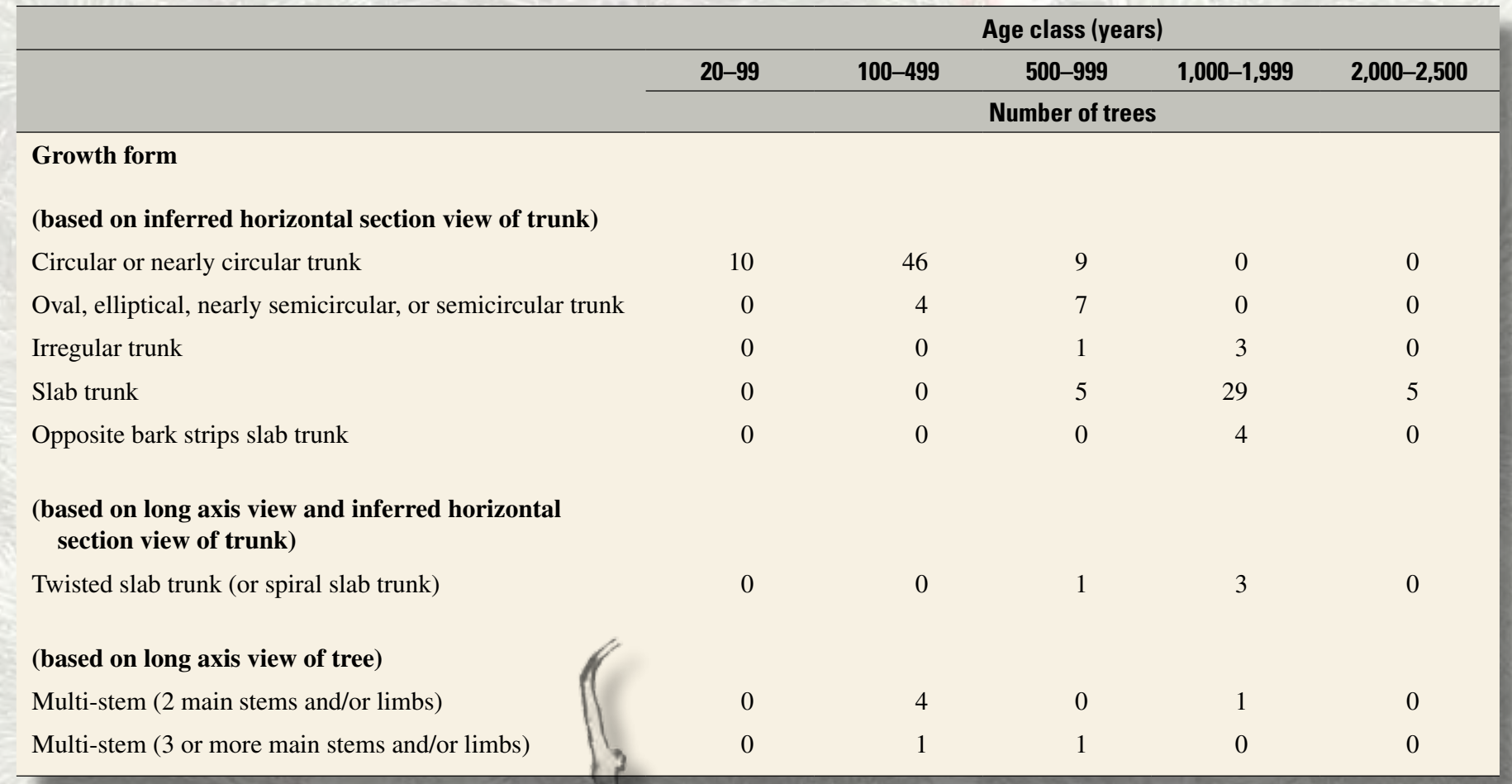

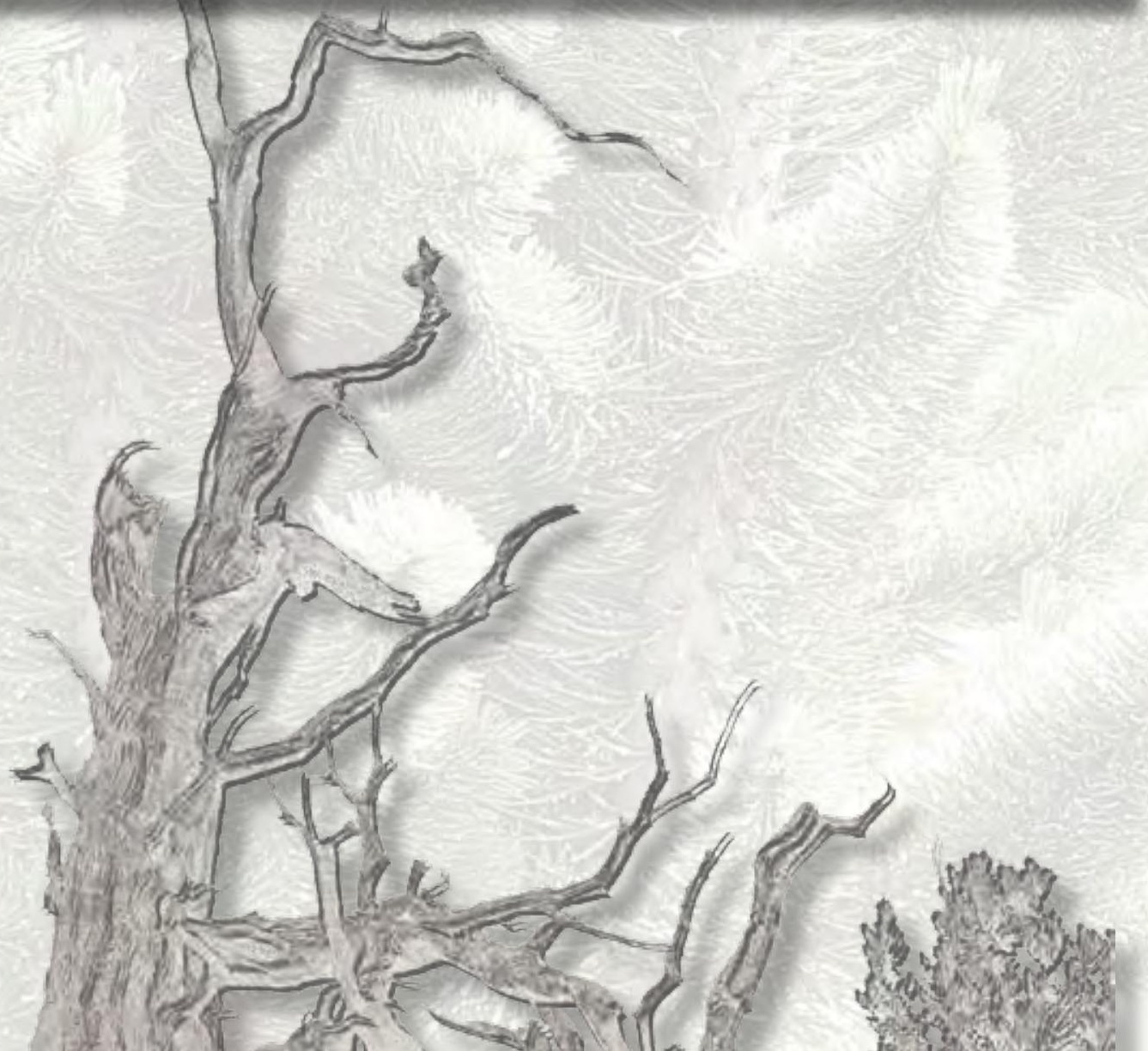


Living and dead bristlecone pines on Precambrian granite bedrock and boulder talus in the Colorado Front Range. (Photograph taken July 14, 1990.) 
Table 13. Data for selected bristlecone pines in this study. Except as noted, bristlecone pines are slab form.

[FRA, southern Front Range site A; FRB, southern Front Range site B; SP, South Park area; SW, Sawatch Range; FRG, northern Front Range site G; FRR, southern Front Range site R. IRD, inner ring date; cm, centimeters; in., inches; No., number. Negative (-) symbol in IRD column indicates a calendar B.C. date; other dates are calendar A.D. Long radius, long diameter, bark-strip width, and slab thickness measurements are in inches. (See figure 21 for an illustration showing long radius and long diameter.) Heights for most trees are visual estimates (see "Methods" section for accuracies). Missing inner radius in core sample

\begin{tabular}{|c|c|c|c|c|c|c|c|}
\hline Site & Tree number & Altitude (feet) & IRD & $\begin{array}{l}\text { Missing radius } \\
\text { (cm) }\end{array}$ & Age $^{1}$ in years & $\begin{array}{l}\text { Long radius } \\
\text { (in.) }\end{array}$ & $\begin{array}{l}\text { Long diameter } \\
\text { (in.) }\end{array}$ \\
\hline FRA & $68-3$ & 11,700 & 14 & $4, \mathrm{H}$ & $1,992 / 2,050$ & 26 & 44 \\
\hline FRB & $69-2$ & 11,080 & 818 & $<1, \mathrm{M}$ & $1,188 / 1,200$ & 13 & 17 \\
\hline FRA & $88-4$ & 11,500 & 756 & $4, \mathrm{M}$ & $1,250 / 1,300$ & 17.5 & 25 \\
\hline FRA & $88-8$ & 11,550 & 815 & $<1, \mathrm{M}$ & $1,191 / 1,210$ & 15 & 16 \\
\hline FRA & $88-9$ & 11,440 & 759 & $<1, \mathrm{M}$ & $1,247 / 1,260$ & 11.5 & 20 \\
\hline FRB & $88-17$ & 11,130 & 872 & $1.5, \mathrm{M}$ & $1,134 / 1,170$ & 11.5 & 17 \\
\hline FRA & 89-2 & 11,700 & 99 & $4, \mathrm{E}$ & $1,907 / 1,980$ & 24 & 36 \\
\hline SP & $90-1$ & 11,100 & -192 & $<1, \mathrm{M}$ & $2,198 / 2,220$ & 26 & 37 \\
\hline SP & $90-4$ & 11,100 & 152 & $<1, \mathrm{M}$ & $1,854 / 1,870$ & 20 & 26 \\
\hline SP & $90-11^{(2)}$ & 11,000 & -443 & $0, \mathrm{I}$ & $2,449 / 2,500$ & 30 & 47 \\
\hline FRA & $91-12$ & 11,600 & 755 & $1.5, \mathrm{M}$ & $1,251 / 1,270$ & 15 & 20 \\
\hline FRA & $91-15$ & 11,800 & 875 & $1.5, \mathrm{M}$ & $1,131 / 1,160$ & 11.5 & 16 \\
\hline SW & $93-39$ & 12,070 & 172 & $1, \mathrm{M}$ & $1,834 / 1,870$ & 22 & 40 \\
\hline SW & $93-40$ & 12,070 & 214 & $4, \mathrm{M}$ & $1,792 / 1,880$ & 22 & 28 \\
\hline SW & $93-45$ & 12,000 & 962 & $6.4, \mathrm{M}$ & $1,044 / 1,180$ & 17 & 21.5 \\
\hline SW & $93-55$ & 11,970 & 509 & $<1, \mathrm{M}$ & $1,497 / 1,520$ & 12 & 21 \\
\hline FRA & $93-61$ & 11,700 & 395 & $0.6, \mathrm{M}$ & $1,611 / 1,630$ & 19.5 & 30 \\
\hline FRG & $34^{(3)}$ & 11,800 & 403 & unk & $1,603 / \mathrm{nc}$ & 19 & 34 \\
\hline \multicolumn{8}{|c|}{ Other tree species ${ }^{(4)}$} \\
\hline FRR & $68-1$ & 10,000 & 1218 & $<1, \mathrm{M}$ & $788 / 800$ & 15 & 17 \\
\hline SP & $91-67$ & 9,350 & 337 & $<1, \mathrm{M}$ & $1,669 / 1,680$ & 25 & 27 \\
\hline SP & $94-1$ & 9,030 & 1318 & $<2, \mathrm{M}$ & $688 / 710$ & 15.5 & 31 \\
\hline
\end{tabular}

${ }^{1}$ First number is minimum age in 2005 based on inner-ring date; second number is age estimate in 2005. See "Methods" section for an explanation of how age estimates were made.

${ }^{2}$ Tree 90-11 was sampled at a height of 12 feet; 50 years was added to the age of this tree to account for the time the tree grew to the sampling height. On June 12,1993 , this tree had eight unopened (immature) seed cones. 
is in centimeters. Cause of missing radius: H, heart rot; M, core missed pith. E, eroded away; I, core includes pith. nc, not calculated; nm, not measured; na, not applicable; unk, unknown. Long-radius and long-diameter measurements include the thickness of the bark; therefore, any calculations of growth rates from these figures should subtract the thickness of the bark-typically 1-2 inches. Note that some of the measurements in this table may slightly disagree with those in figure 4 , because some of these measurements were taken slightly above or below where the inferred sections were measured]

\begin{tabular}{|c|c|c|c|c|c|}
\hline $\begin{array}{c}\text { No. } \\
\text { bark } \\
\text { strips }\end{array}$ & $\begin{array}{c}\text { Bark } \\
\text { strip(s) } \\
\text { width } \\
\text { (in.) }\end{array}$ & $\begin{array}{c}\text { Slab } \\
\text { thickness } \\
\text { (in.) }\end{array}$ & $\begin{array}{c}\text { Tree } \\
\text { height } \\
\text { in feet }\end{array}$ & $\begin{array}{l}\text { No. of living limbs } \\
\text { (height of attachment in feet) }\end{array}$ & Notes \\
\hline 1 & 9 & $4-21$ & 15 & $1(3.5)$ & see figs. 4,10 \\
\hline 1 & 9 & $6-7$ & 15 & $1(7)$ & see fig. 4 \\
\hline 1 & 22 & $10-15$ & 25 & $1(6)$ & none \\
\hline 1 & 12 & $4-6$ & 20 & $1(8)$ & see figs. 4,11 \\
\hline 1 & 7 & $6-7$ & 15 & $1(2.5)$ & none \\
\hline 1 & 9 & $\mathrm{~nm}$ & 20 & $1(8)$ & twisted slab \\
\hline 1 & 12 & $\mathrm{~nm}$ & 9 & $1(1)$ & none \\
\hline 1 & 9 & $4-14$ & 11 & $1(4)$ & see figs. 4,9 \\
\hline 1 & 19 & $10-16$ & 22 & $3(6,7,9)$ & see fig. 4 \\
\hline 1 & 18 & $15-23$ & 27 & $1(7)$ & see fig. 4 \\
\hline 1 & 14 & $\mathrm{~nm}$ & 20 & $2(3,5)$ & none \\
\hline 1 & 17 & $7-9$ & 25 & $4(6,10,12,16)$ & none \\
\hline 2 & 23,34 & $12-18$ & 15 & $3(4,6,7)$ & opposite bark strips slab; fig. 4 \\
\hline 1 & 11 & $4.5-12$ & 11 & $1(5.5)$ & twisted slab \\
\hline 1 & 22 & $9-12$ & 15 & $3(6,7,7)$ & see fig. 4 \\
\hline 1 & 12 & $6-8$ & 13.5 & $1(6)$ & see fig. 4 \\
\hline 2 & 4,8 & $\mathrm{~nm}$ & 25 & $1(14)$ & bark strips merge at 10 feet \\
\hline 1 & 36 & $\mathrm{~nm}$ & 18 & $2(4,12)$ & see fig. 4 \\
\hline \multicolumn{6}{|c|}{ Other tree species ${ }^{(4)}$} \\
\hline 1 & 32 & na & 16 & $1(7)$ & ponderosa pine; see fig. 29 \\
\hline 1 & 11 & $6-13$ & 10 & $1(4)$ & limber pine; see fig. 29 \\
\hline 1 & 42 & na & 23 & $2(3.5,14)$ & ponderosa pine; see fig. 29 \\
\hline
\end{tabular}

${ }^{3}$ This is tree 34 of Krebs (1972). The inner-ring date and tree number are from that report.

${ }^{4}$ Trees have growth-form characteristics that are similar to those of many ancient bristlecone pines, including: prominent pith spike, strip-bark growth, and only one or two living limbs. 

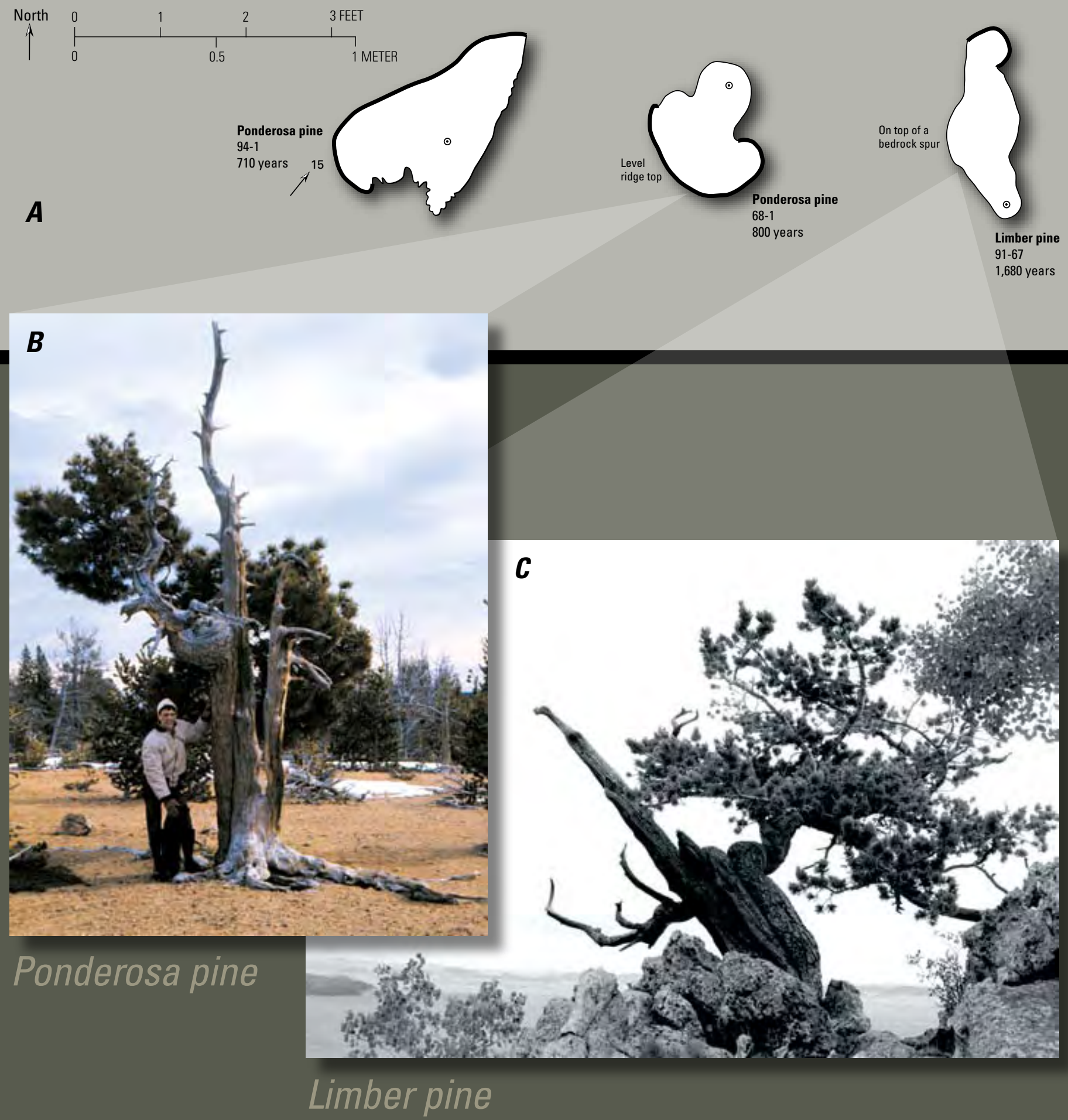

Figure 29. Old ponderosa (Pinus ponderosa) and limber (Pinus flexilis) pines that have growth-form characteristics similar to old bristlecone pines. $\boldsymbol{A}$, Inferred horizontal section views of two ponderosa pines and a limber pine. (None of the trees were harmed to make these sketches.) Inferred sections are 2-4 feet above ground. Note that the strip-bark growth habit of these trees is similar to that in bristlecone pines (fig. 4). Section view of tree 68-1 is of the living, dominant stem of this forked tree. See figure 4 for an explanation of symbols. Additional data for the trees are in table 13. $\boldsymbol{B}$ and $\boldsymbol{C}$, Photographs of trees 68-1 (ponderosa pine) and 91-67 (limber pine), respectively. Note that each tree has a prominent pith spike and only one living limb (first-order branch). The long diameter is in view for both trees. Photograph of tree 68-1 taken December 1968, and photograph of tree 91-67 taken September 15, 1991. 



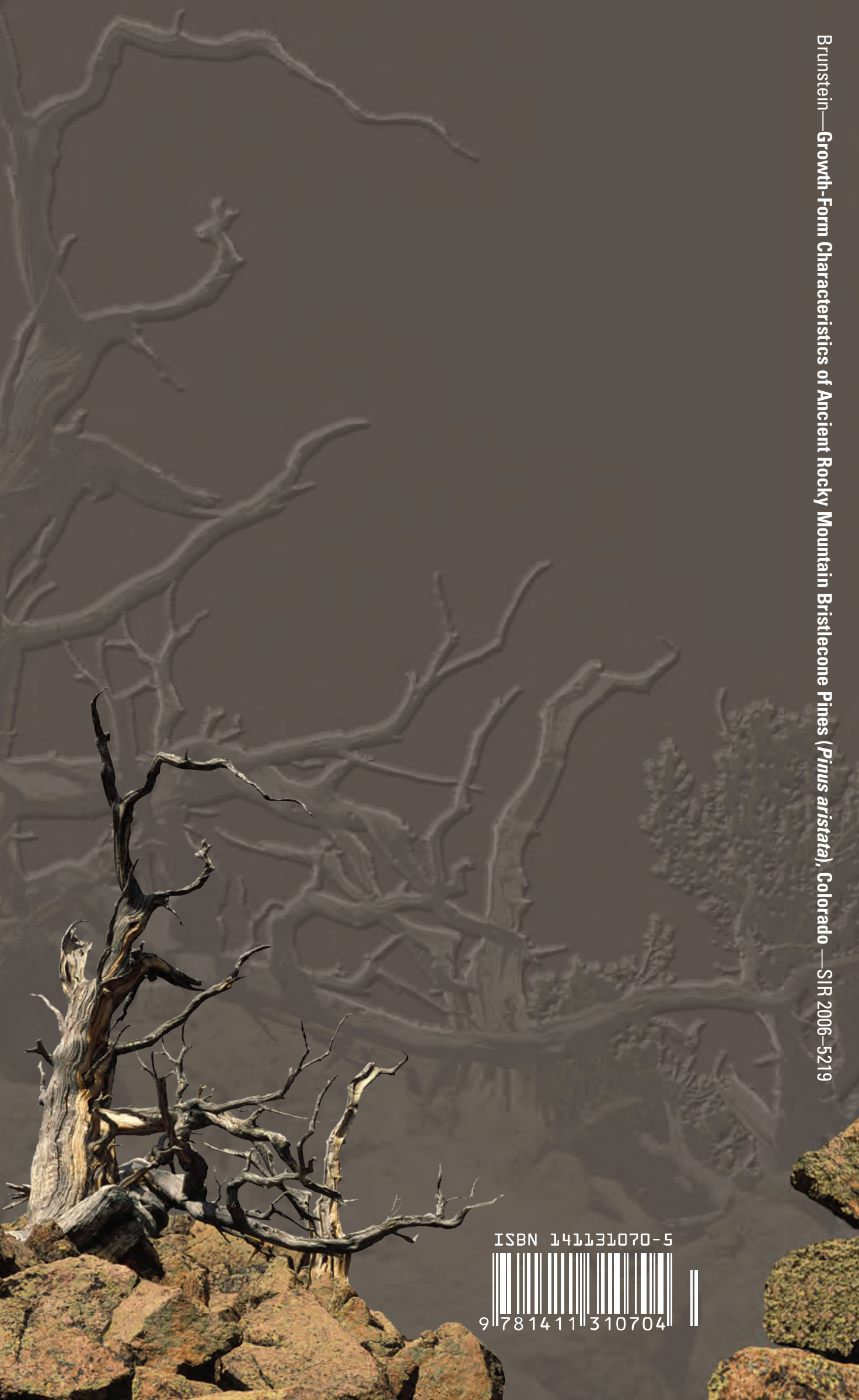

